\title{
RELATIONSHIPS BETWEEN ACADEMIC DISIDENTIFICATION AND INCARCERATION IN AFRICAN AMERICAN MALES
}

\begin{tabular}{c} 
A Dissertation \\
presented to \\
the Faculty of the Graduate School \\
at the University of Missouri-Columbia \\
In Partial Fulfillment \\
of the Requirements for the Degree \\
Doctor of Philosophy \\
\hline TODD F. ROBINSON \\
Dr. Stephen Whitney, Dissertation Supervisor \\
DECEMBER 2013
\end{tabular}


(C) Copyright by Todd F. Robinson 2013

All Rights Reserved 
The undersigned, appointed by the dean of the Graduate School, have examined the dissertation entitled

\section{RELATIONSHIPS BETWEEN ACADEMIC DISIDENTIFICATION AND INCARCERATION IN AFRICAN AMERICAN MALES}

presented by Todd Robinson, a candidate for the degree of doctor of philosophy of school psychology, and hereby certify that, in their opinion, it is worthy of acceptance.

Professor Stephen Whitney

Professor David Brunsma

Professor Craig Frisby

Professor Cheryl Offutt

Professor Timothy Lewis

Greg Holliday, Ph.D. 


\section{DEDICATION}

I would like to dedicate my dissertation, first of all, to Dr. Mercile J. Lee. Without Mercile's support throughout my undergraduate years at the University of Wisconsin, I cannot imagine having the interest or the drive to have completed this work. Mercile is an enduring example of what it means to make a difference, one who is worthy of emulation. I am completely sincere when I say that I did this for you, because you ALWAYS believed in me.

My next dedication is to my oldest brother, Daryl Stacy Robinson. Daryl's fight for his life, nearly three years ago, was one of the greatest inspirations I've ever witnessed. I do not know what it was like for him before he passed, but watching him endure gave me the courage to persevere. Daryl, this is for you, because you showed me what strength REALLY looks like.

It is only right that I also dedicate this dissertation to all of the men that participated in my study. They opened their lives to me in hopes of helping someone, somewhere, someday. They believe in this work, which fills me with the desire to do more of it. Men, this is for you, because you demonstrated to me the possibility of CHANGE.

My final dedication is to my wife, Angel Robinson, and my daughter, Zion Robinson. When Angel let me go for two years to complete my doctorate, I knew we must have something special. I could not let my family down. I am so proud of my daughter, and I want nothing more than for her to be proud of me too. I had to finish this dissertation for them. This is for you, Angel and Zion, because I LOVE you! 


\section{ACKNOWLEDGEMENTS}

I would like to thank Dr. Stephen Whitney for believing in me and supporting me so fiercely through this journey. You would not let me give up even when I doubted myself. Thank you, Dr. Cheryl Offutt. Your smile was always the reassurance I needed. I thank you, Dr. Craig Frisby, for bearing with me, challenging me, and laughing with me in the end. Thank you, Dr. Holliday, for your faith that never wavered. You are a rock. I would like to thank Dr. David Brunsma for validating my work from nearly a thousand miles away (literally). Thank you, Dr. Timothy Lewis, for waiting patiently and never losing interest. There are so many more people that I want to and should thank but have not the room to do so on this page. Thank you, Dr. Paul McKenzie for giving me perspective. Thank you, Dr. Clara New, for listening with your heart and blessing me with your wisdom. Thank you, Aunt Jo, Aunt Patsy, and Aunt Carla, Uncle Donald, Aunt Delores, Aunt Myrtle, for showing your love when I needed it most. I must give a

great, big thanks all of my family and friends. Knowingly and unknowingly, you kept me motivated and hopeful until the end. Thank you, Dad, Big Sis, Stuart, Shelley, Sheldon, Mr. and Mrs. Jackson, and Ronnie and Kay Baker. Thank you, Caren, Angellar, Larence, and Ronnie, for supporting me when you did not have to. Last but absolutely not least I would like to thank my church family for all of your prayers and encouragement and for faithfully taking care of my family when I was away. Thank you, Bishop Freeman, for planting the seed long ago. I must give another great big thanks to my spiritual brothers, Bishops Ware, Woods, Luther, and Peat for keeping me inspired. To everyone that I cannot name who played a part in the completion of this endeavor, I sincerely thank you. 


\section{TABLE OF CONTENTS}

Acknowledgements..................................................... ii

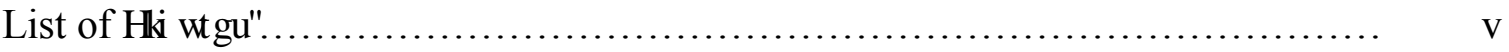

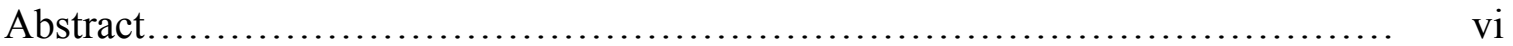

Chapter 1: $\quad$ Introduction................................................. 1

Statement of Purpose and Research Questions...................... 4

Chapter 2: $\quad$ Literature Review............................................... 5

Academic Disidentification..................................... 5

Purposes of Education......................................... 11

African American Male Incarceration and Related Problems......... 20

Chapter 3: $\quad$ Methods....................................................... 28

Sample and Participant Selection.............................. $\quad 28$

Procedures for Selecting Participants............................ $\quad 30$

Data Collection................................................... 31

Data Analysis................................................ 34

Trustworthiness................................................ 37

Chapter 4: $\quad$ Results......................................................... 42

Academic Disidentification..................................... 43

Shift in the Value of Education....................................... 53

Shift in Goals and Value Structures................................. 86

Looking Back............................................. 92

Looking Ahead............................................ 95

Summary .................................................. 96

The Model and Core Phenomenon: Facilitation of Legitimate

Goals......................................................... 98

Chapter 5: $\quad$ Discussion..................................................... 101

Facilitation of Legitimate Goals................................. 101

Limitations................................................... 108

Conclusions and Implications................................. 111

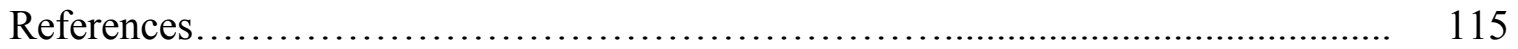

Appendix A: $\quad$ Participant Profiles............................................. 127

Appendix B: Interview Protocol........................................... 152

Appendix C: Informed Consent............................................... 156 
Appendix D: $\quad$ Demographic Pre-Interview Form................................ 160

Appendix E: $\quad$ Peer Debriefer Instructions.................................... 164

Appendix F: Field Note Example ........................................ 166

Appendix G: Coding Matrix............................................. 175

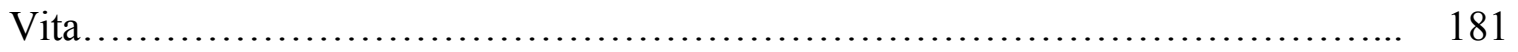




\section{LIST OF FIGURES}

Figure $\quad$ Page

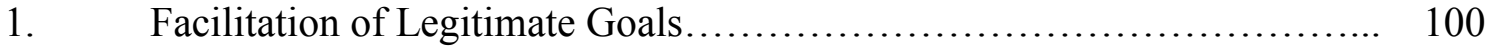




\title{
RELATIONSHIPS BETWEEN ACADEMIC DISIDENTIFICATION AND INCARCERATION IN AFRICAN AMERICAN MALES
}

Todd Robinson

\author{
Dr. Stephen Whitney, Dissertation Supervisor
}

\begin{abstract}
This study was conducted to explore whether a direct relationship could be found between the unique occurrence of academic disidentification and the disproportionately high rates of incarceration among African American males. The concept of legitimate goals is considered as an essential variable that may be adversely affected by the presence of academic disidentification. A qualitative analysis utilizing a grounded theory approach resulted in a theoretical model, Facilitation of Legitimate Goals, positing two developmental paths toward internalizing legitimate goals. Twenty previously incarcerated African American males were interviewed to explore their satisfaction with their lives since incarceration, the past and present value they have associated with formal education, and the types of goals they currently pursue. The model emerging from the participants' data indicated a negative cycle in which academic disidentification acted as an intervening condition for high-risk activities that led to incarceration for each participant. A change trajectory followed, ending in the recognition of the importance of education. The adoption of legitimate goals subsequently occurred. It could not be concluded that academic disidentification directly resulted in incarceration or the absence of legitimate goals prior to incarceration for the study participants. The significance of the model and its implications are discussed.
\end{abstract}




\section{Chapter 1}

\section{Introduction}

Since the early 1990's, African American males have been incarcerated at much higher rates than all other groups in the U.S. (Human Rights Watch, 2003; Mauer \& King, 2007). This is a troubling reality given the relatively small size of the African American male population in the nation. Another unfortunate reality of African American males is poor educational outcomes marked by low achievement and lack of academic engagement in schools. African American males lag behind their White peers in grade point average and on standardized test scores, regardless of their socio-economic standing (Jencks \& Phillips, 1998; Noguera, 2003), suggesting that higher economic status is not a protective factor against low academic performance for African American

males. African American males consistently perform lower academically as a group than most other groups. Moreover, in every state, African American males are more likely to be suspended and expelled from school. Their high school dropout rate surpasses all other groups, although Latino dropout rates are higher in some regions of the U.S. This is extremely problematic because Coleman et al. (1966) make a strong argument for the connection between the low academic performance of African American males and the hardships they continually confront in American society.

Certainly not all African American males are at risk for low academic achievement, school failure, and incarceration. However, as an ethnic group, African American males persistently fair the worst in the nation on the most important quality of life indicators (Noguera, 2003). For example, the graduation rate for African American males in $2005-2006$ was $47 \%$. This is compared to a $75 \%$ graduation rate for White 
males in the same year (Schott Foundation, 2008). In 2005, 2.3\% of African American males were incarcerated. The incarceration figures for White and Latino males were $0.4 \%$ and $0.7 \%$, respectively (Mauer \& King, 2007). By 2011, incarceration figures increased to $3 \%$ for African American males while increasing to only $0.5 \%$ and $1.2 \%$ for White and Latino males (Carson \& Sobal, 2012). It is clear by the proportions that many who do not complete high school do not become incarcerated. Mauer and King (2007) made it clear that the patterns of incarceration, particularly among young males, are a real concern because of the profoundly negative and long term impacts on employment prospects, family formation, and quality of life. The consequences ripple through the broader community for minority groups experiencing higher rates of incarceration.

Relationships have already been established between poor school performance and delinquency (Christle, Jolivette, \& Nelson, 2005). The current study was conducted to explore a potential relationship between the experience of African American males and their disproportionately high incarceration rates. Specifically, academic disidentification (Osborne, 1997; Steele, 1992) was targeted as a possible impediment to educational outcomes which might protect against risk factors for incarceration. The construct describes a separation of self-image and academic performance which may help to explain the performance and outcomes of African American males in school. Osborne (1997) showed that the dissociation from school achievement which Steele (1992) coined academic disidentification primarily occurs among African American males. Where academic identification is addressed in literature, it is treated as a behavioral phenomenon. This seems to discount the emotional and psychological aspects of human functioning which influence human choices and behaviors (Izard, 1977). At some level 
this is an emotional decision (Payne, 2005) that occurs almost uniquely among African American males (Osborn, 1997).

No previous study has directly investigated relationships between the phenomena of academic disidentification and incarceration in the African American male experience. Scholars (King, 1948; Seymour, 2004) have written about what education should produce for individuals and for society. Dr. Martin Luther King, Jr. utilized the term legitimate goals to qualify objectives one determines to pursue by means of intellect and character, traits that are shaped through education. Engagement in behavior placing one at risk for incarceration may be taken as a problem with the formation of legitimate goals.

The prevalence of academic disidentification and incarceration among African American males seems to draw a connection between these two concerns among this group. Confirming the existence of and understanding the nature of any connections that may exist between them can assist in the development of schooling and educational approaches that prevent academic disidentification in African American males. It may be that increasing academic identification among African American males may assure greater success for them in the purpose of education, empowering them to identify their individual attributes, talents, interests, and personal goals, in relation to salient concerns of their communities and in the larger society. Such preparation would presumably enable more of them to define and pursue their legitimate goals constructively and efficaciously. Thus, African American males, who would otherwise be on trajectories toward incarceration, might instead commit their lives, early on, to pro-social endeavors excluding them from activities and associations that would result in incarceration. 
The following chapter contains a discussion of academic disidentification and legitimate goals along with a treatment of potential contributors to the formation of academic disidentification. Academic disidentification is distinguished from academic disengagement. The term legitimate goal is further defined in the course of the discussion on the purpose of education. The discussion of the school-to-prison pipeline gives consideration to more factors that may influence the development of academic disidentification and possibly interfere with forming legitimate goals. Concerns of African American male incarceration are then discussed to further highlight the significance of this study.

\section{Statement of Purpose and Research Questions}

The purpose of this grounded theory study is to understand the relationship between academic disidentification and incarceration for African American males. At this stage in the research, academic disidentification is defined as the absence of a correlation between one's academic performance and one's self-esteem. The two primary research questions are:

1) What interfered with the formation of legitimate goals through formal education?

2) How did academic disidentification contribute to problems in the formation of legitimate goals? 
Chapter 2

\section{Literature Review}

\section{Academic Disidentification}

A variety of reasons have been posited to explain the generally low academic performance of African American students in American schools. Researchers (Comer, 1989; Cummins, 1986; Ogbu, 1997; Osborne, 1997; Steele, 1992) have proposed various theories to explain the persistence of low performance of African American students in general. For the most part, these arguments can be divided into internal factors (ability, motivation) and external factors (environment, culture). Steele (1992) and Osborn (1997) have advanced the term "academic disidentification". The theory of academic disidentification (Cokley \& Moore, 2007; Osborne, 1997, 2001; Osborne \& Walker, 2006; Steele, 1992) offers an explanation of African American students' academic behavior and outcomes in a way that takes into account motivation, culture, and environment. Cokley and Moore (2007) used the construct of "psychological disengagement" - the phenomenon in which self-esteem is detached from performance in a particular area (Schmader, Major, \& Gramzow, 2001) - to define academic disidentification. When a student's overall self-esteem is unrelated to the outcomes he achieves in the academic domain, his disposition is known as academic disidentification (Cokley \& Moore, 2007).

Brown and Jones (2004) found that education contingency, defined as “...student's belief that high educational achievement is necessary for economic success later in life" (p. 254), is moderated by perceptions of minority status. Thus, minority students expect little payoff from education and devalue academic behaviors when they 
are faced with inequality and discrimination in their schools and larger society, even when they recognize the general relationship between academic performance and future success. This is a picture of academic disidentification. Students who are academically identified can be determined by the extent to which they show concern for making earnest attempts to apprehend and apply academic knowledge to be gained through formal schooling. In a practical sense, academic disidentification constitutes rejection of “American achievement ideology" (Brown \& Jones, 2004) and academic achievement as a basis for self-esteem, resulting in lower motivation for academic work. Academic achievement is, thus, devalued as a goal and subsequently viewed as not worth the sustained, goal-oriented effort.

\section{Distinguishing disidentification from disengagement. Academic}

disidentification may be considered a subset of or precursor to academic disengagement. Côté and Allahar (2007) characterized the extent to which students identify with and value schooling outcomes and participate in academic and non-academic activities as measures of academic engagement. The choice to 'identify with and value schooling outcomes' reflects academic identification. The opposite choice constitutes academic disidentification. To 'participate in academic and non-academic activities' refers to behaviors that can be observed as evidence of sustained, goal-oriented effort to achieve specific academic outcomes (Brown \& Jones, 2004). In a study of academic disengagement among African American students in an affluent U.S. suburb, Ogbu (2003) observed time devoted to studying and homework as indicators of student engagement. Conversely, failure to invest adequate time and effort into academic tasks, not working as hard as one could or should, or "just doing enough to get by" were 
descriptives applied to students who were less academically engaged. Academic engagement may be conceptualized as the extent to which a student shows sustained, measurable efforts to acquire, develop, and demonstrate academic knowledge gained through formal schooling. While academic disidentification and academic disengagement appear to be closely related, one should not be equated with the other.

Cognitive ability. To the degree that academic disidentification and academic disengagement are related but distinct constructs, it is useful to consider the contribution of cognitive ability to the presence of either. Gottfredson (2000) and others strongly suggest that the lower academic performance of African American students when compared to their peers is due to lesser cognitive ability. It is argued that disengagement is a function of the student's inability to fully engage with academic material at the same cognitive levels as their more able peers. A primary assumption is that African Americans, as a group, naturally experience depressed academic achievement resulting from weaker ability. However, gender differences in academic achievement regularly appear among African Americans though overall cognitive ability levels as determined by IQ scores appear to be similarly distributed across genders (Herrnstein \& Murray, 1994).

Examining within-group differences in academic engagement and identification, Brown and Jones (2004) and Cokley and Moore (2007) found gender differences which cannot be explained by differences in intellectual ability. Cokley and Moore (2007) found that ethnic identity and racial centrality, the extent to which one considers race an essential part of his or her identity, were positively related to academic achievement and academic self-concept for African American women in their study. However, ethnic 
identity and racial centrality were negatively related to academic achievement and unrelated to academic self-concept for the African American males in the study. Further, the African American women demonstrated lesser tendency to devalue academic success and achieved higher GPA's than the men. These differences were statistically significant.

Brown and Jones (2004) found that African American males in their study espoused stronger beliefs in the utility of education for future success than their female counterparts. At the same time, the males demonstrated greater tendency to devalue academic work. Osborne (1997) examined the differences in academic disidentification among and between disadvantaged groups. Specifically, he was interested in studying the progression of academic disidentification within and across these groups. He found that despite the relative absence of academic disidentification among Hispanics and African American females, African American males, once they disidentified, remained so through the twelfth grade. Since there is no evidence for significant differences in the overall distribution of cognitive ability levels across genders (Halpern and LaMay, 2000), it cannot be said that the apparent gender differences in academic attitudes and outcomes among African Americans are generally due to lesser cognitive ability in males.

The results of studies like those previously mentioned highlight the need for further exploration of the factors affecting African American male academic and lifespan outcomes in two ways. First, the gender differences favoring females in African American academic achievement are persistent. In the absence of proven cognitive explanations for these differences, consideration must be given to experiential factors contributing to these outcomes. Second, understanding the influences instigating the negative outcomes of African American males in the academic domain should provide 
insights for minimizing, if not preventing, problems such as academic disidentification and its associated dangers.

Other possible factors. Cultural and environmental factors that may be associated with academic disidentification among African American males are made explicit by researchers (Mocombe \& Tomlin, 2010; Oswald, Coutinho, Best, \& Singh, 1999; Rist, 1970) who have suggested that ethnicity and social class are characteristics that frequently create negative expectations which in turn lead to differential treatment of students from low SES and minority groups. One of the dominant stereotypes concerning African American males that European Americans tend to hold is that they are hostile, angry, and prone to violence (Foster, 1995). Livingston \& Nahimana (2006) assert that Black children are keenly able to perceive what adults think of them. The implication is that they are very sensitive to preconceived assumptions about them as a part of the social context in which their individual identities and self-concepts develop. Studies have also indicated that teachers' perceptions and lack of cultural responsiveness can result in student psychological discomfort and low achievement (Hilliard, 1976) and in social and academic failure (Pollard, 1993). Ladson-Billings (2001) argued, "Students of color may become alienated from the schooling process because schooling often asks children to be something or someone other than who they really are... It asks them to dismiss their community and cultural knowledge. It erases things that the students hold dear" (p. xiv). Moreover, notwithstanding the implications for poor achievement outcomes when teachers fail to connect students' culture and schooling, the risk for teacher referral for special education services increases (Hilliard, 1992; Oswald, et al., 1999). These can all be considered precursors to or school-based examples of what Sue et al. (2007) and 
others (Pierce et al., 1978; Solorzano et al., 2000) have called "racial microaggressions". (See Sue et al., 2007 for a complete discussion of racial microaggression.)

Microaggressions. In summary, racial microaggressions exist in three forms. The most explicit form, microassault, appears as overt instances of racism inflicted on an individual level. The more subtle microinsult is characterized by insensitive communications which are demeaning to a person's race or cultural identity. Microinsults may be verbal or non-verbal and are usually unrecognized by the perpetrator. The most insidious type of racial microaggression is microinvalidation, which occurs when interpersonal communications or environments effectively "exclude, negate, or nullify the psychological thoughts, feelings, or experiential reality of a person of color" (Sue et al., 2007, p. 274).

Microaggressions lead to anger, mistrust, and diminished self-esteem for people of color and mask the reality of racially different social and psychological experiences for Whites (Spanierman \& Heppner, 2004; Sue et al., 2007; Thompson \& Neville, 1999). The way a recipient responds to microaggressions holds potential for two-fold effects. Non-response may result in psychological disequilibrium and physical manifestations from pent-up anger and frustrations. Speaking up may confirm racial stereotypes. For African American males, in particular, addressing microaggressions may reinforce other's beliefs that they are angry and hostile with bents toward impulsivity and violence. In the absence of research examining the effects of microaggressions in primary and secondary education, it appears reasonable to draw parallels between the existence of and responses to microaggressions in general society and the same in the educational experiences of students of color. That is to say that the formal educational experiences of 
minority students are sure to include instances that marginalize their value within the school community. For African American males, the experiences conceivably engender negative emotions which lead to the unique response of academic disidentification and may trigger anti-social and destructive choices.

\section{Purposes of Education}

In the United States, formal education is provided within a system of compulsory schooling. Students progress through a series of schools at the primary and secondary levels with expectations of learning from instruction provided by their teachers. Many students matriculate through primary and secondary education with aspirations of attending institutions of higher learning or vocational schools. Field (1976) attributed the growth of compulsory education in the U.S., beginning in the mid-nineteenth century, to the emergence of two complementary needs. Increasing industrialization created a strong demand for human capital in the form of an educated labor force. Concurrently, increasing diversity introduced the need for "structural reinforcement" to promote social order and maintain the character and social structure of society.

Seymour (2004) challenges these goals of compulsory education and the methods for achieving them. In the words of Seymour,

...we school for skills and knowledge needed to work and function at an “economically sound" level in society (and we don't do that very well either). By educating primarily for economic being, as opposed to human being and belonging, our system of education has relegated the development of a child's sense of self, his or her ability to make meaning of life and to love and respect others to family and/or civil society. Thus, education has played its role in the 
appalling losses we witness when we survey the landscape of shallowness, moral ambiguity, commercialism, and meaninglessness that pervade society today. (Seymour, 2004, p.4)

Seymour questions, "How can we expect children to become the type of adults we want them to be when one-third of their waking lives (in their most formative years) is spent in forced schooling that does not honor their humanity?"

A similar opinion comes from Dr. Martin Luther King Jr. (1948) who wrote, "Education must enable a man to become more efficient to achieve with increasing facility the legitimate goals of his life." Dr. King clarified the statement in his address on The Purpose of Education by establishing that the two-fold goal of education is "intelligence plus character." Since education is as much about ethics and character as it is content, schools should partner with families and civil society to nurture the heart, character, and deeper thinking of young students (Seymour, 2004).

Assigning the development of intellect and character to the purpose of education, Dr. King (1948) further specified the outcomes of the successful cultural purpose of education. To be considered successful, an individual's educational experiences should empower him to discover and learn to fulfill important, self-identified aspirations. One's education should facilitate development of tools and skills over time that enables him to competently achieve those aspirations with dignity and honor. Dr. King (1948) called those aspirations "legitimate goals".

Damon, Menon, and Bronk (2003) provide an alternative way to understand and partially operationalize Dr. King's term "legitimate goals" in their definition of "purpose". Though they do not use the term "legitimate goals", it is clear that the 
resultant qualities they attribute to pursuing purpose reflect the intellect and character that Dr. King envisioned from a just education. Addressing the social concern of troubled American youth, Damon et al. (2003), suggest that finding purpose leads to prosocial behavior, moral commitment, achievement, and high self esteem - all qualities that fit "legitimate goals." The researchers put forth the following definition of purpose: "a stable and generalized intention to accomplish something that is at once meaningful to the self and of consequence to the world beyond the self" (p. 121). Their definition of purpose encompasses the interests, desires, and needs of the individual as well as some significant, external impact on greater society. Following from Damon et al.'s (2003) definition of purpose, the stability of purpose comes from the far-reaching nature of aspirations requiring directed efforts designed to make continual progress toward anticipated accomplishments. The presence of a goal or set of goals is evident in this definition.

It also follows that three qualities give full legitimacy to the goals one chooses. First, the individual determines that the goals fit with his/her own interests and concerns. The goals are not externally foisted upon him, but self-selected and personally valued. Second, the steps necessary to achieve those goals and the goals themselves are of benefit to the one(s) achieving the goals and to all who are affected by the efforts of accomplishing the goal. Ultimately, the intent of the goals should bring about some beneficial, social change. At the very least, the goals should have a benign and innocuous social affect. The third legitimizing factor is that the goals are stable enough to provide a constant sense of direction over time. 
A just education facilitates the acquisition of legitimate goals, securing one's significance and station in society (King, 1948). While purpose and goals are clearly related, purpose is more general. Goals, by definition, must be specific. Legitimate goals, therefore, focus on ameliorating problematic civil or social situations, for instance, and simultaneously provide a source of ongoing personal satisfaction to the goal-seeker. The purpose of the goals one pursues, especially as defined by Damon et al. (2003), is what gives those goals legitimacy.

Much attention has been given to the concerns as to whether children are achieving as they should in school. The present academic and social skill status of African American learners provides compelling evidence that systematic inquiry is warranted. The consistent underachievement of African American students, particularly adolescent males, justifies culturally responsive inquiry and pedagogy to reverse the present trends toward school and social skill failure. Hilliard (1992) expressed grave concern about the problem of equity in education based on the observation that outcomes appear to be distributed as a function of socioeconomic status, race, culture, or language group. Regardless of their socioeconomic status, African American boys remain especially vulnerable to poor schooling, underachievement, inappropriate discipline, and placement in special education programs (Harvey, 2004).

The following assumptions underlie the theoretical and methodological approaches for this study. The disproportionately high rate of incarceration of African American males may be an indication that their educational experiences promote academic disidentification, reducing their incentive to identify and appropriately pursue legitimate goals (King, 1948) inspired by purpose, as defined by Damon et al. (2003). In 
other words, large numbers of African American males fail to find direction through formal schooling that successfully leads to ideas and actions that are at once personally meaningful and pro-socially advantageous.

Another possibility is that the educational experiences of these individuals do not adequately impart essential knowledge and skills to accomplish their aspirations. Thus, the committing of crimes may be an indication of such underlying problems; 1) failure to identify legitimate goals or 2) failure to acquire tools and learn constructive methods to achieve legitimate goals. The future ramifications of providing all students with the type of educational opportunities and experiences that ensure gainful acquisition of legitimate goals make it necessary to explore whether academic disidentification interferes with development of legitimate goals for African American males. Further, it is essential to understand school factors that may promote the development and unique maintenance of academic disidentification for this group.

Thwarting the purpose: the-school-to-prison-pipeline. In nearly every aspect of the education system, African-American students are over-represented in negative categories (such as sub-standard high school retention and completion; Greene, 2001) and under-represented in positive categories (such as standard diplomas; Greene, 2001). For example, in 2000, African Americans represented only 17\% of public school enrollment nationwide, but accounted for 34\% of suspensions (NAACP Legal Defense and Educational Fund, n.d.). In 2003, African-American youths made up $16 \%$ of the nation's overall juvenile population but accounted for $45 \%$ of juvenile arrests (NAACP, n.d.). Unfortunately, NAACP (n.d.) found multiple studies showing evidence that African-American students are far more likely than their White peers to be suspended, 
expelled, or arrested for the same kind of conduct at school. Additionally, it was found that African American students are more likely to be retained in grade based upon their performance on high stakes tests.

Two recent studies provide further evidence to support the concerns of differential discipline in schools (Fabelo, Thompson, Plotkin, Carmichael, Marchbanks \& Booth, 2011; Skiba, Horner, Chung, Rausch, May \& Tobin, 2011). In a study reviewing disciplinary referrals across 364 elementary and middle schools in the 2005-2006 school year, Skiba et al. (2011) found that African American students were more likely to be referred for problem behavior than White students. In elementary schools, African American students were two times more likely to be referred than White students. African American students were nearly four times more likely to be referred in middle schools. Skiba et al. also found that African American students were more likely than White students to be suspended or expelled for the same or similar behaviors.

Fabelo et al. (2011) conducted a large scale longitudinal study in the state of Texas to examine suspension and expulsion practices of public secondary schools in the state and the impact of those practices on students' academic performance and juvenile justice system involvement. The research team examined the records of all students, state-wide, who began seventh grade in 2000, 2001, and 2002. All of the students were followed for at least six years. The results of Fabelo et al.'s study also showed disparities in disciplinary actions by race. African American students had a $31 \%$ higher chance of being removed from the classroom for disciplinary reasons than White and Latino students. A higher percentage of African American males received discipline referrals over the study period than any other group. Fabelo et al. further corroborate findings 
that, though African American students were no more likely to commit offenses requiring removal from school than students of other races, African American students regularly received more severe discipline for their offenses. This was determined to be especially true for African American males.

Studies like those conducted by Fabelo et al. (2011), NAACP (n.d.), and Skiba et al. (2011) characterize retention and educational problems as causes, as well as results of behavioral issues, because students struggle with stigma and isolation associated with remaining in classes with younger students rather than advancing with their peers. Fabelo et al. stated that the results of their study did not explain reasons for differential disciplinary treatment across race. The authors of the NAACP (n.d.) study suggested that administrators are tasked with appropriating limited resources to, both, address achievement gaps and maintain accountability for performance outcomes. Thus, the preferred solution, for some, is to remove any students who may affect their bottom line. Data indicates that African American students are the ones most affected. Practices that place higher proportions of these students in lower educational tracks and remove them in the name of zero-tolerance and safe-schools strengthens, rather than rectifies, structural barriers to academic success for this group as a whole.

To some degree, differential treatment in schools continues because of ongoing racial attitudes about and social stereotypes of African Americans, especially men and boys, which characterize them as dangerous and predatory (Foster, 1995; NAACP, n.d.). The disparities are further exacerbated by the quality of education historically available to people of color in general and African Americans in particular. 
Historically, African-American children and other children of color have been denied access to equal educational opportunities. Despite a decades-long fight to desegregate schools and the more recent battles around education funding and adequacy, it has become increasingly clear that the problems of access to quality education for African-American students are deeply entrenched and rooted in the legacy of this country's racial caste system. Now, more than fifty years after the Supreme Court's landmark decision in Brown v. Board of Education, the Schoolto-Prison Pipeline poses a new generation of obstacles that serve to further isolate African-American students and deprive them of the opportunity to learn (NAACP, n.d.).

Youth Transition Funders Group (2005) provides more evidence of factors supporting the existence of trait and structure differences for African American students that instigate trajectories from the school system to the correctional system. A midAtlantic study showed that it was possible to clearly identify youth from a particular school district, who would eventually become incarcerated, well before their entry into the juvenile justice system (YTFG, 2005). Enumerated, the factors identified were: 1) They were primarily African American males attending one of twelve high-poverty, neighborhood high schools; 2) Most exhibited high absenteeism - attending school barely half of the time - and were failing most of their courses the year before incarceration; 3) They were suspended more often at eighth grade; and 4) They were more disengaged from their peers (YTFG, 2005).

Administrators of high-poverty high schools, again, struggle with simply maintaining order when required to operate with insufficient funds and resources. All the 
while, pressure mounts to raise test scores and increase performance. Amidst threats of losing their jobs if the results of their efforts draw negative attention, administrative practices suggest very low tolerance for students considered to be problem children within their schools (YTFG, 2005). As a result, in the absence of partnering with families and community service providers to find appropriate solutions, the discipline these children receive frequently leads to involvement with juvenile justice systems.

Suspensions and expulsions are disproportionately applied to students of color, creating an additional entry point into the school-to-prison pipeline. Minorities are heavily overrepresented among those most harshly sanctioned in schools. Nationally, African American students are 2.6 times more likely to be suspended than White students (YTGF, 2005). In 1972, less than nine percent of White students were suspended in any state in the U.S. However the suspension rate for African American students reached nine percent or more in as many as six states. As the number of overall suspensions has increased over time, so have the racial disparities. By the 1998-1999 school year, cumulative disparities in the education and juvenile justice systems reached the point that, while only one state suspended more than nine percent of its white students, 35 states suspended at least that percentage of black students (YTGF, 2005). Between 1972 and 2000, the percentage of White students suspended annually for more than one day rose from 3.1\% to 5.09\%. During the same period, the percentage for Black students rose from $6 \%$ to $13.2 \%$ or more (Losen \& Skiba, 2010; YTGF, 2005).

Research has provided evidence of correlations between suspension and poor academic preparedness, grade retention, court involvement and dropping out, disaffection and alienation, and drug use (YTGF, 2005). Further, expulsion from school amounts to 
denial of education, especially in states that do not make provisions for students to attend other schools after they are expelled or when students, considered trouble makers, are sent to alternative and disciplinary schools without comprehensive assessments to diagnose the nature of their troubles. Thus, suspension and expulsion from school often have far-reaching, negative impacts.

\section{African American Male Incarceration and Related Problems}

African American males are incarcerated in greater numbers than any other group in the United States although they are among the smallest group in the U.S. population. Harrison and Beck (2006) reported at the end of 2005, there were 547,200 African American males, age 18 and over, incarcerated in state and federal prisons in the United States. This is compared to 459,700 White males in the same age range. By year-end, 2011 , those numbers had risen to 555,300 and 465,100 , corresponding to $3 \%$ of the African American and .5\% of the White male populations in the U.S. (Carson \& Sobal, 2012).

Decades of social inequalities underscore the African American experience in every arena in the U.S. It is important to explore the myriad of factors contributing to highly disproportionate incarceration rates for African American males and the perpetuation of profound negative effects on resources such as social status, social capital, and human capital. Aday (2001) stated these effects "have played an important role in exacerbating the vulnerability of many subgroups of U.S. society" in the areas of physical, psychological, and social health. None appear more affected than the African American male. 
The ongoing persistence of over-representation of incarcerated African American males has ramifications in social and psychological health for this population. Because beliefs influence attitudes and actions (Izard, 1977), it is reasonable to suspect that a selfperpetuating cycle of negativity exists in a contributory way to maintain the disparities in question. One question is what does this society believe about this subgroup as a result of and in contribution to their high representation in the correctional system? A related question is what do these individuals believe about themselves with respect to these factors? Ultimately these are questions of image and identity. Schooling, as a subset of education, serves to influence the formation of the beliefs and attitudes which subsequently determine an individual's actions. While it is reasonable to imagine that society would think more negatively about prison inmates in general, it is also reasonable to ask what society thinks about the subgroup among them from which individuals are most likely to go to prison. Thus an underlying assumption of the current study is the inherent interaction between societal attitudes about African American males and the development of their own attitudes about themselves.

Aday (2001) wrote, “The origins of minorities' economic and social disadvantage lie deep in the fabric of American social and political history." Discrimination resulted in barriers to jobs, education, and housing for many decades which has contributed to sustained and substantial poverty levels among African Americans. Clayton (1992) asserts that these conditions have helped to shape a negative value system for many. $\mathrm{He}$ further posits that an individual's value system is the "most significant predictor of" criminal behavior, and that long term exposure to systematic social and economic discrimination contributes to the development of a criminal value system. This would 
suggest a combination of attitudes affecting healthy outcomes. In terms of social status (Aday, 2001), African American males may have turned to their own means of achieving organizational and economic power and success (Harvey, 2004), which appear aberrant from the conventions of mainstream values. For Singh and $\mathrm{Yu}$ (1996), this has resulted in Black males, "especially ones with poor education and low income" choosing lifestyles which increase the risk of "injury and injury-specific youth mortality."

For Harvey (2004), the culture of gangs, inclusive of drug distribution and abuse, becomes an essential vehicle for status and source of demise for many African American youth. These choices for affiliation and livelihood result in violence that is, in part, responsible for shortening the life expectancy of African American males and contributes to drug infestation in poverty stricken African American communities. Since the "war on drugs" (Human Rights Watch, 2003, p. 1) beginning in the early 1980's, 38\% of incarcerated African Americans are serving sentences for drug related offenses (Human Rights Watch, 2003).

Kaba (2005) points out that African American women significantly outnumber their male counterparts on college campuses, earning more undergraduate, masters, and professional degrees than African American men. Currently, slightly higher numbers of African American males are counted on college campuses than prison yards (Kaba, 2005). One huge implication is that the numbers of African American males being formally prepared for professional and socially appropriate leadership is continually diminishing. The ultimate result will be further loss of social status and social capital as African American men find increasingly fewer opportunities to provide for their families through conventional means. A corollary, however, is that African American women 
may lower their expectations for finding compatible partners among African American men, thus further decreasing their social status and opportunities to develop social capital. Aponte, Beal, and Jiles (1999) have indicated that marriage rates have been decreasing among Blacks and identify lack of marriage eligible Black men as a primary reason. Incarceration of African American males also complicates issues associated with fatherlessness among African American families. Mumola (2000) reported that seven percent of Black children, in 1999, had an incarcerated parent and that Black children, in general, were nine times more likely to have a parent in prison than White children. Horn (2002) stated, "Having a father in prison is a powerful predictor of antisocial behavior in general and criminality in particular" and increases their chances of future incarceration by up to six times. Such statistics underscore the vulnerability of children of incarcerated parents. Additionally, they magnify the severity of the cycles instigated by social inequality and legal disparity, for African American males in particular, which consistently result in over-representation in state and federal prisons.

All of the factors discussed, are implications of a societal and systemic problem that unduly and unjustly threaten the posterity of the African American population. African American males are incarcerated up to seven times more than White males (Horn, 2002). This level of incarceration exacerbates the effects of discrimination and poverty such that social and human capital is continually eroded away. The increased likelihood of the children of these incarcerated individuals going to prison perpetuates and widens the resulting cycles.

Samenow (2004) expressed his theory that criminals "know right from wrong...they believe that whatever they want to do at any given time is right for them," 
(p. 2). His extensive background in working with criminals led him to conclude that the problem with criminals is their individual character and the choices they make (Samenow, 2004). He is convinced that criminals think in ways that motivate them to reject familial attachments and social conventions well before they are ever rejected by others. Samenow's work holds significant value in that it has led to approaches and interventions to help criminals take responsibility for their actions and change their criminal thinking patterns. However, he remains unable to explain the considerable disproportion of African American males involved in the correctional system.

The over-representation of incarcerated African American males in the U.S. has profound social effects on the African American community both directly and indirectly. For this reason, it is important to examine the interaction-effect between the phenomenological, intra-psychic experience of this group and socio-political factors of the society in which they live, which may, influence the attitudes, choices, and behaviors for which members of this group are incarcerated. One significant factor is their educational experience. Inherent to the educational process in this country, the institution of schooling plays a role in shaping every child. Phenomena such as the consistent achievement gap and continuing poverty for African Americans mean different effects of schooling for African Americans compared to the White majority. However, education and schooling can potentially play a larger role than it currently does in empowering those who are most effected to make more constructive choices with their lives.

The role of school. According to Livingston and Nahimana (2006), the school system is a primary and extremely important source of socialization in the Black community. They further state that the relationship between early school failure, high 
school dropout, delinquency, and employment requires that the role of the school system and early interventions must be examined to address the challenges facing Black males in America. Unanswered questions such as "What are the structural, social, and psychological challenges our young Black males have to navigate?" and "What are the pervasive expectations of Black males in our schools?” (Livingston \& Nahimana, 2006) are crucial for understanding the interactions between teacher and student, which ultimately determine what the child learns.

Pianta and Stuhlman (2004) found that successful school functioning is related to early literacy and language development and competencies in relationships and selfregulation. They studied the effects of teacher-child relationships on early school adjustment and social and academic functioning at first grade, finding small but significant associations between teacher-child relationships and social and academic functioning in early school years. In another study, Hamre \& Pianta (2001) found that kindergarten teachers' perceptions of relationships with children and their overall adjustment were predictive of academic and behavioral skills through the eighth grade. Moreover, Hamre \& Pianta (2001) found that negativity in teachers' relationships, especially with boys, robustly predicted long term school adjustment.

Downer \& Pianta (2006) argued that pathways for later educational success or difficulty are formed during young children's early adjustment to school (also see: Entwisle \& Hayduk, 1988; Hamre \& Pianta, 2001). Prekindergarten cognitive skills and math and reading achievement during first through third grade tend to be maintained into early and late adolescence (Reynolds, 1994; Stevenson \& Newman, 1986), although there is clear evidence that stability is only moderate in the early grades (LaParo \& Pianta, 
2001). In addition, early academic problems place children at risk for grade retention and school dropout (Alexander, Entwisle, \& Kabbani, 2002; Consortium of Longitudinal Studies, 1983), factors also identified as indicators of subsequent incarceration. If it is true that opportunities remain limited after the third grade to alter an academic developmental trajectory, understanding the factors that shape the early phases of achievement trajectories during the preschool to primary-grade period, has implications for early mobilization of educational resources (Downer \& Pianta, 2006). Educational attainment is often linked to levels of success in later life. It is difficult to say to what extent positive experiences in early education can actually prevent negative life span outcomes. It is reasonable to suppose that such experiences can foster greater success in the early years of primary schooling. Thus, more protective factors may be set in place by the time academic disidentification and negative associations would have manifested.

According to Noguera (2003), we know little about the perceptions Black males form of schooling as a result of cultural and environmental forces upon them. As well, we have yet to understand how their perceptions influence their school behaviors and academic performance. Further, we do not know "why being Black and male causes this segment of the population to stand out in the most alarming ways, both in school and in the larger society" (Noguera, 2003, p. 433). In light of the strength of relationships which seem to be developing between troubled educational histories and subsequent arrest and incarceration, further knowledge of the specific ways in which schools may either contribute to, or prevent, the flow of African American males into the criminal justice system is warranted. The researcher is interested in understanding the lived 
experiences of an affected group of African American males from their own points of view. 


\section{Chapter 3}

\section{Methods}

\section{Sample and Participant Selection}

The participants for this study were selected using the technique of purposive sampling. Specifically the researcher used criterion sampling. The researcher was interested in learning three things about African American males who had previously been incarcerated. First, the researcher wanted to understand how these men structured their lives to avoid recidivism. Second, the researcher wanted to understand how they have determined their choices and what has changed in how they do so. Third, the researcher wanted to explore what bearing the experiences associated with formal education had on the choices these men have made over their lives. Thus, participants of this study were selected among African American males who were previously incarcerated and were managing to live successfully in their communities at the time of their participation in the study.

The inclusion criteria required a minimum of one year since their release from prison with a preferred time of three years. This is because three years is the most common length of time used for measuring recidivism across the U.S. (McKean, 2004). The most recent figure on recidivism in the state where this study was conducted is $51 \%$ (Pew, 2011). Probability of recidivism tends to decline after three years. Only two participants in the sample had less than three years since their release. Each had only been released one year before participating in this study.

In qualitative research, it is acceptable to use more than one type of purposive sampling technique. The absence of theory to answer the questions of the study 
necessitated interviewing ex-offenders of varying characteristics (i.e. age, type of crime, years of incarceration, etc...) to provide maximum variation. This made it possible to examine whether a sample of men of varying ages and criminal histories expressed common themes pertaining to the characteristics of interest. Additionally, the researcher employed snowball sampling, to access members of this population who prefer to remain hidden. In this method, prior participants suggest potential participants who may also meet the study criteria.

The sample size for a grounded theory study is determined by the number of interviews necessary to reach saturation. Creswell (2007) defines saturation as the point at which no new categories of information can be identified from additional interviews. Saturation can occur after 20 to 30 interviews or more (Creswell, 2007). Over the course of data collection, 26 individuals were contacted in five cities across a Midwestern state in the U.S. and asked to participate in the study. Twenty of the individuals that were contacted agreed to participate. One individual declined. Three did not respond to the initial contact of the researcher. One agreed to participate but did not respond to the researcher's attempts to schedule an interview. One expressed interest in participating but did not meet the criterion for length of time since release from his most recent incarceration. All initial contacts were made in person or by phone. With prior permission, the researcher also contacted prospective participants by email.

The twenty participants ranged in age from 27 to 68 years old $(M=45.75)$. They reported their years of incarceration ranging from one to 34 years in prison $(\mathrm{M}=13.55)$. Fourteen of the participants reported serving only one prison term, ranging from one to 34 years in prison $(\mathrm{M}=12.64)$. The remaining six participants each reported serving from 
two to eight prison terms due to new crimes and/or parole violations. The participants who were able to reported their ages at the time of their first incarceration ranging from sixteen to 48 years old. The average age at the time of incarceration for the sample is 24.4, with two missing. For more detailed information about the participants, including demographics and backgrounds, see Appendix A.

\section{Procedures for Soliciting Participants}

The researcher initially contacted in person and by phone eight individuals whom he knew from professional and community associations and believed would meet the study criteria. One declined to participate. One did not meet the study criteria due to the short length of time since his release from his most recent incarceration. The remaining six agreed to meet with the researcher to discuss the study and determine their eligibility. Each was eligible, with $12,11,11,7,5$, and 1 years since their release from incarceration. Each consented to participate in the study. Incidentally, each served only one term in prison. After the interviews, participants were asked if they could refer other participants who might fit the study criteria. Requesting referrals in this way resulted in the researcher contacting eighteen more individuals to participate in the study. Fourteen of them met the criteria and consented to participate. Each of these individuals was contacted by phone or email, with his permission, and informed that he was referred for the study by a prior participant. Meetings were scheduled at their homes or in a private location in the office building where the researcher was employed.

At the start of each meeting, the participant was asked to read and sign the Informed Consent form. Please see Appendix $\mathrm{C}$ for a copy. He was allowed to ask any questions or express any concerns prior to signing the consent form. The researcher 
reiterated that participation was voluntary and that the participant could discontinue at any time without penalty. The participant was also reminded that he would receive no compensation for his participation. Each person that met with the researcher completed the entire interview.

\section{Data Collection}

Data were collected through individual, semi-structured, open-ended interviews with each of the research participants. Each interview was recorded and transcribed for coding and analysis. Interviews were held in the participants' homes or in a predetermined, private location to ensure confidentiality. All interviews were conducted by the researcher to ensure fidelity and adequate exploration of the variety of material that the participants would potentially provide. No incentives were provided for participation. The purpose of the study was explained prior to beginning interviews and informed consent was reviewed and signed. Those who chose to participate did so based on the merit they attributed to the study and their willingness to discuss the personal aspects of their lives that were explored in the interviews. Interview questions were designed to gain a substantial depth of understanding (Rubin \& Rubin, 2005) of each participant's perceptions relating to their school experiences and incarceration. Also of interest were the participants' feelings about their current lives and any contrasts between their current and former goals and values.

The interviews were structured using a list of main questions (Rubin \& Rubin, 2005) to facilitate the participant's discussion of his: 1) understanding and perception of "legitimate goals" (King, 1948); 2) views of connections, or the lack thereof, between his responses to formal education and his choices leading to his incarceration; 3) past and 
present emotions associated with his educational experiences; and 4) perceived needs from formal education to improve his latter outcomes. Please see Appendix B for a complete list of main questions. Prior to conducting any interviews, the interview protocol, which the researcher developed, was reviewed for face validity by two of his doctoral committee members. Two participants were chosen to help pilot the protocol. These men were chosen based on their familiarity with the researcher and the researcher's expectation that they would provide objective feedback about the questions asked and the interview experience. Both reported that the interview flowed well and that the questions seemed clear and logical. Additionally, they expressed that the interview was a positive experience which caused them to deeply reflect on areas of their lives in ways that they had not done before. Their interviews were transcribed to begin the process of identifying themes. The pilot participants' feedback and transcript reviews resulted in no changes to the original protocol. However, it was determined that it may not be necessary to ask all of the protocol questions in each interview.

Demographic pre-interview form. Prior to beginning the interview, the participants were asked to complete a demographic form to provide information about their correctional histories as adults and as juveniles, educational attainment, feelings about himself as a student, current vocation, and any history of incarceration in their immediate families. This information was collected to identify categories for comparison. For example: How are prior and current goals of high school graduates similar to or different from participants who obtained GEDs? The information about how they felt about themselves as students was used to corroborate the presence of academic disidentification during their times of formal schooling. A copy of the Demographic Pre- 
Interview form is provided in Appendix D. The interview followed immediately after a brief review of the demographic form for clarity.

Interview. The primary data collection method was the participant interview, which ranged in duration from one to four hours. The longer interviews were conducted over two sessions. Sixteen were completed in one session. All interviews were audio recorded and transcribed. The researcher employed a semi-structured format, which allows flexibility to expand on questions or probe for clarity. In some interviews, questions were omitted when it was determined that they were answered in earlier responses. The researcher brought to the study previous interview experience from former professional activities and many hours of clinical interviewing in multiple settings, including graduate training, private practice, and correctional institutions.

The interview protocol consisted of 39 questions in addition to an introduction statement and a conclusion statement. The researcher introduced the interview with a quote from Dr. Martin Luther King, Jr. (1948), which inspired the study. The quote was then explained, and the participant was asked for his thoughts about the quote. This was done to provide the participant with an overall framework for the interview while also inviting him to openly express himself within that framework. The interview questions were grouped into three major themes.

The first ten interview questions focused on the participant's level of satisfaction with his life, currently. Questions included: What do you like most/least about your life right now?; How would you like for your life to have been different?; and What choices got you to where you are in your life right now? These questions were to encourage the participant to take a reflective inventory of the choices he has made and the outcomes he 
has obtained. Other questions: What were you trying to achieve before you were incarcerated?; and What would you do differently if you could start your life over?, are intended to stimulate the participant to evaluate the merits of his choices and outcomes. With this information in mind, it was expected that the participant would consciously explore and discuss alternative ways that he might have achieved more desirable outcomes and greater satisfaction in his present life.

The next section of fourteen questions led the participant through a discussion of his feelings associated with school and school-related factors, encouraging him to name the benefits or impact he perceived in his life from formal education. This required participants to reflect on past experiences and try to accurately recall circumstances and events and their emotional responses to them. Four questions in this section begin with the stem: "How did you feel about____?" Each of these questions is followed by two probes to clarify why the participant felt the way he did and when those feelings approximately began. Participants also needed to articulate meaning they assigned to what they remembered, both at the time of the occurrence and in the present day. The final section of fifteen questions was constructed to assess the participants' present goals, values, and value systems, and their related beliefs about school and education.

At the conclusion of the interview, the researcher repeated the quote that was recited in the beginning and asked the participant if he had any further insights to share regarding the quote or if he had any other questions or comments before closing the interview.

\section{Data Analysis}


The intent of grounded theory is to "generate or discover a theory" (Creswell, 2007, p.63). The process entails breaking down, organizing, and reassembling data to achieve a different understanding of the phenomena in question. Through the constant comparative method of analysis, the researcher and three assistants used the process of open coding to determine "major categories" (Creswell, 2007, p.64) of information. After identifying the major categories of information, axial coding identifies the category on which to focus, called the core phenomenon. The other categories are then arranged by their relationship to the core phenomenon. Strauss and Corbin (1990) define the emerging relationships as: 1) causal conditions - causes of the core phenomenon; 2) strategies - actions taken in response to the core phenomenon; 3) intervening conditions - contextual factors influencing the strategies; and 4) consequences - outcomes resulting from the chosen strategies. Open and axial coding happened sequentially and concurrently as the major categories and core phenomenon emerged from the data. The final step of selective coding is providing a model of the interrelationships between the core phenomenon and identified categories with explanations of the hypotheses supporting the model's structure.

The researcher enlisted the assistance of three peer debriefers to add credibility to the coding process and data interpretation involved in creating the theoretical model of Facilitation of Legitimate Goals. Two of the peer debriefers were advanced doctoral students at a large Midwestern university. One was conducting her own study involving qualitative methods and coding. The other had less experience with qualitative methods but was familiar with the constructs examined in this study. The third debriefer is an Associate Professor of Educational Psychology at a large Midwestern university. The 
researcher assigned sections to each debriefer. The researcher and debriefers collaboratively and systematically codified categories emerging from the research data and determined the logical relationships between them. Feedback on the study results and the theoretical model was provided by a Professor of Sociology at a large South Atlantic university.

Open coding. The purpose of open coding is to begin breaking down data into representations of objects and events. To do this, interviews were transcribed, and then the participants' responses were broken down into phrases representing their main ideas. Review of the data from interviews resulted in a list of 221 concepts consisting of ideas, events, and meaningful experiences. A list of phrases representing each participant's response to each question was sent by email to each debriefer according to the section she or he was assigned to review. The researcher provided them with explicit, written instructions to perform their tasks (Appendix E). Each debriefer reviewed the list of phrases and grouped them into categories which they labeled. Next, they returned the reorganized lists with category labels to the researcher. The researcher compared the debriefers' groupings and categories to the original 221 concepts to check for agreement and divergence. This step resulted in regrouping some of the original categories into larger, single categories as well as creating new categories. Through follow-up conversations, the researcher and debriefers determined the appropriate categories which would be organized and reassembled in the axial coding step.

Axial coding. Axial coding consists of arranging the categories produced through open coding into main and subcategories. This process continues until one category emerges as the central focus of the data (Creswell, 2007), called the core phenomenon. 
In essence, the raw data that is disassembled with open coding is reassembled by axial coding to create a more meaningful picture of the participants' experiences. Creswell (2007) referred to this as a "coding paradigm" (p. 67) that may include causal conditions, specific strategies, context, intervening conditions, and consequences that help to explain the core phenomenon. To define the core phenomenon, the researcher conferred with the debriefers through multiple iterations of data configurations until the fewest number of meaningful categories was derived from the participant's interview responses. At the end of this stage, twelve categories emerged as salient themes of experiences. Facilitation of legitimate goals was determined to be the most central theme embedded in the statements of these twenty men as they answered the interview questions and talked about their school experiences and their past and present values.

Selective coding. Once the core phenomenon and major categories are identified, the researcher proposed a model fitting them together with hypotheses for the interrelations between them. Ultimately, selective coding resulted in articulating a theory drawn from the participants' statements about their experiences pertaining to the constructs and phenomena that were studied.

\section{Trustworthiness}

Creswell (2007) suggested that "any report of research is a representation by the author" (p. 207). He made explicit his opinion that “'validation' in qualitative research [is] an attempt to assess the 'accuracy' of the findings, as best described by the researcher and the participants" (p. 206). Qualitative researchers use terms such as "validation" (Creswell, 2007) or other words such as Lincoln and Guba's (1985) terms "trustworthiness," "authenticity," and "credibility" (p. 207). Creswell (2007) proposed a 
list of eight validation strategies to ensure that a qualitative study is worthy of trust as conveyed by these terms and recommended all qualitative studies include at least two ( $\mathrm{p}$. 209). Four validation strategies have been employed in this study and are discussed below.

Thick description. Detailed description of the participants or setting of the study allows the reader to determine the extent of transferability of the results of a study (Creswell, 2007). The concept of providing a high level of detail in qualitative research is called thick description. It provides readers with information about characteristics of the study and the research sample. Criteria for participation in this study and recruitment strategies were discussed previously. A demographic questionnaire was included in the data collection process to gather information about each participant's age, number of years of incarceration, juvenile and adult corrections involvements, educational attainment, current educational and vocational activities, and incarceration of immediate family members.

Field notes were written following interviews and during transcription. See Appendix $\mathrm{F}$ for an example of a complete field note following the interview of a study participant. These notes documented what the researcher interpreted as the essential material that each participant provided to each question during his interview. The field notes also include the researcher's remarks of his own experiences, reflections, and interpretations of what happened and what was said during each interview. Important ideas of individual participants and statements contributing to developing themes were particularly noted in the field notes. Further notations of developing themes as categories were maintained to chronicle which ones were discarded and which ones were confirmed 
and incorporated into the resulting model. In addition to their contributions to thick description, Creswell (2007) explained that creating field notes in this way also enhances reliability in qualitative research.

Theoretical sampling. A systematic approach to grounded theory research employs theoretical sampling (Strauss \& Corbin, 1990). Corbin and Strauss (2008) define theoretical sample as "a method of data collection based on concepts derived from data" (p. 144). This sampling process is guided by the discovery of concepts that emerge as data are analyzed. It is an open and flexible approach intended to sample concepts rather than verify or test hypotheses about concepts (Corbin \& Strauss, 2008). Ideally, the researcher intentionally selects participants based on indicators of the particular concept of study. This allows the researcher to examine how concepts vary under different conditions. Sampling continues until concepts are defined and explained; this is known as saturation. Corbin and Strauss (2008) discussed practical variations of theoretical sampling when the ideal model cannot be employed. Three variations of theoretical sampling were incorporated to add to credibility of this project as a grounded theory study.

Purposeful sampling was discussed in this chapter. Participants were identified and selected who met the study criteria: African American male; previously incarcerated; at least one year since release from incarceration. This allowed for the examination of concepts across demographic and background variables. Data were also gathered using a systematic approach (Corbin \& Strauss, 2008). When individuals were referred as potential participants, the researcher traveled to the cities where they lived and scheduled as many interviews as possible while there. Theoretical sampling identifies significant 
commonalities and variations within concepts by sampling incidents and events. This entails returning to the data repeatedly and reorganizing them according to theoretically relevant concepts (Corbin \& Strauss, 2008). These procedures were instrumental to the completion of this study and the development of the resulting model.

Peer debriefing. Three peer debriefers voluntarily assisted the researcher with external checks of the research process. Roles of peer debriefers include asking questions about study methods, meanings of terms and ideas, and interpretations of participant statements. They may also provide general support to the researcher as needed through the course of the study. In the open coding phase of analysis, each debriefer reviewed participants' responses of sections of the interviews as assigned by the researcher. The researcher and debriefers separately coded the data. The results were compared and discussed for intercoder reliability and to agree on the categories for further evaluation of axial coding. The peer debriefers provided further feedback in the axial coding and selective coding phases of analysis. These discussions helped to determine which categories were most salient to the data the participants provided. After the core phenomenon was identified, the debriefers gave feedback on various configurations of the proposed model and on the fit between the final draft and the data acquired from participants.

Research bias at study onset. It is important to clarify any biases or assumptions of the researcher which may impact the inquiry. Transparency allows the reader to consider how the researcher's position may have shaped the approach to the study and interpretations of the study data. The researcher is an African American male with a professional background in Corrections. While working in the Department of 
Corrections of a Midwestern state, he formed impressions about the lives of the individuals with whom he worked and desired to understand their motivations for engaging in criminal activities. Further, the researcher conceived this study believing that education is a powerful means to promoting self-discovery and preparing students to select and pursue life goals that are both useful and meaningful. The researcher continues to believe that there is value in any exploration that increases understanding of the problems of appropriate goal selection, persistence, and achievement for all individuals, and especially for African American males. These characteristics might suggest a propensity for the researcher to engineer the outcome of this study. For this reason, the researcher took care to employ all of the above measures in this project to increase his accountability and the credibility of the study. 


\section{Chapter 4}

\section{Results}

The researcher was interested in understanding whether academic disidentification plays a role in what appears to be the failure of some African American males to acquire legitimate goals through formal schooling in addition to the skills and agency to pursue and achieve them. To explore this question, the researcher employed a grounded theory approach with a sample of twenty African American males who had experienced one of the most severe social consequences of negative choices in the U.S. incarceration. The decision to interview men who had been previously incarcerated was influenced by the assumption that people who are involved in criminal activities have rejected the concept of legitimate goals as defined by society. The focus on African American males was chosen due to the sizeable disproportion of African American males in prison when compared to the proportion of African American males in the U.S. population and when compared to the numbers and proportions of other U.S. groups in prison. Additionally, researchers (Cokley, 2002; Osborne, 1997) found that African American males academically disidentify significantly more than other groups in the U.S.

This study was constructed to examine the presence of legitimate goals in the lives of these twenty men prior to and since incarceration. During their interviews, these men were also encouraged to reflect upon their school experiences and related feelings. The information obtained was used to determine whether they were academically disidentified. The researcher utilized the constant comparative method of analysis to construct a theoretical model illustrating the development and pursuit of legitimate goals for these men. The flow of the information in this chapter is presented in the way that it 
emerged as the researcher followed the path the participants' data. An indirect relationship is posited between academic disidentification and the lack of legitimate goals as is fitting for this sample.

\section{Academic Disidentification}

Demographic survey results. Three demographic questions were asked to ascertain whether participants disidentified during primary and/or secondary school. The first question asked: What kind of grades did you get in school? The responses allowed were: Mostly A's, Mostly B's, Mostly C's, Mostly D's, or Mostly F's. The next two questions asked how the participant felt about himself as a student and in general. The responses options were: Pretty good, Pretty bad, or Neither good nor bad. Given the definition of academic disidentification that suggests the absence of a positive correlation between school performance and general self-esteem, participants who indicated poor grades with neutral or positive self-regard would be categorized as academically disidentified.

Nine of the twenty participants reported earning mostly C's or worse with neutral or positive regard for themselves as students and/or in general. Two of these nine participants reported graduating from high school. All nine qualified as academically disidentified by the above definition. They attributed the disconnect between their performance and their feelings about themselves to lack of concern, no direction, or other sources of esteem. One participant stated, “I just didn't care and I never really connected the dots. I was always bored in school. I just didn't get it...was probably more concerned about my social status." Another stated, "Not having any purpose or direction." A third stated, "I had a lot of self-esteem. Everyone liked me at school." 
Four participants reported earning mostly C's or worse and feeling pretty bad about themselves as students. Three of these participants also reported feeling pretty bad about themselves, while the fourth indicated feeling neutral about himself, in general at that time in their lives. Explanations given for why they felt the way they did included: "I couldn't keep up with the Joneses," and "I just didn't care." One participant had this to say about his school behavior and his self-regard:

I knew that I wasn't no dummy, but your actions... because your actions make you feel bad. I mean, things that you do make you feel bad, so I wasn't applying myself. I'd go to school and sleep and crack jokes and stuff all the time, so...I felt bad about myself, but I thought I was somebody, but in the inside, I felt bad about myself. [J.A.]

All four of these participants disclosed that they struggled academically. Two experienced difficulty early on in elementary school. The other two encountered their difficulties after transitioning to middle school. The remaining seven participants reported earning mostly B's or better and expressed neutral or positive regard for themselves as students and in general.

The demographic survey results suggested that nine of the twenty participants showed some indication of having been academically disidentified when they were in school. Information obtained through participant interviews revealed somewhat of a different picture about the academic disidentification of the entire sample. Statements from all participants discussing their feelings about and activities in school, regardless of the grades they reported, made evident their lack of commitment to or conscious disconnection from the academic purposes of school and formal education. 
Feelings about school. Fifty percent $(\mathrm{n}=10)$ of the participants responded to the interview question asking how they felt about school with statements that indicated school was meaningless to them. By virtue of their responses to the demographic survey, only seven of these ten participants would be considered to have been academically disidentified in school. However, meaninglessness is historically counted by sociologists as an essential factor in the developmental process leading to students dropping out of school (Finn, 1989). This is likely a better measure of their academic disidentification than the demographic survey items. Their response to the question pertaining to how they felt about school can be characterized in statements like: "It wasn't valuable;" "It was kind of stupid;" "It wasn't important;" and "It was a waste time." All ten of these participants left school prior to graduation. Nine completed GEDs before or during their times of incarceration.

It is interesting to note that two of the participants in the meaningless category reported earning mostly B's in school. However, both of them reported going to school in an era when segregation and blatant racism were still very much the norm where they lived. One expressed a deep enjoyment of school prior to integration which forced him to change schools and exposed him to harsh treatment from White teachers. He stated: ... we had teachers that was sincere about us learning. They cared about us, and they valued education, and they instilled that in us. Well, when I went over here to [the newly integrated school], that wasn't the case at all. The teachers didn't want us there. They were racist. Later on, it became a little different, but by then, I had already done went down that wrong path. When I got to [high school], it was that 60 's atmosphere with the Black Power, the whole... We had some 
brothers from the [the local university] - the first [center for Black students] there was some brothers there that I was introduced to, through partying of course. They came to [my high school], and they was over there talking about, 'This is racism' and all of that. So, the school actually created an after school program...where the two races come together and discuss issues and stuff like that...It was different. The teachers was different, but by then, I had already been molded in that mold. [L.O.]

When asked specifically about how he felt about school, he stated, "I felt like school wasn't valuable to me. It wasn't valuable to me. I had lost my love for it. It wasn't something that I looked at as being necessary for me." The other participant reporting good grades stated:

Studying, I didn’t ever study. I always passed...you know...by...I don’t know. I don't know what it was that got me through, but I always made good grades. I didn't do a lot of studying. I didn't have that academic interest... where I came from and my morals and standards and values that I chose to act on were shaped during the years of segregation, and I experienced a lot of that...not a lot of it. I experienced some of that, you know, going into colored only bathrooms and not being able to sit down at the lunch counters and that kind of thing. I experienced a lot of that as a kid, coming up, and that shaped my ability to be receptive to the class society. I didn't...Education, to me...I began to develop the idea that education, for me, didn't mean anything. What do I need to go to school and...Now that I think about it, that had a lot to do with discouraging my interest in the educational system, because for me, during that era, life looked real 
hopeless for an African American - what I could see. My dad worked all those years out there, and like I said, we didn't have nothing. So I think that turned me off on society and wanting to plug in and... That era, it shaped a lot of people my age. It shaped our psyche as far as our place in the world, and it didn't look real bright. It didn't...You have to understand, at that time, we couldn't see beyond segregation. We thought it would ALWAYS be like that. I think that did a lot to discourage...me I know. It discouraged me a lot from putting in the effort to this educational system, because what we told ourselves was it didn't matter if you had a high school education or not. You still wasn't gonna get the job that was gonna be the kind of job that we could be proud of. And that was at a crucial time. Like I said, '63, '64, and even before then when we traveled down south to visit my uncles and that kinda thing, and I remember going in the filthy bathrooms in the back of the service station for colored only and how they would stink and had feces all on the wall and "nigger" drawn on the wall and all that stuff, and we couldn't even go inside the service station...the water fountain...white only...colored...eating places. When you live in that and see that as a young boy... and it was some places [where I grew up] that were like that at that time. I guess I didn't wanna be a part of the system. [W.I.]

On his feelings about school, he replied:

Generally, just to be honest with you, generally, I liked school. I liked school, but here again, I liked school, but I didn't see the value in it. It's starting to come a little clearer to me. I liked school, but I started devaluing school from the perspective of school and my life experience - what I was actually seeing 
compared to what I was actually hearing, and there was some contradiction there, and I questioned that contradiction... I liked school, and I even liked to learn. I remember learning the constitution and the preamble and all those kind of things. [W.I.]

Both of these participants earned college degrees during and after their times of incarceration and expressed interest in returning to college to earn advanced degrees during their interviews. Other participants expressed different reasons for experiencing feelings of meaninglessness about school. To sum up these perspectives, the content of the curriculum was not relevant for survival in the neighborhood, priority was giving to social status and peer acceptance, it felt like prison, it lacked challenge, and the pace was too slow.

Responses from other participants were categorized as expressing positive, negative, and mixed feelings about school. Four of the study participants reported graduating from high school. Two of them reported making mostly B's in school. None of these four participants made statements about their feelings that suggested school was meaningless. However, one of the four stated that he hated going to school because no one really took an interest in him as a student. He thrived on the social status he enjoyed due to his athletic ability and participation in sports. He explained that the desire to keep him eligible for extracurricular activities worked against him because he was allowed to just get by without being pushed to work hard academically. He reflected primarily negative feelings about school. He reported that he took college courses in prison, where he grew to enjoy learning. The participant referred to this experience as his "re- 
education," which resulted in his discovery of effective learning strategies and increased confidence in his ability to learn academically.

The remaining three who reported graduating from high school made statements about their feelings which were categorized as positive and declining. One of these participants reported that school was a positive place where he could escape from a very broken home, eat breakfast and lunch, and socialize enjoyably with his peers. He affirmed that he was academically inclined and admitted that he put more effort into socializing than into excelling academically. He acknowledged that he did acquire knowledge in school but attributed his discovery of "practical application and wisdom" to the time he spent in prison. After his release from prison, he earned a bachelor's degree and a master's degree at two separate institutions of higher education. He continues to pursue further advanced degrees. At the time of his interview, he held an administrative position at one of the institutions he previously attended. Two of these participants reported enjoying school until they turned their attention to distracting activities and influences. One in particular stated that he enjoyed school when he was young, but lost the enthusiasm around the ninth or tenth grade when he started using and selling drugs. He stated that he became antisocial after that and limited his socializing to a very small circle of friends. His statements were interpreted as expressions of declining feelings about school. He attributed his current discipline and work ethic to the courses he studied in computer programming while in prison. He declared that he became quite good at computer programming and took pride in the problem-solving skills he developed.

All but two of the sixteen participants who reported leaving high school prior to graduation also reported earning a GED before, during, or since incarceration. One of the 
participants who had not earned a GED reported a change in his feelings about school prior to his incarceration based on where he attended. He stated that he enjoyed going to school more when he attended urban, predominately Black schools than he did when he attended a predominately White, county school. At the latter, he stated that he felt inferior to his White peers and compensated by getting into fights with other students. He noted formal education as the source of his math skills, but he credited the knowledge he gained from "street education" for helping him to get where he is today. This participant currently owns and operates a clothing store and also owns and manages two transition homes in the community where he lives. The other participant reported growing up in a very economically depressed area where schools were poor. "Everybody was either - you know - going [their] own way, doing [their] own thing, gang-banging, or strung out on dope... my teacher told me one time. She said, 'If you come in class and sit down and don't talk, you'll pass.' So I did that with, like, three of my teachers." $\mathrm{He}$ indicated a lack of support for educational achievement from home and his community. He reported that he began to focus on improving his academic skills only after he was incarcerated and plans to earn a GED in the future.

Nine of the participants who did earn a GED made statements which fit in the Meaningless category pertaining to their feelings about formal education before they were incarcerated. In other words, they were unable to perceive any value in working to meet the academic expectations that were placed on them in school. The remaining five participants gave responses which suggested mixed, declining, and negative feelings about school over time. Three stated that they just did not like or "hated" school. They attributed their feelings to reasons such as academic difficulty, teasing from others, and 
mean, ineffective teachers. Each of these participants eventually became involved in the use or sale of substances or both.

One participant seemed to indicate mixed feelings about school. He commented, "School was a drag, but I enjoyed it." He added that he could do the work and get good grades but generally earned poor conduct grades. This participant identified a number of factors affecting his psychological and emotional connections to school. He reported that he enjoyed the academic challenge he experienced in the classroom and drew motivation from competitive rivalries with some of his classmates. During the interview, he reflected on his transition to an elementary school where he felt unsafe due to conflicts between children from different neighborhoods. He recollected strategies he used to avoid getting into fights at school including staying home or not returning to the building after recess.

I remember a couple of times, man, I...To not go back to school, I remember, man, I snuck off during that recess, and it was a tree. I got over down by that tree, and...It wasn't no summer day. It was cold out. And I wrapped up, and I stayed there until school was over...trying to get a head start and get away. This [is] the first time I think I've told that that I can remember, but I did. [A.L.]

The strategy he found most effective was to become a part of the group he wanted to avoid fighting. "I had to fight first...you know, and became cool, but it was always a fear that they would turn on me any minute... Didn't nobody know what I was going through...Nobody." He eventually became involved in the use and sale of drugs.

The final participant can be categorized as expressing declining feelings about school. He reported doing well academically, especially in math. He also admitted that 
he was careful to keep his friends from finding out that he was "smart." He shared this story:

...what happened with that was that, they have this request of pleasure. It's like a talent show, and they bring all the honorees out to the stage to introduce them to all the other students. And they was calling them out according to [their] grade point averages. And I'm hearing them, and I'm like, 'Well, my grade point average is above a whole lot of people there. Why they ain't call me?' You know. And I didn't know that I wasn't being called because of my behavior. So I got offended, and I went home. I told my mom everything... [The principal] explained to her, 'Well, he been into this. He been doing this.' I didn't want it to be known that I was doing a whole lot of other things. [A.N.]

He explained that things changed definitively for him after he was expelled from his high school for fighting and was forced to enroll in another school. He talked about how this separated him from his community and all of the peers with whom he had matriculated through school. He was in the eleventh grade at the time. He depicted a bond with his former school and his peers that he was unable to recreate at the new school. After approximately two months, he stopped going. The stories these participants shared contained rather prominent evidence of disidentification with and/or intentional disengagement from formal education at some time during their years of primary and secondary schooling.

Participants were also encouraged to discuss their feelings about their teachers and peers to explore how their feelings in these domains related to their feelings about school. Participants who expressed generally positive feelings about school also 
expressed generally positive feelings about their teachers and peers. Three of four participants who expressed generally negative feelings about school also indicated feeling that their teachers did not care about them. The fourth expressed a general distrust in authority figures, including teachers. Though no other patterns clearly developed between feelings about school and feelings about teachers and peers, more than half of the sample indicated that they got along well with their peers.

Further explorations included discussions about how the participants' families and friends felt about education. This was to glean information about possible influences on the participants' feelings about school. More than half of the participants indicated that their parents and/or others in their families stressed the importance of getting an education. However, no clear patterns developed from this sample between their own feelings about school and the feelings they say their families portrayed. Not quite half of the participants directly indicated that their peers' feelings about school were similar to their own, based on the others' actions and achievements. Nevertheless, the variability of responses to this question made it difficult to determine clear patterns between the participants' feelings about school and those of their friends.

\section{Shift in the Value of Education}

A common pattern appeared among the sample with respect to their past and present perceptions about school and education. The analysis of the participants' assessment of their personal choices and outcomes consistently indicated recognition of the relationship between their early attitudes toward school and outcomes later in life. To varying degrees, each expressed a greater value in formal education than what he understood or accepted when he was in school. Exploration of current goals and values 
suggested that the issues rising to importance among these men now strongly incorporates the roles of school and education.

Current life inventory. More than half of the responses from participants pertaining to what they are doing and what is going on in their lives right now were determined to be positive. Fourteen made statements indicating that their lives are progressing in ways that give them a sense of contentment, a sense of spirituality, and/or a sense of optimism. Four expressed feelings of uncertainty, confusion, or regret, which were categorized as negative. Reasons they gave for their feelings at the time were lack of sufficient finances for a better life style, lack of preparation for the future, desire for more education, and relationship problems. Two made statements that seemed to communicate a combination of contentment and regret. These responses were interpreted as expressions of mixed feelings about their life circumstances.

The picture shaped up differently when the participants were asked to focus on their feelings about what they were actively doing in their lives. Most (13) made statements that were construed as positive, based on expressions of contentment and/or satisfaction from helping others. Only one participant expressed a negative sense of uncertainty with regard to what he is doing in his life. However, six indicated mixed emotions about what they are currently doing in their lives. Two-thirds acknowledged productivity in areas of importance while also expressing concerns about areas in which they were making little or no progress. One participant who owns a business communicated his enjoyment of the work he does but dissatisfaction about his family dynamics. He stated: 
Work. Great! I couldn't ask for nothing better. I kinda, to evaluate myself, I let it take a little more time than I should. Even though it takes a lot of time, I spend a lot of extra time there to keep me super busy. So I will spend it at the shop just getting things ready. I ain't even gotta physically be at the shop, but I'll still be in my mind - I'm at home - just getting things ready for next week. So I spend a lot of time with that business to help me stay busy, which went back to another thought with my sister. Me and her were like this (gestures) when I left. We grew apart over the eight years, but we try to get it back and we were getting it back. We didn't have to try. We were getting it back, but the business kinda took us back apart again, and she just mentioned that about three, four weeks ago. Where I'm at in my life right now, business is great. Social life, I don't really have a whole lot of social friends that I go out with or anything like that. [J.O.] Others with mixed emotions were pleased to have attained a level of self-sufficiency, but were frustrated by their difficulties in securing employment. They earn a living by providing services to others but desire more stability. One stated:

I'm hard on myself, so I'm always wanting to do better. People give me credit and say that I'm doing great, but I'm 35 years old. I had to move back home. I lost my place, had to move back home. I still got a roof over my head. At the same time...I wanna be better. I wanna do better. So I'm never gonna say that I'm doing...that I'm satisfied with the way things are going with my life, because I'm not. However, I may be getting married next year. I'm in a courtship right now...graduating tomorrow...walk across the stage, going back in September, 
God willing, for my bachelors. I got good things going. The job market is giving more attention now than it used to, so that's not bad. [J.S.]

Presently positive. The things that the participants were most positive about in their lives clustered around five main categories: Exercising self-discipline to make good choices, Maintaining sense of peace, Helping others, Experiencing freedom and control, and Family relationships.

Presently troubling. The circumstances they reported as most troubling were organized into four categories: Finances, Job stressors, Exercising patience for desired outcomes, and Problems in relationships.

Previous values. Each participant talked about what was important to him when he was in school and what made those things important. The majority of responses pertained to something other than academic or educational concerns. Only two made reference to any personal importance attached to education at that time in their lives. Both of them explained how other things interfered with their interests in education. One summed up his experience with a rather brief statement:

At first, it was education and sports. Then, man, just, like, the bottom just dropped out. The only thing that was important was getting out, getting out so I could be on my own... cause I wouldn't have to have nobody telling me what I had to do. I could be on my own. I could do whatever I felt like it, when I felt like it. I thought that...In other words, I thought being grown was the cool thing. I didn't know the responsibility that came behind it. I just wanted to be out from up under [my mother's] rule. [I] just wanted to do my own thing. You know, I thought that was cool. [G.A.] 
The other provided more background with his explanation.

I would say that, as I'm looking back, going through my mind, education was just, period, was instilled to be important. Again, you got to go back to that era, and during that era of time, education was extremely important in the African American community. And I'm not sure, but in my mind, it was because it was denied to us, and so it's kind of strange, in my opinion, that when you deny something from folks, that's what they want it the most, and they push for it. That might not necessarily be the case, but I know that it was instilled in our community that education was the number one thing that anyone and everyone should be striving to get... when integration came about, then those teachers that I encountered actually, in my opinion, pushed me away from formal education. Yeah. I mean, education have always been there. It was always a top priority, but what had happened was, when a person, even if it's real important, if you don't feel like there's an opportunity for you, then you get...you become despair in that area. And instead of - and I think that this is true, throughout. Instead of constantly being in despair, you just push it to the back burner...education and money was tied together. And that was something that I saw as a way of prospering in society. I already had that instilled in me that this was the way for me to be socially mobile, upward. Well, when that was seemed to be taken, now I got to figure out another way. So, then that's when I began to look around to see what other methods was people prospering in the community. Well, all the professionals had moved out. Those that were remaining IN the community that we could see was those that learned how to survive illegitimately. And those 
were the people that we begin to imitate, my friends and I, and learn. And, even that became an education. We begin to really study. I did. So it was still me embracing education. I STUDIED the best and how they did it. [L.O.]

Acceptance and social status. Most of the responses omitting education pertained to gaining peer acceptance and maintaining social status. For example, one participant explained, “...it was just important to me how I looked, because I...even though I didn't apply myself, I could still look fly. I mean, just...I may be a dummy, but I don't look like a dummy. You know?" Another offered more insight about what was most important to him:

Probably the other students' perceptions of me... Whether they were white, black, girl, female, teacher, whatever. I had...I don't know. I guess I really let their opinions of me affect ME. Like, even the opinions of the teachers affected me. Like, the opinions of the other students' really affected me. How they viewed me as an individual or how they perceived me as a person, you know, that kinda messed me up, too. I don't know. It's really more what I focused on was like that type of stuff, like them accepting me, whether it was just like these two dudes over here that I'm hanging out with or whether it was the whole classroom to accept me, which that really doesn't help, for real. It's like, if you want the whole class to accept you, you know the whole class ain't gonna accept you, but you got this expectation. You know what I'm saying. So, it just depends. You do certain things to get, like, different results and stuff. [D.A.]

He went further to explain why peer acceptance held such importance to him at that time in his life: 
Like I said, probably just the whole fact of being accepted, for real, because I basically kind of feel like a rolling stone, like I said, like a third wheel. Like, I didn't really have, like, a stable home environment. So, it was just like I was always looking for that acceptance factor. You know what I'm saying? Like, if I crack this joke and she laughs, well then she must like me, or she might like me or she might talk to me or...So, I mean, it's more of that type of thing. [D.A.] Various other values. Other themes of importance arising from information participants shared were labeled as: Desire to have money, Satisfying other needs or interests, Participating in sports, Assurance, and simply Not being there. One participant clarified his need for assurance.

I think I used to always think about what was gonna come out of it. What was it going to amount to? That's what I always thought. What is this going to amount to? That was always the question. I was always curious about that. I didn't allow myself the opportunity to see what it was going to amount to. I don't even know, at my age, what even sparked that on me, but I can always remember that, man, a question. What is this about? Like I said, the concept of mathematics, based on the way that it was being taught to me, became something relevant for me. But every other subject, I was like, what is this reading History going to amount to? I think that that question may have derived from History, because I can always remember, reading the History courses, that we was in this condition, and this people was in this better condition, and that we was always subservient, and that's been our role. Then, as I grew older, I start seeing that's the role that we play. But now, I come to learn, here, in my later years is that that ain't always been the 
case. That period in our life begun somewhere. You know? Then I look beyond that period and I come to find out that we have a whole lot of civilized things going on before we became laborers for somebody else. [A.N.]

Importance of previous values. The quotes from the two participants above provide examples of some of the themes that these men collectively identified as important to them when they were in school. These quotes also offer some insight as to why these things were important to them. As indicated by the reference to lacking a stable home environment, an emerging theme for what made something important was Compensation for something lacking or Facilitation of a personal interest or objective. The majority of the reasons participants gave for naming the things that were important to them were interpreted as fitting this category.

Quite frankly...I didn't have anything else. You know? It's kind of like, I'm thinking of, again, the movie Malcolm X. You know, he says, 'all a man has is his rep,' and that's all I had. I mean, what do you have at home? You have a drug-addicted mother, you know, no food in the refrigerator, etcetera, etcetera... You know, no cable, no TV, no phone, you know? All I had was the image that I presented, projected. I was wherever I found myself, and so, at school, I was Mr. Cool. When I learned how to dance... When I learned how to do that dance, man, I literally...It changed my world... it just opened that social aspect which spoke to something deeper, more significant to me, which was your sense of self. [N.A.] 
That's where I was truly accepted at. That's why I was 'that guy.' You know what I mean? As far as sports, that opened up my social life to these girls who really wouldn't be messing with a black dude for real. But they see me... It's the star who comes with it and physical I guess probably in there somewhere. That's why sports were so important to me. I know sports opened all the doors for me. It opened all the doors. With that, I had no questions if I can come in or not or if somebody might not even want me there for that. They gonna pick me. They want me to be there for that. So with that, being a young kid, I just knew that was my ticket basically. You know what I mean? [J.O.]

The other categories of reasoning determined from participants' responses were: Loss of hope/interest in school; Desire for positive reflections of self; and Social interests and Desire to affiliate.

Merits of personal choices and outcomes. All but two participants reported that they were trying to achieve or were invested in something that would not constitute the pursuit of legitimate goals leading up to incarceration. A major category resulting from the analysis of their statements was called Priority of Self-Centered Values. This category was originally thought to be the core phenomenon around which a theoretical model would be constructed. However, it was determined through further analysis that the formation and maintenance of this value structure for these participants was more accurately posited as one of several distinguishable factors in a much larger process of acquiring a more healthy regard for self and others. Priority of Self-Centered Values and the themes characterizing what participants reported that they were trying to achieve before they were incarcerated will be discussed later in the chapter. 
Meeting important needs. Responses to the same set of questions from which the category of Prioritizing Self-Centered Values emerged also produced rival category that was called Meeting Important Needs. Four participants gave responses contributing to this category. One of these participants whose activities were interpreted as fitting this category reported that he committed his offense in reaction to the violent murder of his older brother. He was approximately nineteen years old at the time and had left school as an eleventh grader two years prior. He denied any involvement with gangs or drugs but disclosed completing two years probation for an unrelated offense prior to this event. He stated that he was employed and was working to provide for his young family.

I had a couple counters that I was working at...I'm working this job, and it's going good. You know, little job, for seventeen, nineteen, whatever. One night, they had a house party in our community, and the young lady that my brother was dealing with, at that time, had gone to this party. Her and a couple of her friends stepped outside the party... on the way back in, the guy tried to accuse her of not paying and they was arguing with him. Her and the guy get into a fight, and he end up beating her up. You know - male against a female. So when my brother came around, they told him that the dude jumped on her. He end up whooping the dude...when he was about to leave, got in his car to leave, about five guys jumped down on the car and started shooting the car. They killed him. So when I got off of work that night, on my way home, I see all these sirens in our neighborhood, and I go down here. Everybody's running towards me telling me what happened. So, he died. So, I snapped out. My brother was, at that time there, my world, being as I didn't have no father at home. That day, there, [my mother's] whole 
world turned upside down, cause she lost both of us in one short hour. I end up killing one of those guys with the intent of killing all of them. I thank God, today, that I didn't, because I know, then, they would have put me on death row. [A.N.] The other respondent stated that he was interested in graduating from high school primarily to please his mother. Though this goal, as he framed it, should be considered a meaningful pursuit, he stated that he left school in the tenth grade and earned his GED only after going to prison. Additionally, he was candid about his gang affiliation and involvement in selling drugs prior to leaving school. These facts about this respondent's former life strongly suggest that his primary activities were not aligned with the pursuit of legitimate goals.

Desired differences-passive. As these men explored circumstances of their lives, they were asked to think about ways in which they would have liked for their lives to have been different. They were further asked to think about what things they would do differently given the opportunity to go back and do so. Two primary themes emerged regarding the differences for which these men wished. One theme related to stronger parental guidance. The second theme entailed personal choices. Two additional, though lesser occurring, themes pertained to community-based factors and the participant's appreciation of his current identity.

Paerntal guidance. A participant had this to say about family support:

I love my folks, man. I love my parents. I wish they'd stayed on my ass a little more about education, about just be who you are. You know, I was who the public made me being an athlete in that small area. It's like that in bigger areas too. If you a star athlete in Dallas, Texas, you're still a star athlete. You are that 
guy. So I wish they'd kinda helped me with that. Because while everybody was making me lazier or taking away from me, they were catering to me so much, I wish my folks would have stepped in and kinda guided me through that. You know what I mean. I wish they'd been a lot more hands-on. But I know what they were thinking. They were thinking he already knows how to be right. I don't have to tell him. We taught him that, but some verbal support would've helped out a lot. [J.O.]

Positive male presence. Some men expressed the desire for greater involvement especially from their fathers. Included in this theme were responses indicating the desire for a close relationship with a father-figure or male mentor. Though such relationships may originate from outside of the family, they do not disqualify one's biological or legal father from participation.

I would like to be, like, more apt to learn [and] my parents to be more stricter on me learning how important it is. Yeah. I would like that. My mom was when I was younger, but my dad wasn't as much. [P.A.]

I always wished that I had a father, and I wanted us to have a home - A HOUSE not a home but a house. You know? And when I say a father, you know, I... that man in the house, or that presence, that teacher, that protector... the nurturer, provider. My stepfather, I think he was a good man. I developed a bond with him. I LOVED him, man. He provided for us, but he didn't...he didn't embrace me the way that you would embrace your child. You know, taken and...'you my 
child, and I'm going to show you how to be a man. I'm going to teach you this.' I never felt that from him. I used to try to emulate him and everything. [A.L.]

I would say the one key thing that I would have asked if I could have is having a positive male figure in my life. I mean intimately in my life. The majority, in fact, everybody that I knew was going down the wrong path - all my uncles. My father wasn't there. You know. I was raised by a single parent mother. And when I look back, I don't see one positive male role model that was intimate enough. I mean, people say, 'Well, you had these...' but they wasn't intimate. It's got to be [an] intimate... Mentors are intimate - someone that you know well enough that you know they care enough about you, where you will hear him and it means something when THEY speak to you. And that's what I'm talking about. I had positive females, but for a Black male, for some reason, it just don't have the same validation. [L.O.]

Personal choices and pursuit of education. Participants who indicated that they would make different choices were split between making better choices for their own well-being and persevering for more education.

I wish, to be honest with you, I wish I had got married at a young age. I wish I had went on and worked and raised my family and been loyal and faithful to my wife, because that is what God ordained. It was a reason for him ordaining that, and I violated that. Not only did I violate it where I thought I was giving my kids all of the things that I didn't have, I wasn't giving them the basic things that I did 
have, which was that constant love, that constant discipline. I was giving them things instead of sustenance. So, I wish that I really would have been a real man and worked - don't matter whatever kind of job it was - went on and worked to raise my family that God had blessed me with, but I guess I can't cry over spilled milk, but I wish I had been the same kind of man my grandfather was. He worked on one job 36 years in steel, steel foundry, National League. And he was an upstanding man in the community and in his church, Sunday school teacher, deacon, and he was well-respected for being that. And I wish I had went in them footsteps instead of trying to get my respect in the other way. [G.A.]

Education-wise, I wish that I would have took more time out in school to better educate myself. Yeah. One thing that I do, now, that I've never done - I read more. I read more books now, and I read a lot of more spiritual books. I don't read just a lot of junk. I try to read something that's gonna help me in life. So I read more of a...positive things, and that was something that I never did, growing up. [E.D.]

Education. I really think, and I know that if I had more education that I think that my life would have turned out differently. I think if I'd paid a little more attention to my education, because the education that I would have obtained and what I have with no education combined, the limit would have been the sky. [C.H.] 
Community-based factors. Participants who expressed community concerns in relation to how they would have liked for their lives to have been different seemed to focus on opportunities and resources for healthy social development.

[I wish] That they'd had some type of program...Well, they had programs, but...some type of program to the point where there was people in there to take time to identify some of my defaults. You know, getting me to look at myself in other words and where I'm going to the point whereas, like they say now, keep doing the same thing and expecting different results. That's what I was doing same thing, and it's gonna lead me right back to the penitentiary. All they wanna know is what did you bring? How much time you got? Whether you gonna beat them out? And that's all my life was. [M.I.]

If I'da had another chance...If I'da had a chance to change my life, it would have been to get the...to get away from there. You know? And start somewhere fresh, but that's where I was born and raised at. Wasn't no positive options. You know. All the positive options we knew, he was standing on the corner drinking a 40-ounce. We called him "O-G". [R.H.]

No desire for change. The final theme arising from this area of exploration is one of identity. Some participants wished nothing in their lives to have been different. They expressed acceptance of and appreciation for who they are today as a result of all that they have experienced in their lives. 
I don't know that I would want [my life] to be different, because I had a conversation with a lady that I work with... and we was just talking about some of my experiences I had been through in life up to this point, and she explained to me. She said, "The reason why you are the person that you are today is because of the things that you've been through previously in your life, and if you had took another turn or went in another direction, you wouldn't be the person that you are now." And she said, "You're talented. You're gifted. You got a lot of things going for you that a lot of people don't have. You shouldn't disparage the things that have happened to you in your life. It's something that had to be for you to be the type of person that you are today." So I don't know that I would want my life to be any different. [K.E.]

Desired differences-active. Four themes emerged from discussions with these men about things they would do differently if it were possible to go back and do so. More than half (13) of the participants indicated that they would make different choices about school and education. Six would make different choices about their activities and affiliations. Four participants gave responses that pertained to both of these themes. Two participants indicated that they would be more accepting of the parental guidance that was offered to them. As with the previous topic, a small group of participants indicated that they would prefer not to do anything different at all for appreciation of who they have become.

Perceptions of the impact and benefits of school and education. In an effort to understand where these men see themselves in their lives today, they were asked questions to help them assess the contributions of school and education to their current 
outcomes. The participants gave responses that reflected three themes: Knowledge and skills; Preparation for vocational and professional opportunities; and Self-worth/Sense of productivity. The majority of the participants identified some type of knowledge or skill that they acquired through the process of their education such as math, reading, logical thinking, and social skills. A quarter of the sample identified outcomes of their education that facilitated employment opportunities. Two participants gave responses that suggested increases in their self-confidence and sense of accomplishment. However, each participant made a distinction between his educational experiences before incarceration and during and after incarceration. Most of the participants strongly emphasized their reality that little credit for what they have attained educationally was owed to their experiences in school. Instead, they recognized their educational experiences and academic efforts during and after incarceration for their current outcomes.

Aw man, when I was in the penitentiary, they made me go to school. I didn't realize how dumb I was until I got in there. When I got in there, I was only reading on a third grade level. To myself, I was like, 'aw, this is embarrassing.' You know what I'm saying? So, I started working at it...cause I didn't want to be dumb. But, yeah, I was reading, and stuff, on that level. I'm like, 'Wow! This is embarrassing.' What I'm going to do now is, I'm going to wait until we get ourselves all the way established, then I am going to go back to school. I gotta get my GED, at least get that to start with. You gotta have that or your diploma before you do anything. [R.H.] 
When I went [to prison], like I said, they had the schools in there. They had trades. I got a paralegal degree... The number one choice was accept Jesus Christ as my Lord and Savior. From there, I was guided by the spirit of God to go back and formally educate myself to begin to correct certain character defaults. I didn't know I had these different character defaults in me, but they was exposed to me and I begin to recognize them, acknowledge them, and then work on them. [L.O.]

I found, really, that my education in society wasn't as profound or as prominent as it should have been. I found that out in prison. So I found myself having to be reeducated in prison. It was more so like being willing to open up to accept the truth about the lies that have been told. You know, like, that past slavery just did a number on us. I realized it did a number on ME. I mean, it stripped me of my...It stripped me of my god, where we was all led to believe that God was real - that he was but not knowing Him, it didn't bear no reality. You can ask, "Do you believe in God?" [The answer is], "Yeah," but there was nothing to that. That made it easy for me to do wrong. I realize that, because I didn't feel that, really, that I was being held accountable... it wasn't hard for me to punch nobody or stab nobody or shoot nobody. It wasn't hard, cause no feeling's there. But, you know, when I learned that concept about God, for real, and when God really showed up in my life, then I understood that I'm not supposed to be lifting my hand to the hazard of another man's health. I understood that. I think, having been reeducated in prison, made me - allowed me - to develop a compassion, not only 
for me to live, but for others to live, too. And I really wanted to exert that passion. I think that that education in prison, for all the studies that I went through...I applied myself to those studies and got from those studies what was prominent. [A.N.]

When I got my GED, I had a great teacher. She really wanted me to get it. When I began to take my GED, I could not understand anything I read. I could read, but I could not understand what I read. She said, “ , this is what you must do," and she outlined for me that I need to remember that character; Why is he talking? What is he talking about? What situation is he in when he was talking? When it was all said and done, the score was 60 for that particular - it was called Literature...I made a 58. It was one of the highest scores. It was one of my greatest achievements. I don't know if it was the one-on-one or is it that once a light bulb went off and once I was comfortable with her, that it just... You know? Now when I look back, that's when I really should have just latched on and kept going, cause I was eating it up. You know, K through 12, I didn't learn a whole lot. That's why I didn't excel, I think, the way that it is designed for you to excel. But in GED classes, my GED teacher, again, when she explained to me and showed me and cared that I got it...I couldn't understand. I could read it, but I couldn't understand why I couldn't get it. I wasn't understanding it. Once I got that, it was like - Wow! [C.H.] 
I can say really just the major part that really has influenced me is just being in prison and just being in that solitude and just reading books, personally. And that's... what I enjoyed reading was autobiographies about black leaders, about slavery. That's what grabbed me the most. I didn't like reading the cowboy books, cause I was really just searching for me, for real. But the schooling ain't talking about me as far as, like, the science...I mean, that stuff really excited me, cause it was a challenge. Don't get me wrong. The gym was where I could show my athleticism. I'd really have to say, me personally, - ME, ME personally - I could be in their shoes to say, "You know what? I'm searching for me." So that's when I began just to read books of my people. I began to see other people who came from somewhat of the same background I come from was reading too. And it was like we just started with the group. You would be reading something, and he would be reading something. We just come up like "Yeah, man. I was reading..." And he would talk about his, and I'd talk about mine, and it'd just go around the circle. What really kinda just made me do it? I can't put a hand on it. It was...It probably came from a conversation that I was having - maybe after learning about my disease, learning about self-esteem, learning about all these other thing things that was dealing with me. Maybe I was just filled up on all that, and I was just like, "Who am I?" I mean, cause I'm understanding this stuff. I'm understanding my criminal thinking. Now, I'm teaching, and it's: "Where do I go from here?" [F.R.] 
Believe it or not, probably maybe not my earlier years, but when I was in prison and that computer, that information systems...it made me...God blessed me with the ability to be able to decipher that code, to create new code, and made it do what the people wanted it to do. That gave me a sense of satisfaction within myself. Not only did it give me a sense of satisfaction, it gave me a sense of discipline and a work ethic that, no matter what I did, I would try to do it to the best of my ability. And I wasn't satisfied with just mediocre. I wanted to make it dance and do the bells and whistles that they asked for. No matter how many hours I had to put into it, I was willing to do that. So that gave me... What would I call it? It gave me a opportunity to express myself in a positive manner and learn how to actually develop some work ethic, cause I didn't have none. [G.A.]

I wasn't doing a lot of reading and writing when I was out here on the streets, so when I got locked back up, I'm saying, what little bit that I did learn kinda almost withered away to nothing. I went in '72, and I was in there from '72 to $1977 \ldots$ I remember this teacher I had. I had been trying for a long time to get my GED, and they sent me over there to [another institution] and there was this lady there named ... She had a way of showing you, "Look, I'm doing this because I care about you, and I have to get on you to make you behave yourself and buckle down and do what you need to do." This lady...inspired me to go ahead and get my GED. Then I actually did take the test, and I passed it...a lot of the things I learned that had to do with schooling, a whole lot of it wasn't really learned in school. Just like I learned how to do mathematics when I was in segregation in 
prison. You know, I was laying around in a cell, and I knew that my math skills was really, really bad. So I wrote over there to the school building in the prison and I asked the principal to send me math books on my grade-level, and he done that, and I, basically, every, like, every night... You know, segregation is a place where you got a lot of racket going on almost 24/7, but I would wait 'til, like, late at night or early in the in the morning when just about everybody would be sleep. Then I'd get up and try to do maybe a few chapters in a book until I got it through. My goal always was to get my GED, regardless of whether I was actually in the GED program or not. I knew it was something I was gonna have to do, and I pretty much, a lot of times I studied on my own. And then I learned a lot of my writing skills on my own, again, while I was in segregation. I got hold to this book called Writing with a Purpose. And I'd read the book from cover to cover, cause I always thought that I had the desire to wanna be a writer. So I studied that book and it gave me a lot of insight. [K.E.]

My education in high school didn't help me get where I'm at. My education reeducation - when I was in prison, it just helped me to stay focused through my term and made me feel good about myself on the academic level. I felt good through my whole life because I was [J.O.], man. It's like, I'm that guy. But education while I was in prison helped me to see that I could go back out here and probably do something different. I mean, I had a lot of big thoughts in there - I'm getting my education. I'm get my associates while I'm here, get out and get my bachelors. You know, everything from sports psychology to...you know... all 
types of different things I was thinking about coming out and getting in to. When I got out, I realized it was gonna be a lot more energy than I thought, going to school and working and trying to regroup with my family. So it's kind of a good thing I did fall into having my own business and didn't go on and finish those big academic dreams, because, man... But while I was in there, it did help me to stay focused, and my education helped me to see that... Even though you feel - I don't know if it's false percep-...I don't know what you call it - when you feel good about yourself, about what you're doing and who you are, but I always knew, man, I ain't got my books together. Man, my kids get in eighth, ninth, tenth grade, man, they gonna want same help. I don't know nothing about algebra. You know what I mean? So I've always kinda been just a little bit down on myself as far as not educating myself. I don't know if I learned anything in school, man, that helps me recognize where I wanna be at now. Bottom line, man, really, my education and things that I took in and kept came from prison, man. [J.O.]

One participant who did find value in his educational experience at school had this to say about how experiences in prison inspired him to improve his life through education. While I was in, I had folks come up to me and say things like, "Why are you here? You're smart. I see you talk, and I see you reading books and stuff all the time. What are you doing here?" And that was one of the first times that I've really had to kind of assess my life, and say, You know...? In other words, this guy was telling me: You're not like the rest of us. You're not supposed to be here. So, then it begins to ask me...you know...myself: Well, if I'm not supposed 
to be here, where am I supposed to be? Then, that's when I began to think: Ok, I need to go back to school. I need to go back to college and defer these pleasures and all this other stuff. Put that on the back burner and take care of business, and believe that in doing so, you'll be able to get these things later. From in there, I started saying: When I get out, I'm going back to school and get myself involved in church and positive avenues and things that will reduce my recidivism possibilities. [N.A.]

Preparation for vocational and professional opportunities was also reflected in participant responses.

I guess, if I wouldn't have had an associate's degree, I probably would not have been offered the opportunity - I don't know that for a fact - to get into the field of substance abuse. It was a combination of my education and my personal experience, because the first real job that I had working as a substance abuse counselor was in the prison. [W.I.]

With just a simple GED, I mean, without that I couldn't have had my job. It helped me to work with other people who were trying to achieve the same goals as far as get a GED. I was able to break things down to them in a way they could understand. And like the last...the last two times I was locked up, I was a tutor as a job, 'cause you gotta work, and that was my job. Every prison that I went to... I tutored. I didn't wanna work in the kitchen, so I went to the education building and told them I would be a tutor. [P.A.] 
...getting a degree, taking those classes - not just those computer classes, but group dialogue, how to work in groups, portfolio - how to present yourself in front of an employer. Classes like that really have educated me in being able to present myself. I was already a businessman before. I've had my own business before, partnered in a business before. But I wasn't trained. I took training. I got a lot of training - training in how to sell. I can sell. Ok. Leadership training, training to be a leader, physical training... [J.S.]

Most remembered. When participants discussed what they most remembered from school, only one gave a response that included learning. He stated that he remembered learning to be "fun" and "challenging." However, he made it very clear that school was primarily social for him. Another, who made reference to learning, only did so to emphasize his perspective that he did not start learning until he went to prison. The emerging theme supported most often by participants' statements was the social content associated with school. Three additional themes were identified from what participants reported to remember: General negativity; Decline in enjoyment/engagement; and Extracurricular and nonacademic activity.

Inadequately addressed needs. Further exploration of the participants' perceived value of school and their educational experiences elicited discussions of needs that they felt were inadequately addressed in school. Most of the participants reflected on curriculum content and delivery. Content concerns were presented with the themes of Understanding school's purpose for him and Cultural inclusion/Knowledge of self. 
Delivery concerns contained the themes of More caring teachers and More individual attention. Though the unmet needs identified by these participants all pertained to something that was lacking in their school experiences, most of the participants took personal responsibility for their part in those needs going unmet.

Needs for better educational outcomes. Four themes developed when the participants discussed what needed to be different in school and in their education for them to have achieved better outcomes by this time in their lives. The four themes were labeled: Self-oriented differences; School-oriented differences; Socially oriented differences; and Family-oriented differences.

Self-oriented differences. Twelve of the participants took ownership of their school difficulties, identifying things that they, themselves, needed to do differently for better outcomes. One participant simply stated, "If I'd been willing to learn, and I wasn't." Others said:

I don't know that there's anything that could have been better. Where I am today in reference to education and what was available then, was a matter of choice. I mean, I chose to ignore the education...I don't think it had anything to do with what school did or didn't do. It's what I did or didn't do. [W.I.]

...in high school is where it fell apart. High school was a fashion show... and that's what I got caught up in. Had I not started using drugs, too. Sixth grade, we started experimenting with marijuana. Seventh grade, we was using it on the regular. Eighth grade, I was mean and I was SELLING it in the eighth grade. This clown was giving me weed to sell. I think about that some...I was only 13 
years old, man. I first got high with [my cousin] when I was about 9 years old. And, man, he was just the coolest cat. You know what I'm saying? I wanted to be cool like him. And I thought smoking weed was being cool. [A.L.]

You know, to give credit to them, because I think it's due, at least at that time period. I got a quality education; [in school] - great people, great educators, folks concerned, really concerned, about you as a person getting your education, and a community which, I think, was committed to folks getting their education. So I'm not sure that there was much of anything that I could have changed, maybe other than, again, the way I viewed its importance, because education took a secondary outlook to social life for me. [N.A.]

If I would have stayed concentrated on my school work and my sports and left the other thing for a later date, I think things would have turned out a whole lot different, but when I broke that concentration...I mean, I couldn't see it then, but when I look back on it, that was the beginning of it. It took a long time before it...for the bottom to fall out of it, but that was the beginning. I just didn't know at that hour, and I was still going through the motions, but the enthusiasm wasn't there for the right things no more. [G.A.]

School-oriented differences. Six participants identified school-oriented differences. 
Well, I'm not gonna blame the teachers for me not learning anything. I think it was probably me. If I had wanted...because it was people in school that was learning things that they was supposed to learn. I don't know that it did them a lot of good, because I run into them years later and they life is not really any better than mine is. In some ways, it's not even as good as mine, but I could've...I can't say that it was all the fault of the educational system. I think what probably, maybe could have been different is that if the teachers hadn't tolerated a lot of my foolishness. If I'd had a teacher that had made me sit down and buckle myself down and try to learn something [I] probably would have. [K.E.]

If teachers were just...were more educated...Well, I won't even say that. I'll say more skillful. I don't think teachers apply the skills to their talent. You know, it's ok to be educated, but if you don't know how to institute your education to educate somebody else, you ain't doing nothing no way - just getting a paycheck...whatever people are doing should be designed to enhance quality of life of people. That's what I think about the school system and teachers. Ok, you educated and you in the field of education, but if you don't have skills to educate, you doing what you did to me twenty-some years ago, thirty-some years ago sitting here talking, like you talking to a dummy, and I ain't getting nothing from you. [A.N.]

Socially-and family oriented differences. Only a quarter of the sample identified socially-oriented or family-oriented differences. 
...we never did have no real interaction with White folks or nothing, you know. So when integration came about, now I got close contact with White folks. And the ones that I had contact with was the teachers, and the teachers was racist. And they treated us like dogs, man. You know. So now, I got a hate for, especially, White teachers, and they was male and female, but the main one was a male, and that was the principal. And he was REALLY racist. They didn't want us there. That integration thing was like, to them, it was the worst thing. It was polluting their kids. Now, I can look back, and I can analyze why they behaved the way...cause, to me, in their minds, what it was going to do is take something away from them and their kids. [L.O.]

If I'd just stayed in it and stuck to it and focused on it. It's hard for...My mother graduated from high school, but she worked two jobs. So it's hard for you to tell someone to get an education, to graduate from high school if you've done it and it hasn't done nothing for you, from our standpoint. So that wasn't a big... See what I'm talking about? That wasn't a big priority for me. [J.S.]

Some responses included some overlap among themes; however, no participant who identified the need for self-oriented differences also indicated the need for schooloriented differences.

Embracing the importance of school and education. In contrast to the reports from most of the participants that their formal education provided a meaningless or largely negative experience for them, their current feelings about school and education 
emphasize their importance. Most, in one way or another, reflected that they have come to embrace the positive value of education.

Without that, you just lost, man. I feel that education...Without education, you really stack the deck against you. [C.H.]

I think it's vital. I think it's an important component that leads to success. It's directly connected to achievement and success and advancing in the world today. [W.I.]

I'm big on education, man. I just think that it just opened up so many doors, so many opportunities, man, and it also can give you visions of how other people are doing things other places. I mean, I'm big on education just because also you can sit and become part of a more quality...You have better quality people in your life. You know what I mean? I don't care what color they are. I can sit and talk to a brother like yourself, well educated, and be comfortable with it, because of who I am. [J.O.]

I understand its importance. I understand that folks don't respect you unless you can demonstrate a knowledge base or a skill set that you have that they don't. Other than that, you become Average Joe. [N.A.] 
Aw, man, today, I feel it's very, very important. When I look back, now, over what I wish I had have done ... I'm just real grateful that my younger three children have all graduated from high school. [E.D.]

It's one of the greatest things a person can have. [M.I.]

It's needed. You have to have it. If you don't have it, you really ain't nowhere. [J.A.]

I feel that kids really need it, because they don't know nothing about the world. They don't know nothing about [their] heritage. They don't know nothing about they life, and all they know...They only gonna give them so much. So what they need to do is take what they give them and dig further instead of settling. [R.O.]

Some, while acknowledging its importance, also expressed their concerns about what they see as serious problems with the educational system in the U.S.

Today, I'm on the outside looking in, but I seen the outcome of what's coming about in the school is failure - failure. And not only am I able to see, but the school system itself is showing it. That's why so many schools are closing down. You know? And what that says about, not only our education, but our society is caving in, cause if you don't have an educational structure, then who is it that's gonna run your country? If you don't have the people that are educated to do it, then what's gonna happen? I think today is the day of reckoning, where people in 
position have lost sight of that. They think that they gonna be there forever, and they're not. You got all these generations coming behind you that don't know NOTHING about what they should know on how to make sure that this nation stands up. [A.N.]

The public school system, I believe, is detrimental to our, especially our young Black males. I believe it's a detriment to them. So, if I had the money, I would create our own. I would do just like Jeff Canada in Harlem Children's Zone. I'd create my own school, because I don't care what it seem like we do, it's still gonna be the way it is...in [the local district]...they don't even really make a effort to recruit Black teachers. I've been on them about it, but it's like beating my head against the wall. So, in order for me to really, really make a change, I got to figure out a way of coming up with my own school system, and I'm gonna do that. I'm living my life to do that. This got to change, and in order for it to change, we got to change it. It have always been like that. It have never changed. That's the reason why we had segregated schools. They didn't create no school for us. We created our own schools. [L.O.]

It's outdated. The Eurocentric curriculum is not developmental and conductive, or conducive to the development of African American MALES in particular. But it's necessary in developing some skills that are useful in life - communicative skills, the ability to read, comprehend, some analytical skills that can help you. 
But, over all, I think this system, for the middle and lower class, is just designed to make us servants, man. [A.L.]

It's important, very important per se, but the curriculum which they teach, I still think that it should be something in there about us, personally. [F.R.]

I think that the educational system needs to be thrown in the trash and rebuild. I know a young man who graduated two or three years ago from high school. He went to school every day. He got good grades. He was the star basketball player, college recruits...colleges was coming up here looking at him play. Well, it came time for his ACT test. Nothing on that test they taught in school...So the school system, now, the educational system, now, to me, is a fraud, even all the way up to the college, to the four year degrees. It's too much for too little - too little knowledge. [J.S.]

One participant expressed sudden recognition, which he attributed to participating in this study, that there was more to gain from formal education than he was willing to accept as a youth. He said:

Believe it or not, it has changed within the last two days, and at the same time it has stayed the same and been reinforced. Your questions allow me to understand that those things that I actually needed that I tend to bitch and moan about were there. But then again, I end up getting bitter, cause why was it there and I didn't get it? It was there. [S.T.] 


\section{Shift in Goals and Value Structures}

Priority of self-centered values. Much of what participants reported they were trying to achieve prior to being incarcerated was found to be driven by self-centered value structures. The themes making up this category labeled Priority of Self-Centered Values included: Image/Reputation; Fun/Pleasure; Money/Material possessions; and Nothing constructive. These themes and related activities were all thought to represent a priority of self-centered values, because participants reflected that they disregarded and hurt others to satisfy their own concerns. They consciously failed to balance their personal interests with social responsibility. Further, they candidly stated that there was no value in what they were trying to achieve.

I really wasn't trying to achieve nothing, just hold down a job and work and get a better job and stuff like that. I didn't have a clue, really, what I wanted to do, because partying was what I was about. I was also a DJ, too. I was a secular DJ one of the best DJs in this area... When I was smoking, I didn't DJ. Actually, I sold all my DJ equipment, and my albums were just all over the place, and I really didn't have very much, but every now and then, somebody would see me and say, 'Hey, come and DJ our party for us.' And I would go spin records, long as they gave me the money to go buy some crack and stuff like that. [L.A.]

I was trying to sleep with as many women as I could, trying to make as much money as I could, and have as much fun as I could. I mean, I really wasn't trying to do anything positive. My life was totally negative. [J.A.] 
All I wanted to do back then, I was really trying to be like a gangster. I wanted to be looked upon as hardcore and trying to make myself look hard. I wanted to drive the six-four Impalas and Blazers and stuff like that, fat rims and hydraulics. I was searching for that. I was...everyday, I prayed for stuff like that. [J.S.]

...my mindset was just having weed and drinking, so that was my mindset. You know. And I had a baby on the way which ended up being born after I was incarcerated. So, really I had no goals except running the streets. That was it. [P.A.]

I got very selfish, and it was about me and having the toys, and now, when I look back, it was a part of this system...the commercialism and all of that; part of who you are and your identity is to have one of these... when I started making these bad decisions... it was the Cadillacs. It was dressing and the jewelry, the blingbling. We was the ones that kind of came out with the bling-bling. It was those Black exploitation films like Superfly, The Mack, and all of that. When we went and seen those things, that's what we...that's who we was gonna be...I can honestly say that when I came away from The Mack, I wanted to be a pimp. And I set out to be one, and I became one, and a very successful one. [L.O.]

I wasn't trying to achieve nothing but get some money and get some dope. That's it. I didn't see myself, when I came home, moving into a brand new house. I couldn't see that far. Before I was incarcerated, I didn't look that far. I had 
different ideas about success and who I was and what I needed to do to protect who I was. So when I think about what I wanted to do before my last incarceration is not anything that...It's not anything of any real value. I was living the fantasy. Yeah. I was living a big fantasy. [W.I.]

Things. I'm just being honest. Things. You know? What they call it? The American way - getting by the easiest way I thought you could. Solomon spoke it best. He said he tried everything, works, he had money, he had women, but he said all of it was fleeting. It was all vanity. You know? Cause when you find out, man, if you ain't got the love of God in you, I don't care how much stuff you stuff in you, you gonna still have a hole. Cause without love, it ain't working, and if you don't love God, it's hard for you to love another man or a woman. So you got to have the love of God in you in order to do it. That's what I was doing, man, stuffing myself with things in here. [G.A.]

Emergence of the theoretical path and structure. To gauge how these men believed their former values and related choices contributed to what they have attained in their lives, presently, they were asked to talk about the choices that got them to where they are today. Three participants referred to their progression from destructive to positive choices. For each of these three participants, embracing spirituality and religion were pivotal to their transitions. One participant was unable to specify choices he has made that contribute to the current circumstances of his life. He explained his perspective of growing up in an environment where "choices" do not exist. In his reality, 
he was to do what was modeled in his home and community. Because he was unable to identify with alternatives he observed, namely on television programs, he did not see them as real options for him. However, other information he shared during his interview suggested that he has made conscientious choices to change his life even if he does not see them as so. For example, he emphatically shared the experience that led him to stop using drugs in prison.

The remaining participants focused on positive choices or habits they began to establish. Often, these changes began at some point during their incarceration. Their responses included a wide array of factors and actions they identified as instrumental for bringing them to where they are in their lives, today. Over all, the information that the participants provided clarified a common process that they all appear to have experienced. The steps in that process include: 1) Internalizing values which support antisocial and self-destructive choices; 2) Acknowledging their choices or the outcomes of those choices as problematic and recognizing the need for change; 3) Seeking support for and taking steps to change; and 4) Setting and pursuing personally and socially acceptable goals.

Legitimate Goals. Discussing with the participants what is currently important to them yielded ideas that were organized into four categories: Living Responsibly to Self and Others; Productivity, Achievement, and Impact; Relationships and Spirituality; and Physical Health. Statements they made about the goals they are presently pursuing seemed to also reflect the categories represented in their discussions of what is currently important to them. Moreover, what they described as their own personal goals seemed to align with themes conveyed in their definitions of legitimate goals. 
Four major categories emerged from participants' discussions of what they believe defines legitimate goals. The categories were labeled: Achievement Goals; Responsibility; Meaningful and Achievable; and Improving Quality of Life. Four similar categories also emerged from the participants' discussions of their current and future goals. Those categories were labeled: Representations of Accomplishments/Achievements; Family; Helping Others; and Possessions/Traits for Higher Quality of Living. Many participants unintentionally talked about legitimate goals and their personal goals simultaneously and communicated the perspective that the goals they are now working to achieve are legitimate goals.

...this Fall, I'm going back and go ahead and get my master's and go on on in to my Ph.D. I wanna lead by example... Cause we're not gonna ask these kids to do something that we're not doing. And we got to SHOW them the value of it. So when I say, "You need to go to college," I'm in college. I'm getting my master's. I'm getting my Ph.D. So, if I can do it, you can do it. [L.O.]

For me, first, is to complete next semester, successfully, and get that AA degree. Not stopping there, but I need that as a short term reinforcement. I need to see that hanging on the wall; [2] to be committed and to do well in [my job] to prove that I am trustworthy - more than to prove it - to BE trustworthy; [3] getting more involved in my son's life. I try to show him by my examples, but I gotta be more involved. Those type of goals - getting my bachelor's degree, getting the master's degree. That's important. I want to be known as a good man and a good person, but the recognition [is] coming without me even, you know, trying to do 
that thing to be seen, because I realize, today, it ain't necessarily in working to be seen. Just do the work. [A.L.]

Something that two years from now, you gonna be better - three years, five years, however far you put it out there. You're gonna be a better person, mentally, physically, emotionally, financially, whatever. You know, goals [are]... Most goals should be betterment. A goal is just something, man, to gauge yourself on your success... something just to gauge your productivity... [J.O.]

...contributing into and being the best that you can in the community in which you live, setting an example and being the best role model for the youth. [W.I.]

I think, for any man to be able to achieve financial security whatever that is in his mind, and to have a life where he's free, he's at peace, and he can attain whatever his ability allows him to attain - you know, where he's not being held back. He's able to put into action whatever he can, long as it's legal. [G.A.]

Owning my own home, own business, getting off parole, seeing my children through college - cause they most definitely steadfast in doing that. It's just a joy, really, just seeing them. Cause I was thinking that my son's gonna be somewhat like me, but he's nothing...nothing...nothing [like me]... cause it's like I'm looking for me. It's like "Yeah I'm gonna be ready to hit it in the head," but it's not there. [F.R.] 
...my legitimate goals are to be, again, as comfortable as possible and to make as much of a difference in this work as I can. Through teaching classes, through writing books, through speaking, through all of those things...Bill Gates, I believe it was that said, 'The journey to success is that you put yourself on a path that you love that leads to somewhere important.' And that's kind of the way I see it... when my days on earth are gone, I want folks to remember where I came from and what I did and my love for people. [N.A.]

\section{Looking Back}

Content learned in school. It was important to evaluate possible connections between the formal education these men did receive and the current paths they have determined for themselves. They were asked to identify what they got from school and what they believe they needed to prepare them for the tasks required to achieve their goals. Three categories emerged from their responses of what they learned in school that applies to what they reported as most important to them now: Useful Skills or Traits; Not Attributable to School; and Value of Family and Education. Half of the participants attributed the knowledge that is currently most important to them to their learning experiences during and after their incarceration. A few of them actually stated that they learned nothing in school that applies directly to what they value most in their lives today. Those with this perspective seemed to recognize their own contributions to their failure in apprehending what they might otherwise have learned in school.

Right off the top of my head, I'm going to say, "Nothing", but I know those teachers, man, they attempted to instill in me to...They were saying to me that I 
had the potential to do more, to do better. They were TELLING me this, and I just wasn't listening. I'm talking about all the way up through high school, man.

\section{[A.L.]}

You know, grade school was...I don't think I learned anything. I think I learn... and I've said this, I learned more in prison than I did in anything the [university], Harvard, anywhere else can teach me. I learned about life. I learned about people. I learned about me in prison. So, school was: $1+2=3$. You know. Stick your hand in a light bulb, you'll get shocked. Ok, that's information that may have no relevant bearing on me whatsoever. But learning how... who YOU are, learning how people are, learning what LIFE's all about has direct bearing on me. See, there's book knowledge and there's street knowledge and common sense... I have knowledge. I thank the school. But, incarcerated, I got wisdom, which is the practical application of that knowledge. [N.A.]

Well, I look at being in prison, that prison was a school for me, so if I could use some of the things that I learned, there, because it was really a school. That's where I grew up at. It taught me how to be respectful. It taught me...It really just taught me respect, to weigh things out. It just taught me how to be a man. That's what taught me. It taught me how to trust, too. Because when I was getting my GED, I had a tutor, and he was a guy, and he kinda reminded me of my father, but he spent time with me and showed me how to do these formulas. He really made 
the difference with me. I mean, even though some of his actions was like my dad, but this guy spent time with me and showed me how to do this. [J.A.]

Being young, I couldn't see past the hate. I couldn't see what it did. It made me hate back... I deprived myself by not learning how to go around that and continue to get what belonged to me, which is my education. That belongs to me... I didn't have the background. I didn't have the support to help me through that. [L.O.]

Well, I learned that in the school, here, in the penitentiary in [the prison]... like I said, they made me go to school in the penitentiary, here, and that's what really made me see that education is important, and you don't wanna be DUMB. Cause, I was 29 years old, reading on a $5^{\text {th }}$ grade level, $3^{\text {rd }}$ grade level, something like that... [R.H.]

.... lot of the things I learned that had to do with schooling, a whole lot of it wasn't really learned in school... It's probably some very valuable lessons that I did learn while I was in school. I just can't recall any at that time, because I've had so many other experiences in my life that overshadowed anything that I had to go through in school... [K.E.]

Three participants indicated that they learned the value of family and education from what they experienced in school. However, they made it clear that the recognition did 
not occur until much later. Their responses demonstrated latency between the school experiences and the meaning they eventually associated with them. As a result the respective category was labeled separately from the one labeled, Not Attributable to School. The remaining seven participants identified some skill or trait learned in school that relates to what they most value now.

Content needed from school. When discussing what they needed to learn in school that might help them with what is important to them now, more than half the sample indicated a need for academic skills or some type of knowledge or skill-set to facilitate learning and problem-solving. Six indicated the need for a stronger understanding of the value of formal education. Four stated that they needed some sort of trait (self-knowledge, discipline, trust) to support learning. Their responses were grouped into three categories labeled; Useful Skills, Value of Formal Education, and Traits to Support Learning.

\section{Looking Ahead}

Each participant was asked to give considerable thought to his own experiences in the processes of formal education. As observed in the previous section, talking about his experiences resulted in each man identifying the impact and deficits he associated with his education. Each also identified ways in which his educational experiences could have helped him achieve more desirable outcomes, whether by self-oriented or other-oriented differences. With this in mind, the participants were asked to think about what they would convey to children about school. All of the participants seemed to convey a unified message. 
These men, most of whom experienced school as meaningless or mostly negative, would and do communicate to children the necessity for success in school to achieve success in life. They also expressed their desires to personally provide their children and grandchildren with the support that some of them felt they lacked from home. In this way they would strengthen the message of the importance of going to school with demonstrations of their interests that their descendants go further and do better than they. To African American males in particular, they want to reflect the usefulness and value of putting forth effort toward getting a solid education. Finally, they suggested a number of school-related ideas that might result in better educational outcomes for African American males.

\section{Summary}

This study was conducted to take a qualitative look at the subjective lives of African American males who have experienced the consequence of incarceration. The twenty study participants discussed certain aspects of their lives salient before, during, and since incarceration. The objectives were to track the development of legitimate goals in their lives and explore the effects of academic disidentification on the determination of their goals.

Demographic survey and interview responses suggested that each of these men disassociated himself from the academic purpose of formal education while attending school. Their devaluation of academic achievement signals rejection of the idea that scholastic achievement is necessary for self-esteem. Some participants indicated that they disconnected very early, even from day-one. Other participants "drifted away" and disengaged later. Reasons for disidentifying were varied. However, for each participant, 
the matter for which he was incarcerated was directly associated with the values he placed ahead of academic achievement.

Eighty percent of the participants dropped out of high school. Those who persevered to graduation did so in spite of interview evidence suggesting that they were psychologically disengaged from the academic element of school. All participants expressed current attitudes embracing the importance of formal education for successful achievement in life. Along with changed attitudes, the participants remarked on things they wish they had done differently or support they wish had received to keep them engaged and make their learning more effective in school.

The values as reflected by these men that interfered with their willingness to fully embrace the academic function of school were set in a structure which prioritized selfcentered concerns. The goals which most of them reported to pursue and the ways in which they pursued them tended to put themselves and others at risk of serious harm. Along the way, they were able to identify problems with the ways in which they were approaching their lives and the goals they were striving to achieve. By their reports, each committed to making changes and found appropriate support to do so. The change process always included acquiring new knowledge and skills to facilitate and sustain the direction of the change. This led to the participants embracing the value of formal education for their current goals as well as to adequately prepare children for successful futures. A shift also seems to have occurred in the value structures of the participants. The present goals they expressed reflect values of family, responsibility, achievement, and helping others. In general, the goals for which they now strive appear to focus on improving quality of life for themselves and others. 


\section{The Model and Core Phenomenon: Facilitation of Legitimate Goals.}

The proposed model starts with an assumption of experiences which influence value development. Critical influences occur in four domains: individual agency, family, community, and school. Two possible paths are developed from the interview data obtained from the twenty participants of this study.

Participant path. A possible outcome of the value development process is a value structure which prioritizes self-centered concerns, with an unhealthy balance between personal interests and social responsibility. In this case, the individual seeks to achieve goals that are self-destructive and/or tries to achieve goals in ways that are potentially harmful. This type of goal structure may lead one to reject an academic identity due to the effort and time required for its eventual pay-off. The individual will, instead, resort to high-risk activities of a delinquent or criminal nature to make progress toward desired goals. Engagement in these high-risk behaviors tends to reinforce his rejection of the academic identity and increase his propensity to further engage in highrisk activities. Outcomes of these activities often reinforce these choices and also increase the level of delinquent and criminal activity. Here, an individual may find himself in a cycle of activity and reinforcement that becomes difficult to break. As such, when he eventually experiences a putatively negative consequence such as arrest, detention, jail, or prison, it does not deter his high-risk behavior.

Each of the participants in this study eventually responded to negative consequences associated with incarceration by the recognition of the problematic identities they had developed and destructive choices they were making. As a result, they began to explore better alternatives for their lives and initiate directional shifts which 
required them to gain new knowledge and skills for the outcomes they desired. The effort they invested in learning and the impact they experienced cause them to embrace the importance of education and recognize the value of formal education which they formerly rejected. This directional shift is completed as the individual redefines his value structure to include ideas such as family, responsibility, achievement, and helping others. His redefined values facilitate the adoption and sustained pursuit of goals intended to increase quality of life for himself and others. These new goals are also legitimate goals as defined within the study.

An alternative path. The model assumes and proposes an alternative path which avoids traversing through prioritizing self-centered values, delinquent and criminal activities, and negative consequences. This path also starts with influences of individual agency, family, community, and school which impact the development of one's values. In this case, however, the resulting value structure consists of a set of values which readily facilitate the pursuit of legitimate goals. Figure 1. provides an illustration of the described model. 


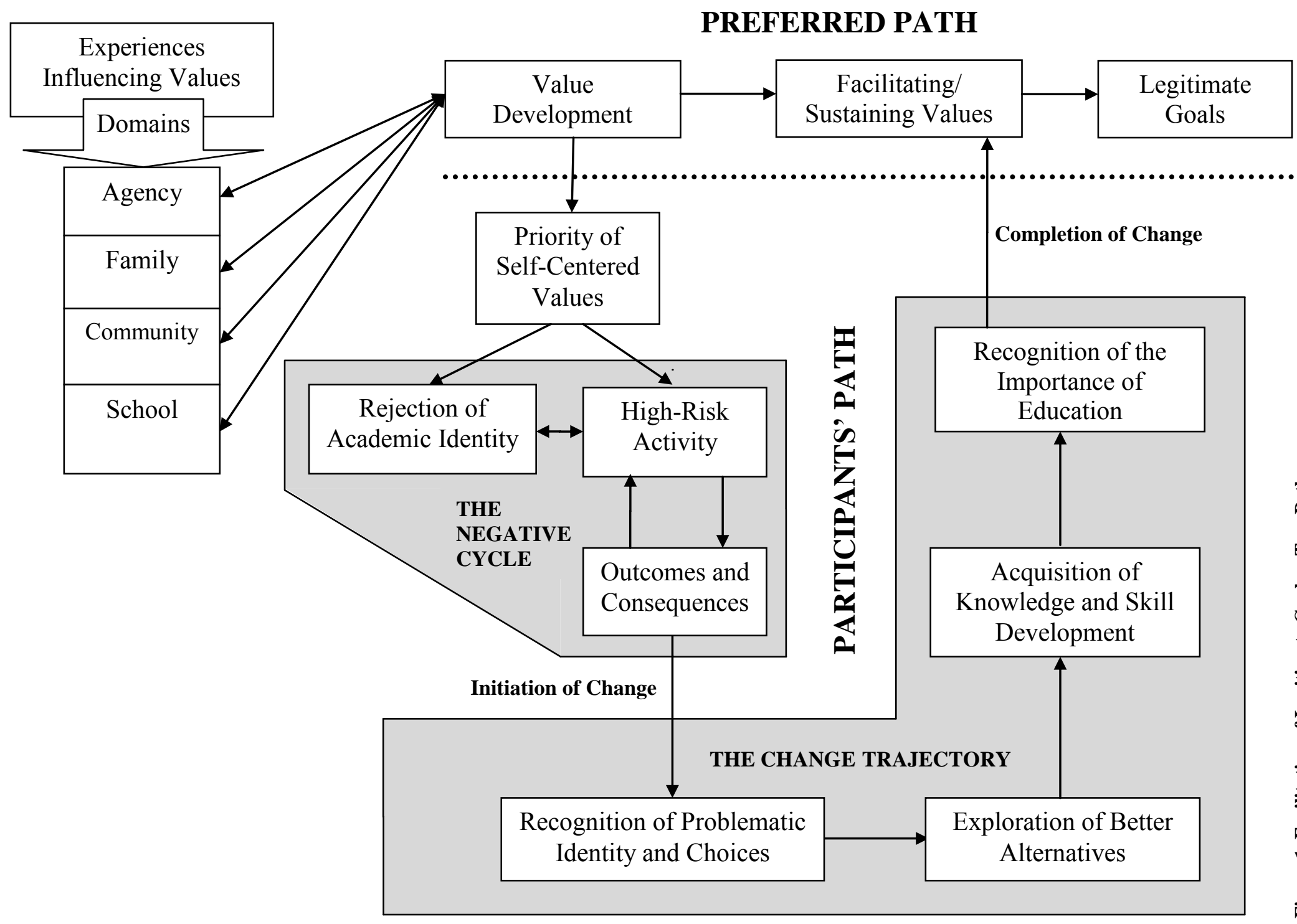

D 


\section{Chapter 5}

\section{Discussion}

Using grounded theory an explanation of how a sample of African American males was able to live successfully in their communities after being released from prison was explored. Of particular interest was whether or not academic disidentification played a role in the failure of these men to choose legitimate goals in lieu of their former activities. The analysis resulted in a model showing two developmental paths to selecting legitimate goals. One path results in the development of values which readily support the selection of legitimate goals. The other path facilitates the rejection of academic identity and shows how academic disidentification contributes to engagement in high risk activities.

\section{Facilitation of Legitimate Goals}

The major premise for this study starts with a declaration by Dr. Martin Luther King, Jr. "Education must enable a man to become more efficient to achieve with increasing facility the legitimate goals of his life," (King, 1948). This statement incorporates King's ideas that the process of education should produce intelligence and character. As such, the top trajectory of the model resulting from this study illustrates the expected path of internalizing values and selecting commensurate goals. The model recognizes that school is not the only source of influences that shape one's values. In fact, school is intentionally placed last in the list of domains of experiences influencing values. That is because the exertion of individual agency, family, and community influences customarily occurs for a number of years before school exposure begins. 
The proportional disparities of African American males in prison compared to their proportion in the U.S. population generated the question of how the development of legitimate goals is being affected for this group. Further, for those who choose to engage in behaviors for which a potential consequence is incarceration, how is education failing to enable the pursuit and achievement of better goals? Analysis of the data collected in this study appears to provide some answers. The stories that the twenty participants of this study shared about their lives illuminated a process of satisfactory goal selection, fraught with adversity and destruction.

Experiences influencing value development. Selecting goals starts with forming values. Fisher (2011), in psychological terms, speaks of values as properties of individuals and properties of collectives. Across individuals, variation in values is related to personality traits, attitudes, and behaviors. Thus, individual agency influences the development of value structures which one uses to evaluate people, events, and situations. A collective observes a "shared meaning system" (p. 1128), which determines the value priorities within the group. Fisher (2011) recognized multiple paradigms that view collectives differently. For example, collectives encompass entire countries or, from a sociological perspective, may represent variant social groups within society. The importance of this distinction is that social groups form out of the experience of differential effects of their social conditions. Their interests and values, as determined from their experiences, may stand in conflict with those of other groups. Moreover, the values of an individual, as formed from his own subjective experiences, may conflict with collective values. The experiences shared by the participants of the current study 
provided information linking the development of their values to the domains of individual agency, family, community, and school.

Family domain. Participants spoke of family-related experiences that they believe affected choices they have made in their lives. The memories they shared represent three family patterns of interaction which affect the social and intellectual development of young children (Guralnick, 2006). For the purposes of this study, it is important to understand that family patterns of interaction occur within a context of family values, expectations, and routines. A child's experiences of family patterns of interaction play a significant role in his social and intellectual development and in his eventual selection of values, goals, and means of attaining those goals.

Individual agency. Guralnick (2006) was careful to consider that the knowledge base informing family patterns of interaction cannot yet account for every influence that occurs within the family domain. Neither can it predict all possible outcomes of influences, known and unknown. Moreover, Guralnick (2006) acknowledged that intrinsic characteristics of children do contribute to relationships between family influences and subsequent outcomes. This constitutes recognition of individual agency as a factor in the selection of one's values and goals. As it pertains to the current sample, these men were able to identify family experiences that have influenced their choices over the course of their lives. Discussing former choices, they frequently identified some sort of loss, conflict, or failure usually in the parent-child relationship that interfered with early reception of values to support positive pursuits. Admired family members, when mentioned, were often involved in illegal activities. Conversely, more recent choices and current values were fondly associated with positive family attributes and role models. 
Community domain. Community influences tend to occur through microsystems as defined by Bronfenbrenner (1979). Thus, parenting practices determine, to a large degree, the extent of community influences on young children (Eccles \& Roeser, 1999). However, neighborhood influences do increase as children get older and become more independent. Community norms, availability of quality resources, and exposure to risk have roles to play in the behaviors, values, and goals children adopt (Jencks \& Mayer, 1990). This was reflected in statements from participants. Participants talked about having status in their communities which could be achieved by dressing a certain way, being known as a good fighter, associating with certain groups of people, and/or using drugs. Some participants expressed an absolute lack of "choices" in their communities due to lack of resources and to the prevalence of negative norms. One story illuminated the benefit of a positive resource and the tragedy of its loss. The participant shared that a member of his community took it upon himself to provide a recreational center for the neighborhood children. He required that the children got good grades and stayed out of trouble. When the man suddenly died, no one stepped in to replace this resource. The participant stated that he and the other children who frequented the center had no more motivation from the community to stay out of trouble and do well in school.

School domain. Entering school brings on an entirely new set of experiences for most children, including academic demands and expectations, formal skill evaluation, containment and structure, work responsibility, significantly more exposure to peers, and relationships with new adults. Not only are these experiences filtered through the child's perspective which has been shaped by previous experiences, they also provide new information to incorporate into the continuing process of values formation. This process 
in conjunction with individual agency plays a large role in determining one's reaction and commitment to schooling over time. Participants expressed a range of perspectives on their school experience. Early school experiences ranged from deep enjoyment to immediate aversion. Regardless of where he started on this spectrum, each of these men became disconnected from the academic purpose of school. Many gravitated to full investment in school as a purely social setting. Some used school as their opportunity to profit financially through illegal activities such gambling and drug sales. Most of them dropped out of high school. Those who graduated lacked any real concern or vision for what formal education could offer them.

Participant responses discussing how they would have liked for their lives to be different seem to support the portion of the model illustrating the connection between experiences and value development. Their statements were easily organized into categories that represented family, community, and individual agency factors. Their responses implied recognition of possibilities in these domains that might have gotten them to better outcomes. They would have had to acquire values to support the necessary choices. Information they provided about their school experiences reflected a clear sense of negativity and indifference toward formal education. The fact that those previous feelings have, over time, become positive should be taken as evidence that their values both formed and have since changed as a result of their experiences.

The negative cycle. The combination of experiences in the domains of individual agency, family, community, and school led these men to prioritize self-centered values. Rather than striving for legitimate goals, they destructively pursued fun, pleasure, material possessions, and image. The portion of the model representing these choices is 
labeled High-Risk Activity. This label was chosen because they began to behave within school and after leaving school in ways that put them and others at risk. Though one of the participants chose the apparently responsible path of getting a job to provide for his family, his decision to leave school prior to graduating can be construed as a rebellious choice. Moreover, it would have severely limited his employment options and earning potential for his family.

In addition to engaging in high-risk activity, prioritizing self-centered values led these men to reject academic identities and the pursuit of formal education. For various reasons, these men did not perceive formal education as a viable route for their goals. Most of them even stated that the base nature of their goals at that time in their lives did not require the kind of education that school provides. Lack of interest, loss of trust, or academic difficulty made the effort to continue in school appear meaningless. Relieving themselves of the burden to perform academically availed them more fully to the activities that addressed their more immediate interests.

High-risk activities included fighting, using and selling drugs, gang affiliation, gambling, exploiting others, promiscuity, violence, and killing. Participants engaged in these and other activities to satisfy interests and achieve goals such as revenge, having money, or maintaining status. Achieving those goals provided reinforcement for the high-risk activities, confirming that those activities were more fruitful than working for academic achievement. Some participants experienced consequences of their high-risk activities such as arrest, prison, loss of relationships, and loss of capital but continued their behaviors. Others recognized the need to change more quickly. Though each of these men was sent to prison for criminal offenses, some multiple times, different 
experiences in prison elicited a desire to change. The commonality among them is that each of them recognized his need for more education and has embraced the value of education since or during incarceration.

Turning around. There came a point when each participant became disturbed with some aspect of his identity which supported his prioritizing of self-centered values and engaging in high-risk activities. As the men talked about choices they would change if they had the chance, they tended to highlight critical concerns that enabled them to behave in self-centered and harmful ways. They acknowledged the consequences of the values by which they previously lived and assessed the directions in which their goals were leading them. In his own way, each communicated a strong regard for what he has accomplished since making these important realizations. Their stories suggested that they have worked to develop respectable characteristics such as forgiveness, honesty, work ethic, spirituality, responsibility, sobriety, openness, etc. - qualities they wished they had possessed earlier in their lives.

When these men talk about the things that are important to them now, gone are the themes of prioritizing self-centered values. They were sure to convey that their lives are not perfect. But they emphasized the reality of having to work continually to keep their lives on the right track and to help others as best they can to do the same. The goals for which they now strive entail some level of accomplishment, helping others, and ideals such as spirituality and relationships with others.

It seems tragic that these men who now understand and seem to accept the responsibilities that come with taking care of oneself while living peaceably with others, broke laws, harmed others, and served time in prison on the way to reaching their 
discoveries. It was after these experiences that they considered viable alternatives to responsibly, yet satisfactorily, meet their individual needs. This required them to expand their knowledge about themselves, others, and the world around them. The ways in which they approached learning what they needed to learn varied, but in the process, they each developed an appreciation for education that did not previously exist. They have redefined their values over time and now constructively seek to improve life for themselves and others. Where once they endorsed self-centered, individual values that conflicted with collective values of social groups and the larger society, their current pursuits tell a different story. Their present goals reflect values that are socially constructive. This is not to say that their individual values are now perfectly aligned with any particular set of collective values. Evidence appears, however, to indicate the pursuit of legitimate goals that are supported by commensurate values to facilitate and sustain those goals.

Study significance. The current study is significant in that it outlines an important developmental transformation in the lives of African American males who have been incarcerated for criminal acts. The transformation revealed through the study methodology illuminated two things. First, the participants of this study took responsibility for rejecting formal education early in their lives and made connections between those choices and consequences they experienced later on. Second, the resulting model shows at what point in time these men began to learn knowledge and develop characteristics which changed their life trajectories.

\section{Limitations}


The tactics for determining the presence of academic disidentification among members of the sample were imprecise. Though the construct of academic disidentification has been studied in educational and psychological research for two decades, there is no existing scale to measure it. Generally, it is detected by comparing measures of one's academic performance to measures of one's levels of self-esteem. To keep primary focus on the semi-structured interviews during data collection, only a crude measure of self-esteem was taken and compared against the participant's self-reported academic performance. This, unfortunately, may not have provided the clearest view of academic disidentification. The additional information obtained through participant interviews did seem to confirm disidentification as well as disengagement. However, the data could conceivably have been coded differently and found to be less confirming. One goal of this research is to contribute to the development of valid and reliable measures of academic disidentification to more effectively study its origins and effects.

Researcher bias created another potential limitation. For this study, the researcher developed the interview protocol and conducted all of the participant interviews. The researcher was also the primary person involved in interpreting the participants' data. As such, the possibility exists that the proposed theory was influenced by the researcher's biases. Steps to reduce potential effects of researcher bias were taken. The interview protocol was reviewed by two members of the researcher's doctoral committee. One of the same professors gave additional feedback contributing to the decision to retain the protocol in its original form after the pilot interviews. Peer reviewers assisted with open and axial coding and provided significant feedback on the construction of the model. 
Attempts at conducting member checks were suspended when transcriptions that were given to participants were not returned.

The fact that the interviewer and the study participants were the same race and gender may have created a tendency toward overidentification with one another during the interviews. Overidentification includes assumptions or expectations of understanding that may not be met. This was potentially problematic when the interviewer misunderstood a participant's response to a question during the interview. Conversely, participants may have been inclined to discuss seemingly irrelevant information or omit relevant information based on his beliefs about the interviewer's background and prior knowledge. To guard against inappropriate interpretations of participants' statements, the interviewer made it a point to probe for clarity when the meaning or relevance of an answer was unclear. Additionally, the protocol was designed with multiple questions to explore similar content. This allowed for some triangulation in that responses could be compared for consistency and meaning during transcription and analysis.

The interview questions were designed to create a logical flow through the interview and maintain rapport between the interviewer and interviewee. The researcher chose to ask multiple, indirect questions to reach the desired content. For this reason, the interview protocol was particularly long and required a significant amount of time to complete. While this did not seem to affect participants' willingness to complete the interviews, the researcher's consciousness of time may have affected the flow of the interview from time to time. During analysis, it appeared that it may have been better to ask fewer and more direct questions, especially on the content of the participants' attributions for their current success in their communities. 
This study was conducted to gain new insights on what connections African American males make between their formal educational experiences and the experience of being incarcerated later on. The twenty-member sample proved sufficient for that purpose; however, it is too small to transfer the resulting model beyond these twenty men at this time. The narrow focus on African American males also prevents the model from explaining or predicting behaviors of other groups. Further investigation of the model is required to determine whether it is accurate and applicable beyond this sample. Finally, the sampling methods that were necessary to meet the objectives of this study created additional barriers to transferability. By nature, criterion and snowball sampling are exclusive of random selection. Therefore, this sample is unlikely to be representative of the general population to which they belong. Maximum variation allowed for a wide range of characteristics (e.g., age, type of crime, amount of prison time served, etc...) within the sample. The resultant model appears to describe the entire sample. However, portions of or the entire model might be configured differently when characteristics such as age range, type of crime, or other specifications are considered.

\section{Conclusions and Implications}

The current study sought the opinions and beliefs of African American males on their own experiences of incarceration and any connections they identified between their educational experiences and later incarceration. The sample of twenty men, among other things, discussed their past and present goals and their feelings associated with school. The feelings they described indicated that the academic purpose of school was meaningless to half of them. For the majority of the other half, the experience of going to school was mostly negative. Even the small minority that reported school as positive 
were significantly more engaged in the social element than they were in the academic element of school well before they finished.

By their own admissions, none of these men acquired a sense of purpose or identified legitimate goals to pursue as a result of formal education. Some would indicate that blatant racism and discrimination interfered. Others described incidents of microaggression and feelings of exclusion from the curriculum. Examples of the schoolto-prison pipeline were also present in their stories. However, it was surprising that each of these men took responsibility for his choices that drew him away from school and prevented him from receiving the eventual benefits of formal education. Though many were able to recall specific school-based problems which affected them, all in some way owned their own responses as significant barriers to better outcomes earlier in their lives. Today, they work to maintain a quality of character in their own lives that gives them hope for attaining their legitimate goals. Moreover, they are contributing to solutions by providing to others the kind of supports which they lacked in their own lives as youth.

Several lessons can be taken from these stories and the theoretical model that has emerged from them. First, these men eventually learned how to live productive, contributing lives after historically pursuing objectives driven by self-centered values. Achieving their current realities after such destructive pasts may indicate that the potential for their current realities was present earlier in their lives. Maybe lives can be changed for the positive prior to one going to prison, prior to one committing a violent crime, or prior to one adopting values that could lead to either. It is clear that school is not the only domain where the development of values is influenced. However, these men recognize school as a place where they could have acquired the tools to make their lives 
dramatically different had they chosen to do so. Thus, it is important to increase understanding of the processes occurring between experiences and values formation. With this understanding, schools, communities, and families might authentically create educational ecologies that inspire purpose and assure legitimate goals for all children, especially African American males.

Second, understanding and preventing rejection of academic identity seems essential. Despite the limitation found in this study, academic disidentification is acknowledged as a real concern under the right conditions. The model emerging from this study suggests that academic disidentification occurs as a byproduct of a negative value developmental cycle. It does not develop as a link in the path. In other words, it is not a direct barrier to the acquisition of purpose and legitimate goals. Instead, academic disidentification forms from the same self-centered value structures as does the preference for high-risk activities. It is the latter that facilitates the immediate gratification for which one's actions are aimed. Rejection of the academic identity simply justifies the high-risk activities directed toward one's interests. Thus academic disidentification appears as an intervening condition, which helps to sustain the process occurring within the negative cycle. It is determined that all of the men in this study were academically disidentified. The methodology could not determine the points at which each disidentified; however, their stories indicate that they disidentified at different points in school and for different reasons. Future research is needed to clarify the factors contributing to students disidentifying and what factors are most salient at different times. Preventing disidentification at various stages in a student's life may make it less likely for him to persist in or even experiment with high-risk behaviors. 
Finally, the resultant model proposes two distinct paths to legitimate goals. On the preferred path, individuals move directly through their experiences to the development of values that support legitimate goals. The second path entails experiences that result in a negative cycle where one primarily pursues self-centered interests. Moving from the negative cycle to acquisition of legitimate goals for current sample included traversing through a change in trajectory where one could accept the possibility of better living, acquire the knowledge and skills to improve his quality of life, embrace the need for education, and value a healthy balance between personal interests and social responsibility. It is critical to understand that approaches for reaching students must be customized to their individual realities and current goal structures. Most importantly, individuals who embrace legitimate goals must be prepared to do so with appropriate discipline, compassion, and dignity. Further research is necessary to determine the value of this theory to inform the developmental and educational needs of African American males and strategies to meet those needs effectively. 


\section{References}

Aday, L. (2001). At risk in America: The health and health care needs of vulnerable populations in the United States - Second Edition. San Francisco, CA: JosseyBass.

Alexander, K, L., Entwisle, D. R., \& Kabbani, N. S. (2002). The dropout process in life course perspective: Early risk factors at home and school. Teachers College Record, 103, 760-822.

Aponte, R., Beal, B. A., \& Jiles, M. E. (1999). Ethnic variation in the family: The elusive trend toward convergence. In M. B. Sussman, S. K. Steinmetz, \& G. W. Peterson (Eds.), Handbook of marriage and the family (pp. 111-141). New York, NY: Plenum Press.

Bronfenbrenner, U. (1979). The ecology of human development: Experiments by nature and design. Cambridge, MA: Harvard University Press.

Brown, W. T., \& Jones, J. M. (2004). The substance of things hoped for: A study of the future orientation, minority status perceptions, academic engagement, and academic performance of black high school students. Journal of Black Psychology, 30 (2), $248-273$.

Bureau of Justice Statistics. (n.d.) Drugs and crime facts: Drug law violations and correctional populations and facilities. Retrieved on October 25, 2008 from http://www.ojp.usdoj.gov/bjs/dcf/correct.htm.

Christle, C. A., Jolivette, K., \& Nelson, C. M. (2005). Breaking the school to prison pipeline: Identifying school risk and protective factors for youth delinquency. Exceptionality, 13 (2), 69-88. 
Clayton, O. (1992). A reconsideration of black homicide: Some not so know facts. Challenge: A Journal of Research on African American Men, 3 (1), 39 - 61.

Cokley, K. (2002). Ethnicity, gender, and academic sefl-concept: A preliminary examination of academic disidentification and implications for psychologists. Cultural Diversity and Ethnic Minority Psychology, 8 (4), 378 - 388.

Cokley, K. \& Moore, P. (2007). Moderating and mediating effects of gender and psychological disengagement on the academic achievement of African American college students. Journal of Black Psychology, 33, 169 - 187.

Coleman, J. S., Campbell, E. Q., Hobson, C. J., McPartland, J., Mood, A. M., Weinfeld, F. D., \& York, R. L. (1966). Equality of educational opportunity. Washington, D.C.: U.S. Government Printing Office.

Comer, J. P. (1989). Racism and the education of young children. Teachers College Record, 90 (3), $352-361$.

Consortium of Longitudinal Studies. (1983). As the twig is bent... lasting effects of preschool programs. Hillsdale, NJ: Erlbaum.

Corbin, J., \& Strauss, A. (2008). Basics of qualitative research - Third Edition. Thousand Oaks, CA: Sage Publications, Inc.

Côte, J. E., \& Allahar, A. L. (2007). Ivory tower blues: A university in crisis. Toronto: University of Toronto Press.

Creswell, J. W. (2007). Qualitative inquiry and research design: Choosing among five approaches - Second Edition. Thousand Oaks, CA.: Sage Publications, Inc.

Cummins, J. (1986). Empowering minority students. Harvard Educational Review, 56 (1), $18-36$. 
Damon, W., Menon, J., \& Bronk, K. C. (2003). The development of purpose during adolescence. Applied Developmental Science, 7 (3), 119 - 128.

Downer, J. T. \& Pianta, R. C. (2006). Academic and cognitive functioning in first grade: Associations with earlier home and child care predictors and with concurrent home and classroom experiences. School Psychology Review, 35 (1), 11 - 30.

Eccles, J. S., \& Roeser, R.W. (1999). School and community influences on human development. In M. H. Bornstein and M. E. Lamb (Eds.), Developmental Psychology: An advanced textbook (pp. 503 - 554). Mahwah, NJ: Lawrence Erlbaum Associates.

Entwisle, D. R., \& Hayduk, L. A. (1988). Lasting effects of elementary school. Sociology of Education, 61, $147-159$.

Fabelo, T., Thompson, M. D., Plotkin, M., Carmichael, D., Marchbanks, M. P. \& Booth, E. A. (2011, July). Breaking schools' rules: A statewide study of how school discipline relates to students'success and juvenile justice involvement. The Council of State Governments Justice Center and The Public Policy Research Institute.

Field, A. J. (1976). Educational expansion in the mid-nineteenth-century Massachusetts: Human capital formation or structural reinforcement? Harvard Educational Review, 46, $521-552$.

Finn, J. D. (1989). Withdrawing from school. Review of Educational Research, 59 (2), $117-142$.

Fisher, R., \& Schwartz, S. (2011). Whence differences in value priorities? Individual, cultural, or artifactual sources. Journal of Cross-Cultural Psychology, 42 (7), $1127-1144$. 
Foster, H. L. (1995). Educator's and non-educators' perceptions of black males: A survey.

Journal of African American Men, 1 (2), pp. 37 - 70.

Garulnick, M. J. (2006). Family influences on early development: Integrating the science of normal development, risk and disability, and intervention. In K. McCartney and D. Phillips (Eds.), Handbook of early childhood development (pp. $44-61$ ). Oxford, UK: Blackwell Publishers.

Gottfredson, L. S. (2000). Equal potential: A collective fraud. Society, 37 (5), $19-28$.

Gottfredson, L. S. (2004). Social consequences of group differences in cognitive ability. Retrieved on June 15, 2010 from http://www.udel.edu/educ/gottfredson/reprints/2004socialconsequences.pdf Greene, J. P. (2001). High school graduation rates in the united states: Revised April 2002. Retrieved on October 22, 2008 from http://www.manhattaninstitute.org/html/cr baeo.htm

Halpern, D. F., \& LaMay, M. L. (2000). “The smarter sex: A critical review of sex differences in intelligence”. Educational Psychology Review, 12 (2), 229 - 246.

Hamre, B. K., \& Pianta, R. C. (2001). Early teacher-child relationships and the trajectory of children's school outcomes through eighth-grade. Child Development, 72(2), 625-638.

Harlow, C. W. (2003). Education and correctional populations. Bureau of Justice and Statistics Special Report, January, 1 - 12. Retrieved on October 2, 2008 from http://www.ojp.usdoj.gov/bjs/pub/pdf/ecp.pdf .

Harrison, P. M., \& Beck, A. J. (2006). Prisoners in 2005 [Electronic version]. Bureau of 
Justice and Statistics Bulletin, November, 1 - 13. Retrieved on October 25, 2008 from http://www.ojp.usdoj.gov/bjs/abstract/p05.htm.

Harrison, P. M., \& Beck, A. J. (2005). Prisoners in 2004 [Electronic version]. Bureau of Justice and Statistics Bulletin, October, 1 - 14. Retrieved on October 25, 2008 from http://www.ojp.usdoj.gov/bjs/pub/pdf/p04.pdf.

Harrison, P. M., \& Beck, A. J. (2004). Prisoners in 2003 [Electronic version]. Bureau of Justice and Statistics Bulletin, November, 1 - 12. Retrieved on October 25, 2008 from http://www.ojp.usdoj.gov/bjs/pub/pdf/p03.pdf.

Harrison, P. M., \& Beck, A. J. (2003). Prisoners in 2002 [Electronic version]. Bureau of Justice and Statistics Bulletin, July, 1 - 14. Retrieved on October 25, 2008 from http://www.ojp.usdoj.gov/bjs/pub/pdf/p02.pdf

Harrison, P. M., \& Beck, A. J. (2002). Prisoners in 2001 [Electronic version]. Bureau ofJustice and Statistics Bulletin, April, 1 - 16. Retrieved on October 25, 2008 from http://www.ojp.usdoj.gov/bjs/pub/pdf/p01.pdf.

Harvey, A. R. (2004). The plight of the African American male in the United States: An Africentric human service provider analysis and intervention strategy. Journal of African American Studies, 8 (3), 37 - 51.

Herrnstein, R. \& Murray, C. (1994). The bell curve: Intelligence and class structure in American life. New York: Free Press

Hilliard, A. G., III. (1976). Alternatives to IQ testing: An approach to the assessment of gifted "minority" children. Final Report to the Special Education Support Unit. Sacramento, CA: California State Dept. of Education.

Hilliard, A. G. (1992). Behavioral style, culture, teaching and learning. Journal of Negro 
Education, 61 (3), 370 - 377.

Horn, W. F. (2002, September). "Responsible fatherhood and the role of the family". Paper presented at the Serious and Violent Offender Reentry Initiative Grantee Conference, Washington, DC. Retrieved October 25, 2008 from http://www.reentry.gove/responsible.html.

Human Rights Watch Backgrounder. (2003). Incarcerated in America. Retrieved on October 19, 2008, from http://www.hrw.org/backgrounder/usa/incarceration/.

Izard, C. E. (1977). Human emotions. New York: Plenum Press.

James, D. J., \& Glazer, L. E. (2006). Mental health problems of prison and jail inmates [Electronic version]. Bureau of Justice and Statistics Special Report, September, pp. 1 - 12. Retrieved on October 25, 2008 from http://www.bjs.gov/content/pub/pdf/mhppji.pdf

Jencks, C., \& Phillips, M. (Eds.). (1998). The Black-White test score gap. Washington, DC: Brookings Institution.

Kaba, A. (2005). The gradual shift in wealth and power from African American males to African American females. Journal of African American Studies, 9 (3), 33 - 44.

King, M. L. (1948). The purpose of eduation [Manuscript]. Retrieved January 8, 2007 from http://www.toptags.com/aama/voices/speeches/pofed.htm.

Ladson-Billings, G. (2001). Crossing Over to Canaan: The Journey of New Teachers in Diverse Classrooms. San Francisco: Jossey-Bass.

LaParo, K., \& Pianta, R. C. (2001). Predicting children's competence in the early school years: A meta-analytic review. Review of Educational Research, 70, 443 - 484.

Lee, C. (2000). The state of knowledge about the education of African Americans. 
Washington, D.C.: American Educational Research Association, Commission on Black Education.

Lincoln, Y. S., \& Guba, E. G. (1985). Naturalist inquiry. Beverly Hills, CA: Sage Publications, Inc.

Livingston, J. N., \& Nahimana, C. (2006). Problem child or problem context: An ecological approach to young black males. Reclaiming Children and Youth, 14 (4), $209-214$.

Losen, D. L. \& Skiba, R. J. (2010, September). Suspended education: Urban middles schools in crisis. The Civil Rights Project at UCLA and the Southern Poverty Law Center.

Mauer, M., \& King, R. S. (2007). Uneven justice: State rates of incarceration by race and ethnicity. Washington, D.C.: The Sentencing Project: Research and Advocacy for Reform.

McKean, L., Ransford, C. (2004). Current strategies for reducing recidivism. Chicago: Developing Justice Coalition and Center for Impact Research.

Mocombe, P. C., \& Tomlin, C. (2010). The oppositional culture theory. Lanham: University Press of America, Inc.

Mumola, C. J. (2000). Incarcerated parents and their children [Electronic version]. Bureau of Justice and Statistics Special Report, August, 1 - 12. Retrieved on October 25, 2008 from http://www.ojp.usdoj.gov/bjs/abstract/iptc.htm.

NAACP Legal Defense and Educational Fund, Inc. (n.d.). The school-to-prison-pipeline: Racial segregation. Dismantling the School-To-Prison-Pipeline. New York. Retrieved on May 31, 2007 from 
http://www.naacpldf.org/content/pdf/pipeline/Dismantling the_School_to_Prison Pipeline.pdf.

Noguera, P. A. (2003). The trouble with Black boys: The role and influence of environmental and cultural factors on the academic performance of African American males. Urban Education, 38 (4), 431 - 459.

Ogbu, J. U. (1997). Understanding the school performance of urban Blacks: The essential background knowledge. In Walberg, H. J., Reyes, O., \& Weissberg, R. P. (Eds.) Issues in children's and families's lives (Vol. 7): Children and youth: Interdisciplinary perspectives, (pp.190 - 222). Thousand Oaks, CA.: Sage Publications, Inc.

Ogbu, J. U. (2003). Black American students in an affluent suburb: A study of academic disengagement. Mahwah, NJ.: Lawrence Erlbaum Associates, Inc.

Osborne, J. W. (1997). Race and academic disidentification. Journal of Educational Psychology, 89 (4), $728-735$.

Osborne, J. W. (2001). Unraveling underachievement among African American boys from an identification with academics perspective. Journal of Negro Education, $68(4), 555-563$.

Osborne, J. W. \& Walker, C. (2006). Stereotype threat, identification with academics, and

withdrawal from school: Why the most successful students of colour might be most likely to withdraw. Educational Psychology, 26 (4), 563 - 577.

Oswald, D. P., Coutino, M. J., Best, A. M. \& Singh, N. (1999). Ethnic representations in 
special education: The influence of school-related economic and demographic variables. Journal of Special Education, 32 (4), 194 - 206.

Payne, R. K. (2005). A framework for understanding poverty- Fourth Revised Edition. Highlands, TX: Aha! Process, Inc.

Pianta, R. C. \& Stuhlman, M. W. (2004). Teacher-child relationships and children's success in the first years of school. School Psychology Review, 33 (3), $444-458$.

Pierce, C., Carew, J., Pierce-Gonzalez, D. \& Willis, D. (1978). An experiment in racism: TV commercials. In C. Pierce (Ed.), Television and education, $62-88$. Beverly Hills, CA: Sage.

Pollard, D. S. (1993). Gender, achievement and African American students' perceptions of their school experience. Educational Psychologist, 28 (4), $294-303$.

Reynolds, A. J. (1994). The effects of preschool plus follow-on intervention for children at risk. Developmental Psychology, 30 (6), $787-804$.

Reynolds, A. J. (1999). Educational success in high-risk settings: Contributions of the Chicago Longitudinal Study. Joumal of School Psychology, 37, 345-354.

Rist, R. C. (1970). Student social class and teacher expectations: The self-fulfilling prophecy in ghetto education. Harvard Educational Review, 40 (3), 411 - 451.

Roper, W. L. (1991). The prevention of minority youth violence must begin despite risks and imperfect understanding. Public Health Reports, 106 (3), $229-231$.

Rubin, H. J. \& Rubin, I. S. (2005). Qualitative interviewing: The art of hearing data. Thousand Oaks, CA: Sage Publications, Inc.

Samenow, S. (2004). Inside the criminal mind. New York: Crown Publishers. 
Schmader, T., Major, B., \& Gramzow, R. H. (2001). Coping with ethnic stereotypes in the

academic domain: Perceived injustice and psychological disengagement. Journal of Social issues, 57, $93-111$.

Schott Foundation for Public Education. (2008). Given half a chance: The Schott 50 state report on public education and black males.

Seymour, M. (2004). Educating for humanity: Rethinking the purpose of education. Boulder, CO.: Paradigm Publishers.

Shaw, D. S., Gilliom, M., Ingoldsby, E. M. \& Nagin, D. S. (2003). Trajectories leading to school-age conduct problems. Developmental Psychology, 39 (2), 189 - 200.

Singh, G. K. \& Yu, S. M. (1996). Public health brief: Trends and differentials in adolescent and young adult morality in the United States, 1950 through 1993. American Journal of Public Health, 86, 560 - 564.

Skiba, R. J., Horner, R. H., Chung, C., Rausch, K., May, S. L. \& Tobin. T. (2011). Race is

not neutral: A national investigation of African American and Latino disproportionality in school discipline. School Psychology Review, 40 (1), 85 107.

Skolnich. J. H., Currie, E. (Eds.). (1994). Crisis in American institutions (9 $9^{\text {th }}$ ed.). New York: HarperCollins.

Solorzano, D., Ceja, M., \& Yosso, T. (2000, Winter). Critical race theory, racial microaggressions, and campus racial climate: The experiences of African American college students. Journal of Negro Education, 69, 60-73. 
Spanierman, L. B., \& Heppner, M. J. (2004). Psychosocial Costs of Racism to Whites Scale (PCRW): Construction and initial validation. Journal of Counseling Psychology, 51, 249-262.

Spinrad, T. L., Eisenberg, N., Cumberland, A., Fabes, R.A., Valiente, C., Shepard, S. A., Reiser, M., Losoya, S. H., \& Guthrie, I. K. (2006). Relation of emotion-related regulation to children's social competence: A longitudinal study. Emotion, 6 (3), $498-510$.

Spring, J. (1994). Education and segregation: African Americans. In, Deculturalization and the struggle for equality (pp. 42 - 59). New York: McGraw-Hill, Inc.

Steele, C. M. (1992). Race and the schooling of black Americans. The Atlantic, 269 (4), $68-78$.

Stevenson, H. W., \& Newman, R, S, (1986). Long-term prediction of achievement and attitudes in mathematics and reading. Child Development, 57, 646-659.

Strauss, A., \& Corbin, J. (1990). Basics of qualitative research: Grounded theory procedure and techniques. New York: Cambridge University Press.

Sue, D. W., Capodilupo, C. M., Torino, G. C., Bucceri, J. M., Holder, A. M., Nadal, K. L.,

\& Esquilin, M. (2007). Racial microaggressions in everyday life: implications for clinical practice. American Psychologist, 62 (4), 271 - 286.

Supplee, L. H., Shaw, D. S., Hailstones, K., \& Hartman, K. (2004). Family and child influences on early academic and emotion regulatory behaviors. Journal of School Psychology, 42, $221-242$.

The Pew Center on the States. (2011, April). State of recidivism: The revolving door of 
America's prisons. Washington, DC: The Pew Charitable Trust.

Thompson, C. E., \& Neville, H. A. (1999). Racism, mental health, and mental health practice. Counseling Psychologist, 27, 155-223.

Youth Transition Founders Group (2005, November). Redirecting youth from the schoolto-prison pipeline: Addressing cross-cutting issues in youth services. (Briefing Paper \#2). www.ytfg.org: Miller, J., Ross, T., \& Sturgis, C. Retrieved on May 31, 2007 from

http://www.ytfg.org/documents/BeyondtheTunnelProblemBriefingPaper2Nov200 $\underline{\text { 5fin.pdf }}$ 
Appendix A

Participant Profiles 


\section{Participant Profiles}

A.L.

$\begin{array}{ll}\text { Project interview date: } & \text { December 22, 2010 } \\ \text { Birth year: } & 1966 \\ \text { Age: } & 44 \\ \text { Number of incarcerations: } & 1 \\ \text { Years in prison: } & 17 \\ \text { Year released from prison: } & 2005 \\ \text { Education completed: } & \text { GED (1983) } \\ \text { Occupation: } & \text { Property Manager }\end{array}$

A.L. was the youngest child in a family of several siblings. His parents were not married and he saw his father only a few times in his life before his incarceration. A.L. reported that he initially enjoyed going to school. After the second grade, his school was shut down. Rather than allowing him to go to the school his older brother attended, his mother sent him to the neighborhood school. This created problems for A.L. with his neighborhood peers because of rivalries that existed between the children who attended his previous school and those attending his new school. When there were altercations between the groups, A.L. was caught in the middle and was not trusted by either group. He reported that he had to fight every day at the new school. He emphasized how unsafe and fearful he felt going to school each day. This was something he could not recall ever disclosing before participating in this study. A.L. spoke of feeling alone and unable to talk to anybody about what he was going through at that time in his life. He also described harassment he and others received from students who were unable to do the work and being bullied until he fought back. Fighting enabled A.L. to align himself with the "Big Boys" and "bullies" for safety, though he never experienced a complete sense of trust among this group. Eventually, A.L. began using and selling drugs despite encouragement from his mother, stepfather, and teachers that he had the potential for high achievement. A.L. left school and got his GED prior to his incarceration. He continued his involvement in the use and sale of drugs which led to the crime for which he was incarcerated. While incarcerated, A.L. participated in a variety of programs, including an intensive drug treatment program. He became sober and began developing his speaking and leadership skills. A.L. served as a facilitator in a number of the programs that helped him to change his thinking and his behavior. He eventually became a training for new facilitators. A.L. also became very active with the Nation of Islam. After his incarceration, A.L. settled in a different city than his home town, found employment, and eventually began working on an Associate's Degree in Business Administration.

At the time of the interview, A.L. was near completion of his degree and seeking entry into a four-year degree program at a local university. He was involved in re-entry programs assisting previously incarcerated individuals to successfully integrate into the community when they were released from prison. 
R.H.

$\begin{array}{ll}\text { Project interview date: } & \text { January 4 \& 9, } 2011 \\ \text { Birth year: } & 1981 \\ \text { Age: } & 29 \\ \text { Number of incarcerations: } & 1 \\ \text { Years in prison: } & 1 \\ \text { Year released from prison: } & 2010 \text { (Jan) } \\ \text { Education completed: } & 11^{\text {th }} \text { grade } \\ \text { Occupation: } & \text { Newspaper Courier }\end{array}$

R.H. is one of two men in this sample who has not earned a high school diploma or GED. He grew up in an impoverished urban community in which he perceived very few choices for African Americans. School for him was someplace he went to have fun, especially in high school. R.H. said that he did not do work in class due to "laziness" which he attributes to smoking marijuana. He stated that he started smoking marijuana because, "It was the thing to do. It was cool." This was a behavior he initially engaged in at the age of 13 with his older brother. However, he spoke of the choice to start smoking marijuana as a mistake that took his life in a more negative direction than he might have gone otherwise. Regarding parental involvement, he did not speak of the presence of his father. Discussing his mother's involvement, he reflectively stated that "she could have done more." R.H. speculated that having choices or awareness of more choices than he knew, might have resulted in him taking a different path. In the absence of exposure to other realities until he moved to a different city, R.H. simply thought things were as they were in his life because that was the way they were supposed to be. R.H. expressed acceptance of his past mistakes and indicated that he has learned from them. Some of the lessons he mentioned were: 1) It does not work out to do as he pleases without regard for the potential consequences; 2) You have to keep your focus on what you are trying to accomplish and stay on track; and 3) Be wary of circumstances, people, places, and things that may result in loss of focus and unwanted consequences. Over all, R.H. seemed to recognize the need to take care of responsibilities before wants. At the time of the interview, he and his wife were both working full time. He expressed plans to get his GED once he felt that his family was more financially secure.

N.A.

$\begin{array}{ll}\text { Project interview date: } & \text { May 11, 2011 } \\ \text { Birth year: } & 1971 \\ \text { Age: } & 40 \\ \text { Number of incarcerations: } & 1 \\ \text { Years in prison: } & 5.75 \\ \text { Year released from prison: } & 2000 \\ \text { Education completed: } & \text { Master's Degree (2005) } \\ \text { Occupation: } & \text { College Administration }\end{array}$

N.A. is one of four men in this sample who graduated from high school. He reported that he made above average grades with very little effort. N.A. stated that his mother, who 
only went to the eighth grade, cared about his education and was proud of his good grades. His mother wanted him to get the education that she didn't get and constantly insisted that he read. Though resented it, he did it. N.A. has older siblings who did not finish school. He and his friends all intended and expected to finish school. They ridiculed students who did not graduate. N.A. described a very troubling times a child due to his mother's drug addiction. They were frequently without electricity and heat, because the bills were not paid. He reported that there were times when his mother would get high made him leave the house. Some of those times, he chose to sleep in a car belonging to relatives rather than disturb them in the middle of the night to ask for food or shelter. N.A. found ways in school to compensate for what he lacked at home. He was motivated by the social life that school offered. He felt competent to compete in the classroom but was not invested for learning's sake. It was the thing that gave him an edge over his peers that he didn't have anywhere else. Additionally, he saw education as the vehicle to get him to a better place in life. N.A. decided as a preteen that he was going to go to college to study Business Administration but had no plan for how that would happen. He expressed a keen sense of wanting to be something that his children could be proud of and was influenced by the attire of businessmen. N.A. looked forward to matriculating through high school and college. However, he confessed that he no longer had a need apply himself academically after he gained social popularity. He remembered one teacher who took interest in him and pushed him. He believes she recognized in him what he did not recognize in himself. Elementary school was fun. Race and ethnicity were not much of a factor. Pecking order began in junior high school when social life became more prominent - dating, clothing, sports, skills for interacting. What became important for N.A. was having fun with friends, making money, pursuing pleasure, and avoiding things that got in the way of those interests. Some of his activities for achieving these goals included selling marijuana cigarettes and alcohol at school. Thus, education was secondary to social life when he was in school. N.A. accepts that his choices made him who he is today and expressed feeling that he would be farther along had he made different choices including finishing his bachelors at either of the two universities he attended prior to his incarceration. Though he took the initiative to go to college, he lacked access to important information he needed to finish. He speculated that this might have led to a series of different choices resulting in a higher quality of life. N.A. assumed personal responsibility for things he could have done differently. Namely, he stated that he needed to have attached more importance to it than he did.

At the time of the interview, N.A. was employed as an administrator at a large Midwestern university, and in the process of completing a doctorate degree. N.A. credits the combination of "book knowledge" and "street knowledge" for where he is today. He stated that his formal education alone did not qualify him for his current job. It was complemented by a range of knowledge and individual talent that he gained or developed from his experiences outside of school. He stated that he learned more in prison than in classrooms about life, people, and himself. N.A.'s current goals are similar to those he pursued in his youth though his motivations are more conscientious and his approach more constructive. Rather than achieving to fulfill a need to compete with others, he expressed that his strivings are for himself and his family. 
L.O.

Project interview date:

Birth year:

Age:

Number of incarcerations:

Years in prison:

Year released from prison:

Education completed:

Occupation:
May 19 \& 26, 2011

1953

58

1

18

1999

Bachelor's Degree (1992)

Director of a non-profit organization

L.O. was raised by his grandmother who emphasized education and communicated her expectations to him. Though her children dropped out of school, as the first grandchild, L.O. was expected to finish school. Primarily, L.O.'s grandmother instilled in him the importance of education. L.O. was raised prior to the time of desegregation and stated that he loved going to school during his first four years of schooling. At that time, he attended a segregated school. He expressed his belief that the community embraced the school, and the teachers were held in high esteem. He described a dramatic change in his school experience after the schools in his community were desegregated. "It was like being sent to a foreign country and being made to assimilate into their culture. It was like going into a slave system." Though some of his Black males peers excelled, L.O. remembers that those from single-parent homes did not do as well. L.O. believed that the teachers he had before desegregation cared about him and instilled the value of education in their students. He did not feel this to be true about his teachers in the school he attended after desegregation. There, he felt unwanted. L.O. reported that his first interactions with White people occurred with teachers whom he experienced as racist. he stated that "they treated us like dogs." Thus he developed a hatred, especially for white teachers. Feeling rejected and unfairly mistreated in the school setting led to feelings of despair for L.O. about gaining success through education. Wanting to prosper and avoid poverty, L.O. emphasized that he "STUDIED" those who were doing well, financially, in his community. As the professionals left the inner city after integration, his examples were those who made money "illegitimately." He saw this as an important education for him. L.O. dropped out of school in the $11^{\text {th }}$ grade to be with his girlfriend who hung out in the streets. He reported that he formed a gang that made money by illegal means. He attributes some of his negative choices to early sexual activity, disclosing that he has two sons and grandchildren he does not know L.O. recounted that he detested not having a father in his life and lamented that he had repeated the same behavior. He explained that he learned to appreciate the value of family after he became a Christian. Seeking spirituality helped him to overcome his anger and hatred of White people. Additionally, he learned to appreciate the value of formal education. L.O. realized that his response to his perception of racism in the integrated schools he attended resulted in him depriving himself of the education that "belonged to" him. He earned his GED and Bachelor's degree while incarcerated, making him the first college graduate in his family.

At the time of the interview, L.O. was actively pastoring a church, employed as the Executive Director of a community development agency that provides guidance and support to community youth and their families. Through his organization, L.O. founded 
fathering and mentoring programs to help young males in his community understand constructive ways of responding to difficulties in and out of school. He has learned the importance of conflict resolution and working with others through adversity. L.O. explained that his decision to drop of school resulted from knowing only "fight or flight" responses. His work involves making youth aware of more options for responding to challenging circumstances and equipping them with tools to avoid making poor choices that will adversely affect their education.

D.A.

$\begin{array}{ll}\text { Project interview date: } & \text { June 11, 2011 } \\ \text { Birth year: } & 1983 \\ \text { Age: } & 27 \\ \text { Number of incarcerations: } & 1 \\ \text { Years in prison: } & 0.33 \\ \text { Year released from prison: } & 2004 \\ \text { Education completed: } & \text { Associate's Degree } \\ \text { Occupation: } & \text { College Student, House Cleaner }\end{array}$

D.A. lost his mother when he was in the first grade. His father was not involved in his life, and D.A. has received no support from him. He described himself as a "good kid" before that event but remembered getting into fights after his mother died. He indicated that his misbehavior was probably motivated for attention, as he felt out of place living with relatives, sometimes in situations that were unsavory and unsafe. He also expressed feelings of anxiety about being accepted and fully welcomed in the homes where he lived. D.A. recalled repeated visits to the school counselor during his elementary school years. He reported that he had no positive males in his life as a child. D.A. recounted a story of having been accused of being in a gang and sent to the principal's office on his first day in sixth grade year for carrying. He denied any gang-affiliation at any time in his life and explained that the experience embarrassed him tremendously. He learned to think of himself as a "problem-child" and remembered getting sent to the hallway frequently. D.A. admitted that his behavior was "over the top" sometimes and stated that he felt like he could not stop himself at times. It was "fun and games" to him then. Retrospectively, he realizes that his attitude and behaviors created a reputation for him that he did not really want. D.A. reported that he started using drugs in the seventh or eighth grade. He also started selling marijuana at school and in his community while he was a junior high school student. He dropped out of high school in the tenth grade after an extended suspension for fighting at school. D.A. was convicted of a crime when he was seventeen. He explained that he did not know how the justice system worked and that he did not realize his crime was as serious as it actually was. He earned his GED in a matter of a few months of his incarceration in compliance with the stipulations of his sentence. He gained confidence in his academic and intellectual abilities as a result of passing the GED test on his first attempt. D.A. admitted to selling crack cocaine shortly after his release from prison. He also resume using drugs which resulted in probation violation and a new stipulation that he complete an intensive drug treatment program in the Department of Corrections. D.A. reported that he continued to sell drugs for a few 
months after his release until he decided that he wanted to change his life. He invested his money, got a job, and enrolled in college. He expressed that he finds little support from his family for what he is trying to accomplish. However, he indicated that the examples of success he finds most meaningful are those who have achieved through education and hard work. D.A. stated that all of his choices - "selling drugs, investing his money, hustling, going to college" - have been to take care of his family and prevent himself and them from being in vulnerable situations. He finds it hurtful that his "culture" demonstrates more respect for a drug dealer than for someone going to college.

At the time of the interview D.A. was working full time to support himself. He has earned an Associate's degree and completed course toward a Bachelor's degree in Business Administration. He indicated that he is working to pay an educational debt so that he can continue taking courses to complete his degree. D.A. described it as a battle to stay focused because of the lack of support from family and his limited ability to help others when they need it. He confessed that, due to his circumstances, he does consider returning to selling drugs for an immediate income. However, he emphasized that careful consideration of the consequences keeps him from making that choices.

\section{A.N.}

$\begin{array}{ll}\text { Project interview date: } & \text { June 19,2011 } \\ \text { Birth year: } & 1967 \\ \text { Age: } & 44 \\ \text { Number of incarcerations: } & 1 \\ \text { Years in prison: } & 22 \\ \text { Year released from prison: } & 2008 \\ \text { Education completed: } & \text { GED (1989) } \\ \text { Occupation: } & \text { Self Study: Historic Science, } \\ & \text { Moorish Culture and History }\end{array}$

A.N. reported that he liked school until an incident in high school resulted in him being suspended and transferred to another school. He stated that he recognized his enjoyment of school as early as the third or fourth grade. He seemed to particularly remember athletic and playground activities in elementary school. However, he reported that he was good at math and enjoyed helping others with their math work. His description of the morning routine going to high school accentuated the social camaraderie he enjoyed with his peers as he got older. He also reported making the honor roll in high school. A.N. stated that he went to school with the same children from kindergarten until his junior year in high school. He felt a sense of belonging and enjoyed being with his peers. A.N. also boxed outside of school with a group of guys who were known to be tough. He indicated that he had to hide the fact that he was smart starting in the $9^{\text {th }}$ grade. Though he got good grades - As, Bs, and Cs - he protected his rough image by fighting and giving his teachers a hard time. The school he was transferred to was a great distance from his home and he did not know anyone there. He stated that he tried to adjust at the new school but grew very disconnected after just a couple of months and stopped going. A.N. reported that he was never involved in the juvenile system largely due to the 
influence of his grandmother and the influence of a neighborhood mentor who established a gym in his home. Kids could not come to the gym if they were in trouble or were not doing well in school. When the mentor died around 1980, that influence was lost. A.N. gave some rationale for how he was able to "drift away" from school after his transfer. Though he did well academically, he expressed a lack of understanding regarding what school was providing him. Except for math, he never received a clear concept of the role the content of his courses was to play in his life. He wanted some assurance that the education he was receiving was going to amount to something. His perspective was that there were more failures out of the school system than successes. In his experience, the numbers of the accomplished didn't compare to the numbers who had not. In the same year that A.N. left school, he found out that his girlfriend was pregnant. He responded by getting a job to support them. He was coming home from work one night when he learned that his older brother had been killed. A.N. retaliated. He was charged at the age of nineteen and began his incarceration the following year. A.N. was candid about his perspective that his path steered him toward coming to know himself more deeply. He fully believes that all of the things he did that he knew were wrong were things he needed to do to search for himself, as is the case with a lot of the young men of "our" culture cause - they don't know themselves. He opined the African American males get involved in things trying to find out who they are. In prison, A.N. challenged himself to study and practice peace. His impetus seems to have come from being introduced to Islam. Through programs like Restorative Justice, he learned empathy, forgiveness, and acceptance. He spoke of his experiences in prison as a reeducation through which he learned compassion for himself and others. He eventually became conscious of developing a persona that he and others could be proud of. $\mathrm{He}$ decided to try to keep growing in that direction.

At the time of the interview, A.N. was doing a self-study on the historic science for the Moorish culture and history. He is active in the Moorish Science Temple and recently received an honor for helping to start a program to teach appropriate social and character development to young men. The program has been adopted in one of the more troubled high schools in his community. A.N. works to maintain a healthy presence in his children and grandchildren's lives.

E.D.

Project interview date:

Birth year:

Age:

Number of incarcerations:

Years in prison:

Year released from prison:

Education completed:

Occupation:
June 21, 2011

1957

54

4

12

1998

$10^{\text {th }}$ grade

Retail store owner, Owner and manager of a transition home, \& Mentor/Re-entry Specialist 
E. D. is one of two men in the study sample who has not completed high school nor earned a GED. E.D. reported that he loved going to elementary school and never wanted to miss a day. He stated that he also enjoyed going to middle/junior high school because he looked forward to going to high school. E.D.'s excitement changed when he moved and had to a go to a different high school than the one he was looking forward to going to. He stated that he moved from the inner city where he went to school with only African American peers to an area where he went to school with whites. This was a new situation for him, which he found intimidating because he grew up believing that white people were "better than" him. E.D. rebelled at the new school and engaged in gambling and selling cigarettes. He reported that he did not engage in these behaviors at the city school for fear of being kicked out. He expressed his belief that he would have gotten more out of high school had he gone in with an open mind, believing that he could compete and get as much out of going to school there as the white students. Because E.D. disliked going to school with whites, he responded violently, getting involved in riots and earning a reputation as a bully. E.D. was one of five children. Both parents abused drugs. His father was not in the home and had no relationship with him to speak of. Each of the children abused drugs, and only his two oldest siblings completed school. E.D. stated that he was the only one of them to go to prison. He stated that he was raised in a community where drug abuse was prevalent. E.D. started "shooting heroine" around the age of 16 and supported his habit by shoplifting. This started a pattern of using drugs, committing crimes, and going to jail. When he had a job, he spent his paycheck on drugs. When he did not have a job, he committed robbery, burglary, and theft to support his habit. E.D. attributed the start of his substance abuse to peer pressure. He went into an inpatient treatment program as a requirement of his bond after he was first charged with a crime. He was eventually sentenced to 90 days in prison, during which time he got over his fear of going to prison. He found that many of his friends were there and that prison, for him, was not necessarily a place to be feared. As a result, he also lost his fear of committing more serious crimes to support his habit. E.D. dropped out of school in the same year that he was charged with his first criminal case. He stated that it was easy for him to drop out of high school, partially because "everybody else was dropping out of school." Additionally, he experienced image problems due to the dark shade of his skin, his type of hair, and academic difficulty. He reflected that he acted out on purpose when he was asked to read or perform other academic tasks in front of the class to hide his difficulties from his peers. He explained that he came to understand this about himself as he worked through his steps in drug treatment. He served four terms in prison over a 21-year period and attended long term drug treatment during his last incarceration. E.D. stated that his motivation to change came when he realized that he did not want to die in prison but, rather, hoped to successfully be a part of his children's lives. He stated that he adopted good habits as a result of the drug treatment program and read literature to learn about addiction. Upon his release from his final incarceration, E.D. chose to live in a city that was close to the correctional center where he completed long term drug treatment. He got a job right away, and then took a different job with another employer shortly after. E.D. understood and accepted during his last prison term that he had to change his way of thinking. He worked on doing that and learned tools that helped him to be successful living in society. He admitted that he intentionally did not return to his home town for fear that he would not maintain his sobriety. 
At the time of the interview, E.D. was the owner and operator of a small clothing store which he opened eight years prior. He also owned and managed a transition home to help reentering offenders integrate successfully into the community. He was working on plans to open a second transition home to offer a residence for women re-entering from prison. Additionally, E.D. worked as a Job Placement Director for a local re-entry program.

M.I.

$\begin{array}{ll}\text { Project interview date: } & \text { June 22, } 2011 \\ \text { Birth year: } & 1942 \\ \text { Age: } & 69 \\ \text { Number of incarcerations: } & 5 \\ \text { Years in prison: } & \sim 13 \\ \text { Year released from prison: } & 2000 \\ \text { Education completed: } & 9^{\text {th }} \text { grade } \\ \text { Occupation: } & \text { None }\end{array}$

M.I. was candid about his dislike for school which started early on. He explained that he stuttered and experienced a lot of teasing because of it. He also struggled with reading. M.I. disclosed that he felt out of place at school for these reasons and because he was unable to wear clothes that were in style. He stated that he attended speech class but developed a "don't-care" attitude and did not try. Instead, he was attracted to people who wore nice clothes and drove nice cars and did not believe that he was going to have the things he wanted by going to school. Nothing about school inspired him. He went only to please his mother who really wanted him to go to school but remarked that he had no real sense of direction at that time. He indicated that he was "straddling" between the streets and where his mother was trying to lead him. Reflecting back, M.I. identified a desire to learn about himself and about success among Blacks. The circumstances of the times in which he grew up made it difficult for him to connect school and education with future success. He further explained that he did not believe that "doing the right thing" would result in social changes for African Americans. M.I. left school in the ninth grade and got married at the age of 16 , because he had a child on the way. He started smoking marijuana also around the age of sixteen after learning that he was actually having two children with two different girls. M.I. eventually began using heroin and continued to do so for 37 years. He served five prison sentences for a total of 13 years. M.I. indicated that he believed he could change his life in important ways after he saw others do the same. He sought help to improve his reading skills and earned his GED while he was incarcerated. M.I. attributed his past history to his desire to identify with a particular crowd without thought for his future. Lacking a sense of direction, he was only concerned about the moment. He indicated that this kind of thinking influenced all of his choices at that time in his life. He speculated that he might have taken the time to try to achieve something in school had he had the kind of sense of direction that he has now.

At the time of the interview, M.I. expressed a sense of purpose in his life, which entails helping others. His goals are to continue learning himself, be comfortable and remain 
independent, and to help his children, the way he was "supposed to when [he] should have."

J.A.

$\begin{array}{ll}\text { Project interview date: } & \text { June 23, 2011 } \\ \text { Birth year: } & 1975 \\ \text { Age: } & 36 \\ \text { Number of incarcerations: } & 1 \\ \text { Years in prison: } & 6.50 \\ \text { Year released from prison: } & 2000 \\ \text { Education completed: } & \text { GED (1995) } \\ \text { Occupation: } & \text { Driver/Preacher }\end{array}$

J.A. hated school. He hated doing homework and having to be responsible. At the same time, he liked going to school to escape being at home with his father, whom he feared and did not like. J.A. was raised by his grandfather while his father was incarcerated. Eventually, he moved to a different state to live with his father until he left again to return to prison. He stated that this was actually a relief to him and his siblings because of the great fear they all had of their father. For J.A., school was like a social gathering - place where he could get away from home and feel good for a while. However, he found that school became more difficult in junior high school. He remembered feeling like a failure when he put forth effort and did not get his work right. He chose not to do the work rather than look like a failure. He made a connection to the way his father treated him when he didn't get something right. He could not disengage from the task with his father, but he could at school. He had no power to say "no" to his father, but he did have the power to say "no" at school. J.A. stated that he earned mostly Cs and Ds in school. He recalled starting out each year making and effort in his classes only to slack off and get Ds and Fs later in the year. He indicated that he felt bad about himself because of the way that he was behavrf in school. He explained that he knew he wasn't a "dummy" and that he was not applying himself. Instead of attending to his school work, he slept and cracked jokes in school. While this made him seem like "somebody," he stated that he felt bad about himself on the inside. J.A. found his escape from his father and from school in the streets. He recounted the story of the day he was kicked out of school in the ninth grade. It ended with his principal dropping him off at a liquor store. J.A. never returned to school after that day. J.A. started selling drugs to make fast money. He left home at sixteen, because he did not want to follow his parents' rules. He openly stated that there was nothing positive that he was trying to do at that time, though he would go to church occasionally. He viewed life as a big party back then. His goals were to sleep with as many women, make as much money, and have as much fun as he could. He was still a teenager when he went to prison. J.A. reflected that going to prison made him grow up and learn that he needed to take life more seriously. He indicated that if it hadn't been for going to prison, his circumstances would be worse right now. He explained that going to prison helped him to see that his choices were hurting people, something that he needed to take seriously. He saw that he was "breaking up families" and "destroying people rather than building them up." In prison, J.A. recognized that he 
previously allowed others to dictate to him what he should do. He indicated that he felt that he was being judged when he did not do as others wanted him to do. In contrast, he started making his own decisions and he realized that he didn't have to be negative just because he was in a negative environment. He worked with a tutor and got his GED within a month of going to prison. J.A.'s experience with the tutor, who reminded him of his father, helped him to learn how he learns best and to feel valued. More importantly to J.A., it helped him to learn to trust - something he was unable to do when he was in school. J.A. has two brothers who have also been incarcerated. His older brother has been incarcerated twice. There was a time that both of his brothers and he were all incarcerated at the same time.

At the time of the interview, J.A. was formally employed as a driver for a construction company. He also maintained his own lawn care business and worked as an assistant pastor in a local church in his community. He strived to provide for his wife and child and indicated that he was interested in finding a way to go to college while taking care of his family.

C.H.

$\begin{array}{ll}\text { Project interview date: } & \text { June 27, } 2011 \\ \text { Birth year: } & 1959 \\ \text { Age: } & 51 \\ \text { Number of incarcerations: } & 1 \\ \text { Years in prison: } & 2 \\ \text { Year released from prison: } & 2009 \\ \text { Education completed: } & \text { GED (1992) } \\ \text { Occupation: } & \text { Cook }\end{array}$

C.H. grew up in a two-parent household and described his parents as supportive. He was in his late 40's when he went to prison, which makes him the member of this sample who was the oldest at the time his incarceration began. C.H. had committed felonies prior to the crime that resulted in his incarceration and was sentenced to probation. He stated that he started using drugs in 1985 and explained that he committed his crimes to get money for drugs. He recounted the story of how he went to prison due to a probation revocation after absconding for nearly seven years. However, during that time, he continued to live in the same community and worked a full time job without being apprehended. $\mathrm{He}$ continued to use drugs while on probation and simply stopped going to see his probation officer. C.H. explained that he started using drugs as a result of peer pressure, though he did not recognize it as that at the time. To him, it was just partying and having fun with his friends. Ultimately, it was something he wanted to do to fit in and be a part of the crowd. C.H. struggled with reading in school. He stated that he had a low status among his peers and that he felt bad about himself as a student and in general. To compensate, he played the role of the class clown. He remarked that everyone knew him because of this whether they liked him or not. About school in general, C.H. stated that it was boring. He indicated that he had a hard time understanding how he would ever use some of the things he was learning. This made it hard for him to find motivation to focus. He 
admitted that he wasn't interested in going to school, but just wanted to have fun. He also explained that his priority was having money, so he worked multiple jobs even while he was in school. C.H. left school after repeating the $11^{\text {th }}$ grade twice. He took his father's advice and got a job. He earned his GED in 1992. He explained how learning changed for him as a result of working with the teacher who helped him study for the GED test. It was during that time that he learned strategies to help him remember and understand what he read. C.H. boasted that by using these strategies, he passed the GED test by earning a very high score in the reading section of the exam. C.H. stated that he stopped using drugs approximately one and one-half years prior to going to prison. His reason was that he was tired of "hustling" to get money for drugs. He turned himself in as an absconder after the police came to his home for an unrelated incident.

At the time of the interview, C.H. stated that he was happy with what he has achieved since his release from prison. He was involved in leading groups to help others overcome substance abuse. He was also researching entry into the counseling profession so that he can help more people.

W.I.

$\begin{array}{ll}\text { Project interview date: } & \text { June 27, 2011 } \\ \text { Birth year: } & 1949 \\ \text { Age: } & 62 \\ \text { Number of incarcerations: } & 4 \\ \text { Years in prison: } & 17.50 \\ \text { Year released from prison: } & 1996 \\ \text { Education completed: } & \text { Associate's Degree (1989) } \\ \text { Occupation: } & \text { Certified Substance Abuse } \\ & \text { Counselor }\end{array}$

W.I. grew up during the segregation era in a two-parent household with one older sister. His parents both worked to provide for the family's needs and to give their children opportunities that others did not have. W.I. stated that he started school early and was skipped from the third to the fourth grade. As a result, he was always the youngest in his class, starting high school at the age of twelve. This caused W.I. to think that he was "smarter than everybody else." However, he reported that he just was not interested in school. He characterized himself as preferring short cuts and wanting to take the easy way out in most things. He called this his downfall. W.I. was experimenting with drugs and alcohol from the age of twelve or thirteen. He preferred to associate with older children and explained that he did not resist their influences because associating with them offered him protection. W.I. reported that he was arrested six times as a juvenile, starting from the age of thirteen. He was expelled from one high school and suspended from another. W.I. made it clear that he got good grades in school, but was uninterested in academic learning and did not study. He identified that the social realities of that time may have helped to shape his educational outlook in that it was difficult for him to see beyond segregation. He did not expect life to change and felt discouraged from putting in effort to this educational system, because a Black man was not likely to get a job that he could be proud of regardless of his education. Consciously or unconsciously, he did not 
want to be a part of that system. He described some of the racial discrimination he experienced and indicated that the psychological effect deterred him from wanting to "work for the white man." He reported that he actually did like school and learning but that it lost its meaning for him in middle and high school. W.I. eventually went to Job Corp where he earned his GED and completed a welding program. He recounted the traumatic event of observing a friend commit suicide playing Russian Roulette while he was at Job Corp. He started using drugs intravenously during that time but was unable to say whether this choice was related to his friend's death, as he was already experimenting prior to that time. W.I. completed Job Corp in nine months and returned home at the age of sixteen. He was too young to get a job as a welder. He explained that he used his inability to get a job as an excuse to do nothing. He eventually began hustling, stealing, and running confidence games for money. W.I. was convicted of a crime at the age of nineteen and went to prison four times over a period of two decades. He disclosed that he continually got high until his final release from prison. However, he stated that he also went to school in prison, eventually earning an Associate's degree. W.I. has been in recovery now for seventeen years. He explained that the idea and possibility of recovery became real to him when he attended long term drug treatment during his last incarceration. He particularly connected with the spiritual nature of the recovery process that he was learning. Reflecting on where he was in his life, he realized, at 44, that he was in the same place the he was at 22, and was ready to change that. W.I. stated that he had never worked a job prior to his final incarceration. During his final incarceration he was worked at a construction factory on work-release status. He reported that he remained in prison for nine months past his release date in order to keep his job and avoid going back home, where he would be concerned about losing his sobriety. W.I. eventually rose to a position of a foreman at the company. He worked there until he retired at age 55. He remains the only black male to have held a foreman position in the history of the company. While he was there, he was asked to counsel addicts in prison and began doing so part time.

At the time of the interview, W.I. worked as an addictions counselor. He expressed pleasure in working making a positive impact on individual's lives and the community. Continually helping others is an essential part of his own success in recovery. He gave examples of how people entrust him with the care of important things and discuss the community and civic awards for his service to others over the past 17 years. W.I. identified his family as his top priority.

\section{F.R.}

Project interview date:

Birth year:

Age:

Number of incarcerations:

Years in prison:

Year released from prison:

Education completed:

Occupation:
June 29, 2011

1975

36

1

15

2009

GED (1995)

Sanitation Worker 
F.R. was the third of five children, raised in a single-parent household by their mother. He described his mother as hardworking but unavailable to oversee her children's activities because of the amount time that she was away at work. The children looked after each other. F.R.'s father was not involved in his life as much as F.R. expressed he would have liked for him to be. F.R. stated that school was lots of fun. He had the experience of going to school in urban settings from kindergarten to third grade and in the county where he lived from fourth to the eighth grade. Going to school in the county was much different than going to school in the city. He got kicked out of the county school for racially motivated fighting. He returned to going to school in the city to complete eighth grade. He stated that the eighth grade work he did in the city was work they he had already done in the fifth and sixth grades in the county. He indicated that this caused him to feel superior to his African American peers and diminished his enjoyment of school. F.R. explained that he did not do homework because his parents were not there to enforce it and check it. This made homework less important to him. He only did what was required to be able to do what he wanted to do, like go outside and play. F.R. started having conflict with his mother once he started high school. He left home and began using drugs and associating with a gang. Though he continued going to school, he stopped doing homework all together and refused to participate in extracurricular activities. F.R. also discussed his concern with the lack of exposure Black leadership and accomplishments in the curriculum. He admitted that school was not personally important to him but that he attended to please his mother. F.R. dropped out of school in the tenth grade. He was convicted of a crime at eighteen and went to prison at nineteen. Initially, F.R. associated with individuals in prison who had long sentences and negative attitudes. Like them, he began using heroin and crack cocaine without concern for the consequences. Eventually, he decided to participate in programs that were offered inside the institutions, including intensive drug abuse treatment, and began to see that there were more acceptable alternatives to the way he was living. His experiences opened him up to turning from his antisocial outlook to talking with and learning from others. F.R. began reading literature that helped him learn about himself. Through treatment, he understood that he was using drugs to escape rather than face and change his circumstances. F.R. began working to get out of prison and became a program facilitator, teaching classes and encouraging others to consider positive alternatives to negativity and destructiveness.

At the time of the interview, F.R. was working full time and involving himself in activities to maintain his sobriety and avoid negativity. He emphasized the importance of remaining involved in his children's lives and making sure they understand the value of education. He expressed his plans to start his own business and purchase a home.

R.O.

Project interview date:

Birth year:

Age:

Number of incarcerations:
June 29, 2011

1952

61

1 
Years in prison:

Year released from prison:

Education completed:

Occupation:
15

2003

High School (1971)

Car Detailing \& Lawn Care

R.O. is one of four members of this sample who graduated from high school. R.O. was approximately 36 years old when he went to prison, making him the second oldest member of this sample at the time he went to prison. R.O. grew up in a two-parent household with two older siblings. R.O. experienced a traumatic event when his brother was shot and killed standing on their balcony. He stated that he started carrying a gun to prevent the same thing from happening to him. R.O. reported that he liked school and found the subjects interesting at times but got distracted by other things which he focused on more than school as he got older. He most identified with sports and baseball in elementary school. In high school, his attention switched to playing dice and girls. Once he shifted his focus, he did only what he needed to to get by. R.O. indicated that he regularly created gambling operations in school to have money for clothes and for the social image he desired. His activities in school resulted in multiple suspensions. Despite his strong relationship with his mother and her expressed desire for R.O. to go to college, he chose life in the streets. After his mother died, he began to get into more serious trouble. R.O. disclosed that he had dreams of starting his own car detailing business; however, his desire for "fast money" derailed his motivation to plan for the business he wanted. R.O admitted that he spent whatever money he made on women and drugs. He indicated that he still struggles with the pain he caused by the act leading to his incarceration. He acknowledged that he did the same thing to someone else's family that was done to his family so many years earlier. This event and his subsequent incarceration helped him to learn that everything is not as easy as it seems. He reported that he stayed away from negativity in prison and kept busy in school and working. He earned diplomas in drafting and paralegal. R.O. continued to pursue positive choices after he was released from prison. He persistently searched for a job until he was hired. He also began working in lawn care with his cousin. Eventually, he began his own lawn care business. R.O. indicated that one of his best decisions after his incarceration was marrying the mother of his oldest child.

At the time of the interview, R.O. was working full time as a detailer at a car dealership. He was also focused on building his lawn care business which he hopes to pass on to his grandson. He stated that his life consists of working every day and taking care of his grandson. R.O. expressed appreciation for the opportunity to do with his grandson what he did not do with his own children. He hopes that his grandson will learn the value of working and that he will go to school to get a good education. He explained that he learned from watching his daughter go through school that you have to make school what you want it to be and that it could have been better for him had he given more effort. He further expressed that he now understands that "you need education to go farther in life than what you can really know when you are young."

\section{G.A.}


Project interview date:

Birth year:

Age:

Number of incarcerations:

Years in prison:

Year released from prison:

Education completed:

Occupation:
June 30, 2011

1957

54

1

18.83

2004

High School (1975)

Coordinator (Glass Tempering)

G.A. stated that he really enjoyed school when he was younger but lost the enthusiasm around ninth or tenth grade. It became something that he just had to finish, mostly to please his mother. In the absence of his father, his grandfather was his primary fatherfigure. He graduated with a 3.2 grade point average, despite repeatedly being kicked out of different schools. He explained that whatever he did, good or bad, he always tried to do it to the best of his ability. G.A. remembered initially being interested in education, music, and sports. Later on, he was only concerned with getting out and being on his own so he could do what he wanted to do. He expressed that he only saw usefulness in math. He didn't see how he would ever use any of the other material he was learning in his classes. When other interest took precedence, school became a drag. His interests turned to drinking, smoking marijuana, and pistol play with the group he associated with. He described it as having isolated himself from the mainstream. G.A. stated that he starting to become distracted by girls in the eighth grade. He began smoking marijuana when he was 14 or 15 and learned that he could make money selling it. He eventually escalated to selling and using other drugs as well. G.A.'s mother sent him away to live with an uncle in another state after the last time he got kicked out of school to make sure he finished school. He believes that he was the only one of his circle of ten or fifteen that graduated high school. G.A. explained that he started in the drug game for the "easy money." He stated that the love of money gave way to the love of violence. He became a dictator and acted violently when his orders were not completed. G.A. indicated he decided to change after a conversation with his mother at the start of his incarceration helped him to see how his behavior was affecting his mother and other people. $\mathrm{He}$ started going to NA and turned to Christianity to take his life in a positive direction. G.A. emphasized that he committed to practicing Christianity with the same intensity that he sold drugs. He reported that he has been growing ever since. Vocationally, he chose to pursue computer information systems training in prison, because it was interesting, challenging, and something he could use immediately. He completed the program with a 4.0 grade point average. G.A. learned to decipher and create code when he studied through his training. He also acquired discipline and a work ethic. He put in the effort to give his customers what they asked for and felt satisfaction when he accomplished the tasks. G.A. describe this as well as his current work as opportunities to express himself positively.

At the time of the interview, G.A. expressed satisfaction with his current job. He stated that he continues to work to provide his customers with the same level of service as he did when he worked in computer information systems in prison. G.A. assumes responsibility for positively influencing the youth in his community. He stated that he 
feels good about teaching the youth in his Sunday school class. He was clear that he feels that he should be doing more to support positive development in his community, but finds it difficult to do so because of his work schedule. G.A. also strongly expressed his belief in family and discussed his efforts to be the kind of role model for his children and grandchildren that his grandfather was for him.

P.A.

Project interview date:

Birth year:

Age:

Number of incarcerations:

Years in prison:

Year released from prison:

Education completed:

Occupation:
June 30, 2011

1966

45

4

15

2001

GED (1993)

Patient Care

P.A. grew up in a community which he described as "very rough." School was something he did because he had to, but he did not indicate any real investment. He alternated living between his parents' residences in two states. When living with his mother, stepfather, and two brothers, school was emphasized and important, and P.A. was made to do homework. When living with his father, going to school and doing well was not stressed. P.A. stated that his father would allow him to skip school to go fishing or do other activities. P.A. also remarked on other school-related differences between the settings. He reported that he experienced racism at the schools he attending when living with his after. The schools he attended when living with his mother were predominately Black. While he felt more comfortable with his peers and teachers in the predominately Black schools, he indicated that he was constantly getting into fights and that the teachers also behaved in ways that he found threatening. P.A. spoke of one teacher who made learning engaging. He enjoyed going to that class and felt that the teacher actually cared about his students. Other than that, academic learning did not interest him. He explained that his mother worked outside of the home and that his stepfather was uninvolved. When he lived with them, his mother stressed school, but was unable to provide sufficient oversight to keep him from getting in trouble. He started experimenting with alcohol and marijuana when he was around fifteen. P.A. was kicked out of school and confined to a juvenile facility for hitting a teacher. As he progressed in the use of drugs and alcohol, his primary interests were "running the streets," having marijuana, and drinking. He explained that his motivation for all of his crimes was to get money for things he wanted and to support his habit. He experienced four incarcerations in adult correctional centers in different states. P.A. was motivated to get his GED in prison to avoid working in the kitchen. Once he got his GED, he worked as a tutor in the school whenever he was incarcerated. He participated in substance abuse treatment and decided to stop drinking and using drugs. Like other members of this sample, he stopped associating with family members and former friends with whom he previously used substances. He also moved to a different city to avoid familiar places and temptations. 
At the time of the interview, P.A. had been sober for eight years. He was working in patient care at a local hospital. He reported that he enjoys being able to relate to people now that he is sober and looks forward to seeing the people he works with every day. P.A. has maintained a structure in his life to remain sober, maintain employment, and avoid behavior that might result in the loss of his freedom.

S.T.

Project interview date:

Birth year:

Age:

Number of incarcerations:

Years in prison:

Year released from prison:

Education completed:

Occupation:
July $6 \& 7,2011$

1972

38

2

21.25

2010 (Aug)

GED (1989)

Barber \& Photographer

(Self-employed)

S.T. is the member of this sample who was the youngest at the time of his incarceration. He was charged with his crime at the age of fourteen and went to prison at sixteen with a life sentence. He reported a three-month stay in a juvenile detention center prior to committing the crime for which he went to prison. S.T. described a disturbing childhood, during which he was exposed to a wide array of illegal activity. He stated that his mother ran gambling houses when he was young. As her only child, he often spent time in the houses among the people that frequented them. This meant exposure to handling weapons and other dangers that shaped his view of life in his community. S.T. reflected that the environment where he grew up provided more negative influences than positive. He expressed the he wish this had not been so, as he believes that he would have utilized the tools he would have gained from positive influences to be product, much in the same way that he did with what he learned from the negative influences around him. Being very young when he went to prison, S.T. conveyed the idea that he didn't really have choices or that he was not aware of other choices that were present for him with which he could identify. He did not believe he would have committed his crime otherwise, because, "The circumstances around it never would have happened." He express remorse and continuing regret over the pain he caused his victim's family. He went on to explain that he was following what was expected of him in his environment. He indicated that there was really no thought about prison as a consequence. S.T. made it clear that he does not justify what he did, but explained that he felt his victim threatened his life, and he believed in his capability of carrying out his threat. Though he understood that he did something wrong when he committed his crime, he stated his belief that a jury of his peers from his own environment would likely not have convicted him. S.T. affirmed his belief and understanding that he did deserve to go to prison for what he did. However, explained that the rules and expectations in his environment are different than the laws by which he was convicted and that a majority of those where he comes from would have done the same thing he did. S.T. reported that he got his GED when he was sixteen and began taking college courses until they were discontinued in the institutions where he 
was incarcerated. S.T. remembered going to a number of different schools as a child because of family moves and behavior problems. He went further to say that the lessons in school often did not hold his attention, so he found ways to occupy his time. He also reported that he tended to be violent, especially when he felt threatened or provoked. This gave him a reputation so that, by middle school, people tended not to provoke him. He was unable to remember anything academic from middle school; however, he recited high school schedule and reported that he did well only in his math class. He explained that he still remembered these things because he got "locked up" when he was fourteen. S.T. made it clear that most of his memories from school were not related to academic learning. His answer seemed to indicate that he did not understand the importance of what school offered academically. In retrospect, he recognized that everything he needed to learn was there and was accessible. He just didn't know what direction to go or that it was his responsibility to get it. He further explained that the lack of recognition of what was available actually did make it inaccessible at the time. Felt that there were a lot of things he missed but did not know I was missing. He indicated that he needed this explained to him in ways that made what he was learning make sense and useful every day.

At the time of the interview, S.T. was self-employed as a barber and photographer. He was stressed about making a sustainable income and spoke at length about his efforts to avoid resorting to illegitimate means of making money. He expressed pride in the level of self-awareness he has developed evaluate his choices. He underscored this by discussing his work to overcome drug addictions and maintain his sobriety over a number of years. He emphasized his need to keep doing what is right in order to build the future he wants for himself. During the interview, S.T. demonstrated that he is coming to terms with the very real possibility that school may have provided much more for him, educationally, than what he recognized. He maintained that education happens outside of school as well, but professed the importance of the taking advantage of the educational opportunities offered in school.

L.A.

$\begin{array}{ll}\text { Project interview date: } & \text { July 6, 2011 } \\ \text { Birth year: } & 1958 \\ \text { Age: } & 53 \\ \text { Number of incarcerations: } & 8 \\ \text { Years in prison: } & 15 \\ \text { Year released from prison: } & 1997 \\ \text { Education completed: } & \text { Associate's Degree (2009) } \\ \text { Occupation: } & \text { Cook }\end{array}$

L.A. grew up in a household where education was hardly stressed. His father went to the eleventh grade, his mother to the eighth. Neither of them made a big deal about education. L. A. was one of five children. His sister and one of his brothers completed school. The same brother earned a master's degree and became an accomplished musician. He and two of his brothers did not graduate from high school. One of them 
never earned a GED. He was not sure if the other brother ever did either. L.A. explained that his more accomplished brother attended schools for the blind and lived away from his family most of the time. L.A. admitted the he didn't really like school that much because the teachers were mean and the students picked on each other frequently. He stated that he went for the fashion and the girls. L.A. also stated that he made acceptable grades prior to moving to a new city with his mother and attending a different school after his parents' divorce. He disclosed that he began experimenting with alcohol at eleven and smoking marijuana at fourteen. By the time he moved, he was drinking and smoking marijuana regularly and began to experience a drop in his grades. L.A. indicated that this is when he lost interest in school. He frequently skipped classes and school altogether to drink and smoke marijuana with his friends. He stated that by this point, he was going to school only for the girls. He also began stealing in order to keep up his appearance and dress the way he wanted to dress. He reported that this helped him to feel good about himself. L.A. was arrested four times as juvenile and was assigned to a juvenile officer. He disclosed that he continued to steal while under supervision. L.A. was kicked out of school prior to finishing his senior year and stated that he just never went back after that. L.A. expressed a strong interest in music as a youth. He stated that he worked for a time as a DJ and became pretty good at it. His desire was to establish and night club. His addiction to crack cocaine destroyed his hopes of accomplishing that dream. L.A. went to prison eight times for a total of approximately fifteen years as a result of illegal activities to get money for crack. He overcame his addiction to substances through treatment. During his last prison term, he established a goal of becoming the manager of a specific restaurant in his community. He achieved that goal within two years of his release from prison while, and then pursued his GED. Next, L.A. attended college and earned an associate's degree. He explained that having goals is what helped him to remain on a positive course with his life

At the time of the interview, L.A. was working as a minister in the church he attends and full time as a cook in a local hospital. He was working on his Bachelor of Social Work degree and looking forward to becoming a drug and alcohol counselor when he obtains it. He also desires to work in ministry full time at some time in the future. L.A. emphasized that getting education is part of his life now and that he will continue to do so as long as he can. He had been going to school year-round in effort to achieve his goals. As other members of this sample have indicated he has embraced spending time with and being a role model for his grandchildren, especially because he was not there for his own children.

K.E.

$\begin{array}{ll}\text { Project interview date: } & \text { July 8, } 2011 \\ \text { Birth year: } & 1955 \\ \text { Age: } & 56 \\ \text { Number of incarcerations: } & 1 \\ \text { Years in prison: } & 34 \\ \text { Year released from prison: } & 2008 \\ \text { Education completed: } & \text { GED (1977) }\end{array}$




\section{Occupation:}

\section{Charity Work}

K.E. came from a family and community background of poverty where most drank on the weekends and no one was really expected to amount to anything. Both parents were incarcerated from time to time, but no other immediate family members that he is aware of. He reported that he was put out of multiple schools for behavior problems including assaulting teachers. He experienced school as an "intrusion" in his life, so he went with the intention to "clown" and be disruptive. He explained that he saw school as a waste of time. Though he could recall some social and moral lessons he found valuable, he could not remember learning anything academically in school. Because of the environment he came from, K.E. did not care what people thought about him as a student. He stated that he was a D-student and described himself as "not having a sense of purpose or direction" at that time in his life. He reported, however, that he has never used alcohol or drugs. He explained that he fought back when teachers attempted to discipline him with corporal punishment. He continued to have trouble in the special school and was arrested a couple of times. He stated that he fought police as well when they "put their hands on [him]." K.E. was placed in a newly formed high school for children with behavior problems, which he perceived as a juvenile detention center. He expressed his belief that this was not a good situation for him, because he learned ways to commit crimes that he might not have learned until much later, otherwise. He stated that he committed a crime at the age of fourteen as a result of what he learned from others in the juvenile detention centers. He stated that he had never thought about committing such a crime before he had contact with others in the detention centers. K.E. went to the highest level of juvenile detention in his state two times before entering the adult institutions at age seventeen. He spent 32 years in prison on a 45 -year sentence before he was released. He stated that he went back to prison for two years. However, each time he was released, he was incarcerated again after only five months for an accumulative total of an additional two years in prison. Though K.E. has been doing well since his final release in 2008, he explained that he lives with the fear that his parole could be violated at any time "for no real reason." This makes it hard for him to feel comfortable making long term plans. K.E. stated that he never tried to deny anything that he did in the past. He explained that he knew what he was doing was wrong but thought his actions were solutions to his problems. He indicated that he sees things differently now and acknowledged that his choices only added to his problems. K.E. indicated that he became motivated to learn in prison when he recognized knowledge as a tool of protection. He took the time to learn to read, write, and do math and earned his GED in the early years of his incarceration. He worked as a paralegal and also took some college courses. He expressed interest in going to college in the future when he feels the time is right.

At the time of the interview, K.E. had been out of prison three years since his final release and stated that he was free of any legal problems. His age at the time of his release qualified him for social service programs that helped him transition back into society more successfully. K.E. has had difficulty finding a job because he is always truthful with potential employers about his history. However, he was involved in volunteer work that he believed was contributing to the lives of others in positive ways. 
K.E. developed an interest in graphic arts and has put together a small portfolio in hopes of creating opportunities to advance the skills he has developed through service to others.

J.S.

$\begin{array}{ll}\text { Project interview date: } & \text { July 8, 2011 } \\ \text { Birth year: } & 1976 \\ \text { Age: } & 35 \\ \text { Number of incarcerations: } & 1 \\ \text { Years in prison: } & 11.66 \\ \text { Year released from prison: } & 2004 \\ \text { Education completed: } & \text { Associate's Degree (2011) } \\ \text { Occupation: } & \text { Information Technology }\end{array}$

J.S. grew up in a two parent household with two older siblings. His parents separated when he was in the sixth grade. His father died while he was still young. J.S. went to a lot of different elementary schools but reported that he made good grades. His grades started dropping in seventh grade. He started smoking marijuana in eighth grade and getting into trouble. J.S. recounted the number of suspension, including three ten-day suspensions, he was given for tardiness and inappropriate behavior. He acknowledged was not working to improve his situation. He reported that his grades dropped to all Fs and speculated that he was promoted to the next grade because they wanted to get rid of him. J.S. indicated that he did not get in much trouble in high school, though he is sure that some of the teachers knew he was smoking marijuana. His parents also knew and made him see a drug counselor in school after he was caught selling marijuana to another student in the hallway. J.S. reflected that school was not important to him, because his mother graduated from high school and worked two jobs. In his mind, graduating from high school did nothing for her. He expressed his feeling that school was boring, but stated that he paid attention and performed well in the classes that he found challenging and interesting. In general, however, he refused to do homework but stated that he was able to maintain a C-average. J.S. never saw himself going to college, and expressed that he really didn't know what he was going to do with his life at that time. While in high school, J.S. worked at a fast food restaurant. He reported that he was robbed twice coming home from work between the ages of fourteen and fifteen. In response, he bought a gun. He subsequently experimented with committing robberies. He was caught after attempting his third robbery and went to prison at age sixteen with a 23-year sentence. Prior to this event, he was arrested four times as a juvenile for stealing. J.S. completed a number of programs in prison, including substance abuse and long term drug treatment. He completed his GED in 1993, prior to the time he would have completed high school. He reported that he really wanted his GED and was proud of his accomplishment. J.S. began taking college courses soon after getting his GED but was unable to finish the quarter as the college program was discontinued in the institution. J.S. found employment soon after his release from prison and also started a moving company with his brother. 
At the time of the interview, J.S. was working hard to find new employment, searching for jobs daily. He kept a notebook log of all of the employers he had contacted or been interviewed by. He was also one day away from graduating from an Information Technology program he was completing. J.S. was maintaining an income through product sales and entrepreneurship and keeping careful records of his business transactions. He spoke of his desire to provide a good future for his two children and to help others.

\section{J.O.}

$\begin{array}{ll}\text { Project interview date: } & \text { July 10, 2011 } \\ \text { Birth year: } & 1970 \\ \text { Age: } & 40 \\ \text { Number of incarcerations: } & 1 \\ \text { Years in prison: } & 8 \\ \text { Year released from prison: } & 2008 \\ \text { Education completed: } & \text { High School (1988) } \\ \text { Occupation: } & \text { Business Owner }\end{array}$

J.O. was raised in a two-parent household with an older sister and an older brother. He is one of four members of this sample who graduated from high school. He is the only member of the sample to have attended college prior to his incarceration. He admitted that he couldn't stand going to school. He enjoyed socializing and participating in sports and felt like his life started after the end of the school day. From the very beginning, he could remember always being preoccupied and having difficulty concentrating on the activity in the classroom. He remembered being a good reader and speller and being shy. He lived in an community where he was the only Black student in his class. He explain of how he felt ignored and that teachers allowed him get by without doing his work rather than requiring that he complete it. J.O. described a time when he worked hard to earn an $\mathrm{A}$ in a class that he was failing in order to play football. While this experience increased his confidence, it also convinced him to see that his teachers neglected to take an interest and push him to do better than Cs and Ds. Because J.O. was a good athlete, he was allowed to get by in high school without having to do much work. He stated his belief that he was spoiled by his community because of his athletic ability. They catered to him which he said made him lazy. He stated that he continued to be lazy and only worked when he needed to. J.O. expressed his wish that his father had gotten involved and made him study. He stated that his parents never looked at his report card his last three years of school but just took it for granted that he was passing. He went to college on an athletic scholarship and continued to get Cs and Ds in college. J.O. reported that he had roommates on two difference college campuses who sold drugs. J.O. eventually began selling drugs also. He was convicted at 29 and started his prison sentence at the age of thirty. He admitted that going to prison forced him to be honest about his life. He perceived that other prisoners, who were pursuing GEDs, demonstrated greater knowledge than he. His embarrassment led him to increase his own education while he was in prison. Though he did not use substances, he completed long term drug treatment to learn about himself. He came to understand his addiction to the lifestyle of a drug 
dealer and learned ways to combat the problem. The institutions where J.O. lived during his incarceration offered various opportunities to learn academically. He took advantage of them and took some college level course. He referred to this as his "re-education" in prison. On his own, he figured out how he studies best and learned ways to overcome his difficulty focusing on academic material. He stated that he found the guys that he wanted to associate with in the educational centers. These were the ones with whom he felt comfortable and developed good relationships. J.O.'s older brother has been to prison four times for drug related offenses. He also has a number of cousins who have been incarcerated for like offenses. He expressed frustration with his family's mindset that allows them to continue to put themselves at risk of harm or loss. He explained that he has learned not to allow negativity in his life. This is his assurance again every returning to prison. However, it also puts him at odds with members of his family. J.O. finds this difficult to deal with. J.O. found employment soon after he was released from prison. When he was laid off, he found employment at another company. He has since become the owner of that company.

At the time of the interview, J.O. was very satisfied with his business. He stated that it fits him well. It keeps him busy and allows him to travel around the state. It provides an outlet for him to use the organizational skills he developed while in prison and exposes him to new people constantly. He kept himself on track by setting goals and remaining focused to achieve them. He was committed to making sure his children get what they are supposed to get in the classroom. This meant helping them to develop good habits and learn how to make good choices. He was concerned with prepare them for challenges they will face in society and demonstrating how to living a clean, quality life with peace. He expressed a strong respect for education and the benefits it provides. 
Appendix B

Interview Protocol 
Interview Protocol

Interview Questions for previously incarcerated African American males

\section{Introduction}

The idea for this study came from a quote written by Dr. Martin Luther King, Jr. in 1948. He stated,

"Education must enable a man to become more efficient to achieve with increasing facility the legitimate goals of his life".

To say this in different words, education is a process that must be measured by its results. The result of a good education is a mature person that has learned to think of her/himself, her/his community, and the larger world around her/him in ways that allow her/him to choose specific goals for her/his life. At the same time that the individual is learning to think like this, s/he is also learning the skills s/he will need to successfully achieve her/his goals. The goals a person chooses are "legitimate" if the person is both able to and interested in achieving them and feels that her/his life is good because of them. Also, the goals must have positive effects for the greater community and beyond.

What does Dr. King's statement mean to you?

\section{Personal assessment of choices and outcomes}

1) How do you feel about what's going on in your life right now?

2) How do you feel about what you are doing in your life right now?

3) What do you like most about your how your life is going right now?

4) What do you like least about your how your life is going right now?

5) If you wrote a book/movie/song about your life, what would you call it and what would it say about you?

6) How would you like for your life to have been different?

7) What would you do differently if you could start your life over?

8) What things were you trying to achieve before you were incarcerated?

9) What [choices] got you to where you are today?

10) What choices would you make the second time around that you did not this time?

\section{Exploration of affect connected to school experience and past perceptions of the value and impact of formal education}

11) In what ways did your education help you to get where you are today?

12) What do you remember most about school (elem/mid/jhs/hs)? 
13) What could have been different about school or your education that would have made your life better today?

14) How did you feel about school?

a. What made you feel that way?

b. When did you start to feel that way?

15) How did you feel when you were at school?

a. What made you feel that way?

b. When did you start to feel that way?

16) How did you feel about your teachers?

a. What made you feel that way?

b. When did you start to feel that way?

17) How did you feel about the other students at school?

a. What made you feel that way?

b. When did you start to feel that way?

18) How did your family feel about school and education?

19) How did your friends feel about school and education?

20) What was important to you when you were in school?

21) What made those things so important to you then?

22) How did school address what was important to you at that time?

23) What did you need from school/your education that you did not get?

24) What did you get from school/your education that you did not want?

\section{Alignment of current goals and values with the definition of "legitimate goals" used in this study}

25) What is important to you now?

26) What did you learn in school that helps you to deal with what is important to you now?

27) What did you need to learn when you were in school that would better help you with the things that are important to you now?

28) When would have been the best time to learn those things?

29) How do you feel, today, about school and education?

30) Who are your heroes, and what do they want for you?

31) If they wrote a book/movie/song about you, what would they call it, and what would it say about you?

32) What, to you, are "legitimate goals"?

33) What are your goals for your future?/What do you want for your life?

34) What are you doing to achieve your goals? 
35) If your book/movie/song was to be rewritten, what would the new title be?

36) Looking back on your experience, what is the most helpful thing that you would want to say to children, in general, about school?

37) What would you say to Black boys about school?

38) What would you say to your own children?

39) How would you design schooling for Black boys and young Black men - what would it look like?

\section{Conclusion}

Now that we've finished our conversation, do you have any new or different thoughts about Dr. Martin Luther King, Jr.'s statement that you heard at the start of this interview? "Education must enable a man to become more efficient to achieve with increasing facility the legitimate goals of his life".

To say this in different words, education is a process that must be measured by its results. The result of a good education is a mature person that has learned to think of her/himself, her/his community, and the larger world around her/him in ways that allow her/him to choose specific goals for her/his life. At the same time that the individual is learning to think like this, s/he is also learning the skills s/he will need to successfully achieve her/his goals. The goals a person chooses are "legitimate" if the person is both able to and interested in achieving them and feels that her/his life is good because of them. Also, the goals must have positive effects for the greater community and beyond. 
Appendix C

Informed Consent 
Todd Robinson, M.A., LPC, Doctoral Candidate

Investigator:

Dept. of Educational, School, and Counseling Psychology, University of Missouri, 573-424-2835

INVESTIGATORS' STATEMENT

The purpose of this consent form is to tell you what you need to know to help you decide whether or not you want to be a part of this study. Please read the form carefully. You may ask questions about the purpose of the research, what I will ask you to do, the possible risks and benefits, your rights as a volunteer, and anything else about the research or this form that is not clear. When all your questions have been answered, you can decide if you want to be in the study or not. You can choose not to be a part of this study at any time, even if you have already started. This process is called 'informed consent.'

\section{PURPOSE OF THE STUDY}

I am interviewing Black men who have been in prison and are now released and doing well in their communities. The purpose is to learn about their past and current attitudes about school and education and connections between their educational experiences and past criminal choices. From the voices of these men, I hope to gain better understanding of their; 1) ideas about their own goals and dreams, 2) thoughts and feelings about their educational experiences, and 3) ideas about any differences in their education that could have helped them make different choices.

\section{PROCEDURES}

Everyone who will be interviewed for this study has been in prison in the past. Each interview will be held in a private place and will last about two hours. You will be asked to complete a Demographic Pre-Interview Form. Then you will be asked to answer a list of questions. All interviews will be recorded on a computer or other electronic device. Your answers will be typed out at a later time. At the end of the interview, I will ask for your permission to contact you again if I need to make sure I heard and understand your answers. I will use study codes to keep track of your interview and the written information you will give me. Your name will be removed from anything and everything that could cause anyone else to know what you told me during your interview. All storage devices with information from this study will be kept in a locked file to protect your identity and your information.

\section{RISKS, STRESS, OR DISCOMFORT}

I do not anticipate any risks, stress, or discomfort from being part of this research, beyond what would be experienced discussing personal goals and feelings about education under normal circumstances.

\section{BENEFITS OF THE STUDY}

This study gives recognition to the voices of African American men who have experienced the hardships of prison life. I hope that the results of this study will be increased understanding of how to provide education that leads to the eventual reduction of the disproportionate incarceration rates and higher quality of life for African American males in the United States. You may not directly benefit from being in this study.

\section{OTHER INFORMATION}

Taking part in this study is voluntary. You can stop at any time. Taking part in this study, or not taking part in this study, will not affect your supervision status in any way. Information about you is completely private. All written and recorded information you give me will be coded so that your name will not appear with it. I will keep the link between your name and the code secured in a separate file. All research materials must be securely stored for a minimum of seven years, according to the Office of Human Subject Research Protection. After that time, I will destroy the link between your identity and the information you provide for this study. If the results of this study are published or presented, I will not use your name.

Campus IRB Approved Date, May 11, 2011

Project Expiration Date, October 29, 2011

Project Number 1177980 
$\underline{\text { Subject's Statement }}$

I WANT TO PARTICIPATE IN THE STUDY

This study has been explained to me. I volunteer to take part in this research. If I have questions about the research I can ask the investigator, Todd Robinson, M.A., LPC. If I have questions about my rights as a research subject, I can call the Campus Institutional Review Board at (573) 8829585. I will receive a copy of this consent form.

I do/do not give the researcher permission to contact me for follow-up after my interview is completed.

Printed Name

Signature

Date

PLEASE SIGN AND RETURN

Campus IRB Approved Date, May 11, 2011

Project Expiration Date, October 29, 2011

Project Number 1177980 


\section{$\underline{\text { Subject's Statement }}$}

\section{DO NOT WANT TO PARTICIPATE}

This study has been explained to me. I do not volunteer to take part in this research. If I have questions about the research I can ask the investigator, Todd Robinson, M.A., LPC. If I have questions about my rights as a research subject, I can call the Campus Institutional Review Board at (573) 882-9585. I will receive a copy of this consent form.

Printed Name of Participant

Signature of Participant

Date

\section{PLEASE SIGN AND RETURN}

Campus IRB Approved Date, May 11, 2011

Project Expiration Date, October 29, 2011

Project Number 1177980 
Appendix D

Demographic Pre-Interview Form 


\section{DEMOGRAPHIC PRE-INTERVIEW FORM}

A Qualitative Study of African American Male Education and Incarceration

\begin{tabular}{|l|l|}
\hline 1) What year were you born? & \\
\hline 2) What date were you released from prison? & \\
\hline 3) Are you currently on parole? & \\
\hline 4) What date were you released from parole? & \\
\hline 5) How many total number of years were you in prison? & \\
\hline
\end{tabular}

6) What charges were you convicted for?

7) How old were you when you:

a) Were charged with the crime(s) you were convicted for?

b) Went to prison?

8) What programs did you complete while you were in prison?

9) While you were in prison, was your mental health score ever 3 or higher?

10) What was your mental health score at the time of your release?

(Circle one.) Yes / No

(Circle one.) 1234 or 5

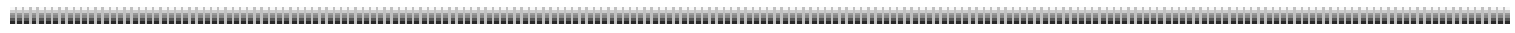

11) Were you ever arrested as a juvenile?

12) Did you ever spend time in a juvenile detention center?

\begin{tabular}{|l|l|l|}
\hline $\begin{array}{l}\text { Yes / } \\
\text { No }\end{array}$ & $\begin{array}{l}\text { If yes, how many } \\
\text { times? }\end{array}$ & \\
\hline $\begin{array}{l}\text { Yes / } \\
\text { No }\end{array}$ & If yes, how long? & \\
\hline
\end{tabular}


FOR MISSOURI RESIDENTS:

13) Did you ever spend time in the Missouri Department of (Circle one.) Yes / Youth Services?

a) If yes, how old were you?

b) How long were you there?

EDUCATION AND VOCATION

\begin{tabular}{|c|c|c|c|}
\hline Education Completed & \multicolumn{2}{|c|}{ Where Completed } & Year Completed \\
\hline \multicolumn{4}{|l|}{$\begin{array}{l}\text { 14) High School } \\
\text { Diploma }\end{array}$} \\
\hline \multicolumn{4}{|l|}{ 15) GED } \\
\hline \multicolumn{4}{|l|}{ 16) Associates Degree } \\
\hline \multicolumn{4}{|l|}{ 17) Bachelors Degree } \\
\hline \multicolumn{4}{|l|}{$\begin{array}{l}\text { 18) Professional } \\
\text { Degree }\end{array}$} \\
\hline \multicolumn{4}{|l|}{ 19) Graduate Degree } \\
\hline \multicolumn{4}{|l|}{ 20) Others } \\
\hline \multicolumn{4}{|c|}{$\begin{array}{l}\text { 21) What was the last grade you completed in school BEFORE } \\
\text { you went to prison? }\end{array}$} \\
\hline \multicolumn{2}{|c|}{$\begin{array}{l}\text { 22) What kinds of grades did you get in } \\
\text { school? }\end{array}$} & \multicolumn{2}{|c|}{$\begin{array}{l}\text { (Circle One.) Mostly A's Mostly B's } \\
\text { Mostly C's } \\
\text { Mostly F's }\end{array}$} \\
\hline \multicolumn{2}{|c|}{$\begin{array}{l}\text { 23) How did you feel about yourself as a } \\
\text { student? }\end{array}$} & \multicolumn{2}{|c|}{\begin{tabular}{|lr}
$\begin{array}{l}\text { (Circle One.) } \\
\text { bad }\end{array}$ & Pretty good Pretty \\
bad & Neither good nor \\
\end{tabular}} \\
\hline \multicolumn{2}{|c|}{$\begin{array}{l}\text { 24) How did you feel about yourself in } \\
\text { general? }\end{array}$} & $\begin{array}{l}\text { (Circle One. } \\
\text { bad } \\
\text { bad }\end{array}$ & $\begin{array}{l}\text { tty good Pretty } \\
\text { Neither good nor }\end{array}$ \\
\hline
\end{tabular}

25) What made you feel that way about yourself? 
26) What is your current vocation?

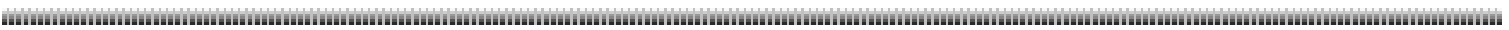

27) Were any of your parents or caregivers $\quad$ (Circle one.) Yes / No ever incarcerated

28) Which One(s)? Circle all that apply.

29) Were any of your other relatives ever incarcerated?

30) How are they related to you? Write in your answer(s).

Father / Stepfather / Mother /

Stepmother Other

(Circle one.) Yes / No 
Appendix E

Peer Debriefer Instructions 


\section{Dear Debriefer,}

What I've done is reduced to one or a few phrases the responses that my participants gave to each of the 39 questions that I asked in my protocol. I think these statements best represent their answers to the questions.

Each question is represented on a single page. The respondents' answers are below the questions.

What I'm asking you to do for each question is to look at the responses and group them into categories as you think they fit together. Give each category a name to indicate the theme(s) portrayed by the responses you have grouped together.

Send that back to me when you are done. That's it. I will compare you groupings and categories to mine to see where there is agreement and divergence.

Let me know if you have any questions. Thanks a ton!

*We did not discuss this in our conversation, but I'm also including a copy of the field notes from one of my interviews. For this particular participant, I reduced the transcript from 117 pages to 8 pages of text that capture the ideas I believe he was expressing in his answers. Don't feel obligated to read through this thoroughly. I'm sending it because I think it will help to give you a feel for my movement from the complete interview to the representative phrases that you grouping into categories for me. Also, you might find the answers interesting. 


\section{Appendix F}

Field Note Example 
185 explained his family and community background as one of a low income environment where most drank on the weekends and no one was really expected to amount to anything because of where they came from.

He reported that he was put out of multiple schools for behavior problems including assaulting teachers. He explained that he fought back when teachers attempted to discipline him with corporal punishment. He stated that he fought police as well when the "put their hands on [him]." He stated his opinion that what he was doing was probably not much different than what children are doing in school today. He was placed in a newly formed high school for children with behavior problems. He perceived it as a juvenile detention center. \{It sounds like this may have been the start of the Special School System in Kansas City.\} 185 expressed his belief that this was not a good situation for him. He stated that he learned ways to commit crimes that he might not have learned until much later, otherwise. He reported that he continued to have trouble in the special school and was arrested a couple of times.

He stated that he committed a robbery at the age of fourteen as a result of what he learned from others in the juvenile detention centers. He stated that he had never thought about robbing anyone before he had contact with other in the detention centers. 185 went to the highest level of juvenile detention in his state two times before entering the adult institutions at age seventeen. He spent 32 years in prison before he was released. He stated that he went back to prison for two years. Each time he was released, he was out for only five months before he was reincarcerated. His has been out three years since his final release and stated that he hasn't had any problems at all. He gave credit to programs that his age qualifies him when he accounted for his successful transition after his last release. He further stated that he has had difficulty finding a job because he is always truthful with potential employers about his history. (His self reflections are demonstrative of the kinds of changes I'm seeking to understand through this study and how to engender these characteristics and qualities through education prior to young males becoming risks for unsavory behaviors resulting in incarceration.\} Though 185 has been doing well since he release, he explained during the interview that he lives with the fear that his parole could be violated at any time for no real reason. This makes it hard for him to feel comfortable making long term plans.

185 stated that he never tried to deny anything that he did in the past. He explained that he knew what he was doing was wrong but thought they were solutions to his problems. He indicated that he sees things differently now and acknowledges that his choices only added to his problems. He reported that he had a 45-year sentence and that he probably would not have gotten out had it not been for changes that were made after the destruction of the WTC. 
185 worked as a paralegal while he was incarcerated. He got his GED while in prison in 1977 and took some college courses. He is considering going to college in the future but doesn't feel this is the right time for him to do so.

185 stated that he was a D-student; however, because of the environment he came from, he did not care what people thought about him as a student. School was a low priority. He described himself as "not having a sense of purpose or direction" at that time in his life. Both parents were incarcerated from time to time, but no other immediate family members that he is aware of.

185 reported that he has never been a drinker nor used drugs.

185 is interested in graphic arts and has put together a small portfolio.

\section{Introduction}

185 felt that the statement was more relevant at the time that it was made. He stated that society has changed so that there are a number of overqualified people such that having an education is not a big deal for advancement anymore.

\{He used the example of computers, stating that having computer skills used to be a big deal. But now, computers are everywhere. Kids are now exposed to them when they are very young. Everyone is using them and the skills have become essential just to function in society.\}

\{My interpretation was that he was communicating on the limits of education. I explored this further before moving on to the first question.\} 185 reflected that Malcolm X said that a good education no longer guarantees you employment. He expressed his belief that this is even more true now. He went further to say that his history has prevented things from happening for him and seems hopeful that they may happen in his future. \{It was not fully clear how he was connecting this to education, but it seemed that he was suggesting that more education is not likely to pay off for him presently.\}

\section{Personal assessment of choices and outcomes}

\#1) "I feel pretty good about what's going on in my life." He explained that he had nothing when he got out of prison. He stated that patience has paid off and that he has gotten a lot of good breaks since he's been out. He indicated as an important point that one must understand is that things can happen for you when you are out that cannot when you are in prison.

\#2) 185 stated that he feels good about what he is doing because he is working with charities and involved in helping people. He helps deliver food to the elderly and edits a newsletter for a charity that informs the community about homelessness and other issues in the community.

\{He disclosed that he recently ended a relationship with a woman who wasn't going anywhere and seemingly tried to keep him from going anywhere. He stated that he takes 
time every morning to think about what he has accomplished so that he doesn't risk mistakes that would jeopardize that.

\#3) He likes having more freedom and not being told what to do in every area of his life, but being able to make his own choices about what to do, when, and how. He also likes having his own space to separate himself from others when he wants to.

\#4) He has found it challenging to find a woman he can have a healthy, satisfying relationship with and his finances are not what he would like them to be. $\{185$ indicated that he has other things in his life that give him hope and that he really enjoys being able to help others even though his resources are very limited.\}

\#5) He shared that he is writing a book, but is having trouble with the cohesion and has not come up with a title yet. He stated that his perspective on life has changed since he started writing the book, such that he may have to actually start it over. He explained that he has seemed like a different person to himself as he has gone through different things and that it is disconcerting trying to figure out who he is now at his age. He also explained that he is still adjusting to differences in the world he lives in now from the world he lived in in prison, recognizing that he if he tries to live the same way in his current world that he lived in prison, he will end up back in prison. He also explained that his learning process is somewhat disorganized and hopes that does not result in him getting himself in trouble.

$\{185$ stated at question \#11 that he wants to write a book that has the power to touch people and change their lives like the books he's read have done for him."

\#6) Probably nothing, what he has experienced has made him who he is today; if anything, 185 stated he would be rich, though he discussed the pitfalls of having money [value of identity]

\#7) Everything happens for a reason - 185 stated that he hasn't had anything so tragic happen to him that he would want to change it. He started out saying that he has done some foolish things, but seemed to be indicating that he would not necessarily make different decisions about those moments because he learned from them.

\{However, he directly stated later in the interview that he wants to do whatever he can to prevent others from going through what he's gone through if he can.\}

\#8) Acceptance from other people. He admired those in the ghetto that had money, dressed nicely, and had notoriety and popularity. He wanted to be like them.

\#9) Trying to be like those people in the ghetto whom he admired. He explained that he didn't understand what it would lead to and realized as he got older that those who he thought were so admirable did not turn out so well. Many of them are dead, in prison, or 
strung out on drugs. He stated that he now knows that he didn't really want to be like those guys.

In prison, 185 joined the Moorish Science Temple and began to change his way of thinking. Though he was raised Christian, he stated that it didn't have much meaning to him in his youth

\{185 stated that he desired to offer guidance to people that were younger than he, especially when he was in prison. This came from people having taken interest in him to provide guidance.\} 185 also used his time in prison to learn to read and write.

\#10) He stated that he would certainly not have chosen some of the things he did had he known what he was going to go through (shot, stabbed, and spent most of his life in prison). At the same time, he reiterated that those experiences have shaped him into who he is today. He seems to have an appreciation for that.

\section{Affect associated with school experience; Perceived value and impact of formal education}

\#11) He likened his education, formal and informal, to a puzzle, getting a little bit here and a little bit there, until it all comes together. As such, he was unable to pinpoint particular things. He listed a number of people that he has learned from over time including Martin Luther King, Jr., Malcolm X, Gil Scott-Heron, Thurgood Marshall, Fredrick Douglass, Barak Obama, Al Sharpton, James Baldwin, Eldridge Cleaver, and Marcus Garvey.

\{He seemed to identify more with the education he received by reading the works of these individuals and working to understand their philosophies.\}

\#12) Chaos and confusion. I was in the dark. I wasn't learning anything. He indicated that he went to school with the intent of being a clown and disruptive. He speculated that this may have been his way of rebelling. He further stated that he really did not start to learn until he went to prison. He stated that there was a particular teacher in one of the institutions that was very firm with him but showed that she cared. He stated that she inspired him to get his GED.

\#13) If the teachers hadn't tolerated a lot of my foolishness.

$\{185$ recounted a story of one teacher who affected him positively. He indicated that she was firm, but his story was more suggestive that she showed and communicated to her students that she cared about them.\} He reported that he did learn in this teacher's classroom. He also stated that he had various people, throughout his life, show love and demonstrate caring toward him.

\#14) It was a waste time. He expressed value in the moral and positive influences he received, but could not remember having learned academically. \{At question \#28, he stated that he experienced school as an intrusion in his life.?

a) I just really didn't have my mind on it. I didn't learn anything. I chose not to learn. 
b) 185 stated that it was like prison for him from day one when he was told that he had to sit down and couldn't get up and couldn't leave. It was just someplace I didn't want to be, but had to be. Only reflecting back now does he make the connection that he felt it was a waste of time. \{It seems that this may be where his rebellious attitude started in that he refused to do anything at school, because he didn't want to be there.\}

\#15) Restricted and imprisoned; He explained that he didn't see examples of success among people who went to school or graduated from high school. He supposed that some of this was due to the times and the lack of opportunity for blacks at that time.

\#16) He got along best with teachers who took a special interest in him.

$\{$ Here he recount a story about one of his niece whom he stated is acting the same way in school that he did. He talked about how he handled her and indicate that he is concerned about her and wants her to get her education.\}

\#17) He bonded with the students who behaved like him and laughed at his antics and shied away from those who did not find him funny.

\#18) 185 explained that his parents worked and focused on providing a home and food. They did not take on helping with homework when 185 needed help.

$\{$ His father was not present. His stepfather was in his life from the time 185 was two years old until his death. 185 expressed gratitude that he was able to spend a few years with him after he was released from prison, before his stepfather died.

\#19) They seemed to take school more seriously than 185 . They paid attention in class and did their work.

\#20) Getting out so I could go do what I wanted to do. I always wanted to be able to do what I wanted to do on my time not what was important to everybody else. He stated that he has spent a lot of his life doing what others wanted him to do or what was important to them and has resented that.

\#21) 185 explained that he believed he was going to do something important that was going to make him amount to something and that what was being taught in school was irrelevant. He did not see that people were learning anything in the classroom that was doing them any good, so he didn't feel he needed to be there.

\#22) 185 acknowledged that there were a lot of important things that school attempted to address which he just didn't realize at the time. He understands now that the fact that he didn't want to be there made it impossible for him to learn regardless of how important it was for him to learn it. He stated that he felt confident that he would be able to learn what they were trying to teach him at a later time. He stated that he was interested in being a kid at that time and wanted to put off learning until later. 
\#23) Discipline and inspiration to want to learn. They didn't captivate his interest. \{185 developed an awareness of how he needed to be approached by someone who was attempting to teach him something. He stated that he used that approached when he taught others and found it successful.

\#24) Failure. Failure. $\{185$ acknowledged that he did not actively do anything to try to change his situation. He offered that he had to wait until he got to the stage where he thought it was important. He explained that learning became important to him when he got to prison and saw that knowledge was a weapon. He recognized it as something he could use.\} He seemed to express a willingness to stay incarcerated as long as he needed to to learn what he needed to learn if it meant that he would never have to lose his freedom again.

\section{Current goals and values; legitimate goals}

\#25) His health and eyesight - this was salient because he's not attending to his health as he did in prison and recently received news about a potential eye condition he may be developing; making sure his family is ok

\#26) 185 stated that, having done so poorly in school, he could not identify anything he learned that he can say impacts him in his life now. He, again, explained that he really received his education when he was in prison. He described his motivation for learning at that time as well as his approach. Once he found the motivation, 185 took the initiative to begin to learn academically on his own. He reported that he requested math books from the school when he was in segregation and did the work on his own. He also reported that he read books on how to write, because he had a desire to be a writer.

185 was able to say that he remembers fighting a lot, especially after school, and seemed to identify this as a learning experience.

\#27) [Respect for education] 185 reflected that he might have avoided a lot of the things he went through in his life had he been interested in what they were trying to teach him in school. He reiterated that his incentive to learn academically when he saw the knowledge could be used as a weapon in prison. He went further to explain that prisoners respect a fellow prisoner who is educated because of the way that he stands out. He believes that having that same initiative earlier in life would have served him well. \{He expressed his

admiration for those who are articulate, like the list of authors and leaders he mentioned earlier. These have been inspirations for him to learn to articulate his own thoughts well. One of the ways he did this was by reading a lot. He also tried to surround himself with educated people in prison.\}

\#28) \{185 provided two distinct answers to this question. $\}$ When they were trying to teach me; When I actually really did [learn it]. 
\{Here, he returned to discussing how he felt about school, stating that he did not understand why he had to sit in the classroom "to learn this stuff. He saw no relevance or significance to his life and experienced it as an intrusion.\}

He expressed recognition which came later that he might have avoided some of the difficulties in his life had he learned it when it was being taught.

\{While 185 entertained the idea that things happen when they are supposed to happen, he also expressed concern that some learning opportunities are lost forever when they are rejected at the first presentation. He stated that this is a "danger" that young people do not understand. He indicated that he learned a lot of lessons the hard way and that many may not have survived what he has experienced.\}

$\{185$ also shared, here, that he did go to school for business education when he got out of prison, but had too many things going on in his life at that time to continue.\}

\#29) 185 stated that it is something that he wants to integrate into his life now but is concerned that he does not have the time, at his age, to accomplish all that he would like to accomplish. He said that he sees himself going back to school in the future if he can work some things out.

\#30) His heroes are listed above. They want me to carry on the work that they started. \{He gave some examples of how he has used what he's learned from their writings to determine the best approach to accomplish some important tasks.\}

\#31) I would hope that it would describe my life as something that closely resembled their own.

\#32) family responsibility, social responsibility, being an example to others, having peace about your choices and intentions - doing the best I can with what I have to work with (from Thurgood Marshall)

\#33) financial independence, continue learning things that are beneficial to me and helpful to other people, help other people accomplish their goals.

\#34) learning and trying to stay informed.

\#35) did not ask this question due to time

\#36) Any knowledge you learn is going to be beneficial to you. It's better to learn it now, but if you can't learn it now, don't give up on it. Make sure that you get it at some point.

\#37) basically the same thing with the added message of helping them to understand the dangers in this society for black males.

$\{185$ referenced the book Black Rage and explained their theory that it was the mother's responsibility to "break" the black male child to teach him to behave in ways that would 
keep him safe in a hostile society. He suggested that reading this book helped him understand that conflicts he had with his own mother. He remarked that his own experience has seemingly exposed him to a number of black men that have had similar difficulties with their mothers. This reflects some recognition of suppression of black males to obey laws and rules that marginalize and minimize them in society.\} It's important to recognize that even after the end of slavery, there are still real dangers in this society that black males must understand and learn how to negotiate.

\#38) I would not tolerate the things my parents and teachers tolerated from me when I was in school. He would be involved in their education and use discipline to help them understand the importance of learning in school. He stressed that his focus would be on making sure they learn to behave appropriately and receive proper discipline to help them become good citizens.

\#39) Talk with teachers and students to find out what they need, create a better environment for them to learn, try to have as many afterschool programs as possible, provide opportunities for students to socialize and integrate themselves into the social environment.

\section{Conclusion}

I think it's valid when you look at education in the overall sense, but I'm not convince that it always has to be applied to public education. I'm concerned that education has taken a backseat to a lot of other things. For example, funds are going to prisons that could be going to schools.

If you don't learn what you need to learn in school, you're going to end up in prison. 
Appendix G

Coding Matrix 


\begin{tabular}{|l|l|l|}
\hline Selective Coding & Axial Coding & Open Coding \\
\hline
\end{tabular}

\begin{tabular}{|c|c|c|}
\hline \multirow{8}{*}{$\begin{array}{l}\text { Experiences Influencing } \\
\text { Values } \\
(\text { Context })\end{array}$} & Agency & Rejection of parental guidance \\
\hline & \multirow[t]{3}{*}{ Family } & Parental Guidance \\
\hline & & $\begin{array}{l}\text { Needed a close relationship } \\
\text { with a father-figure or male } \\
\text { mentor }\end{array}$ \\
\hline & & Family relationships \\
\hline & \multirow[t]{3}{*}{ Community } & Lack of positive opportunities \\
\hline & & $\begin{array}{l}\text { Lack of resources for healthy } \\
\text { social development }\end{array}$ \\
\hline & & Growing up with no choices \\
\hline & School & $\begin{array}{l}\text { Contributions of } \\
\text { School/Education }\end{array}$ \\
\hline \multirow{15}{*}{$\begin{array}{l}\text { Value Development } \\
\text { Internalizing values which } \\
\text { supported antisocial and } \\
\text { self-destructive choices } \\
(\text { Context })\end{array}$} & \multirow[t]{7}{*}{ Important } & Acceptance/Social status \\
\hline & & Having money \\
\hline & & Formerly, education \\
\hline & & Peripheral need or interest \\
\hline & & Assurance \\
\hline & & Not being there (in school) \\
\hline & & Sports \\
\hline & \multirow[t]{8}{*}{ Reason for Importance } & Safety \\
\hline & & $\begin{array}{l}\text { Facilitation of personal } \\
\text { interest/Compensation for } \\
\text { home environment/self- } \\
\text { concept }\end{array}$ \\
\hline & & Loss of hope/interest in school \\
\hline & & $\begin{array}{l}\text { Desired positive reflection of } \\
\text { self in curricula }\end{array}$ \\
\hline & & Interests were strictly social \\
\hline & & Desire to affiliate \\
\hline & & Independence \\
\hline & & Added meaning to instruction \\
\hline \multirow{6}{*}{$\begin{array}{l}\text { Priority of } \\
\text { Self-Centered Values } \\
\text { (Causal Condition) } \\
\text { of the Negative Cycle) }\end{array}$} & \multirow[t]{2}{*}{ Image/Reputation } & Recognition \\
\hline & & $\begin{array}{l}\text { Sense of identity through } \\
\text { others }\end{array}$ \\
\hline & Fun/Pleasure & Addiction to lifestyle \\
\hline & \multirow[t]{2}{*}{$\begin{array}{l}\text { Money/Material } \\
\text { possessions }\end{array}$} & Obtaining money \\
\hline & & Obtaining drugs \\
\hline & $\begin{array}{l}\text { Nothing constructive or of } \\
\text { real value }\end{array}$ & $\begin{array}{l}\text { Nothing constructive or of real } \\
\text { value }\end{array}$ \\
\hline
\end{tabular}




\begin{tabular}{|c|c|c|}
\hline \multirow{16}{*}{$\begin{array}{l}\text { Rejection of Academic } \\
\text { Identity } \\
\text { (Intervening Condition } \\
\text { of the Negative Cycle) }\end{array}$} & \multirow[t]{5}{*}{ Feelings about School } & Mixed \\
\hline & & $\begin{array}{l}\text { Meaningless/No value or } \\
\text { relevance }\end{array}$ \\
\hline & & Positive \\
\hline & & Declining \\
\hline & & Negative \\
\hline & \multirow[t]{6}{*}{$\begin{array}{l}\text { Most Remembered about } \\
\text { School }\end{array}$} & Social \\
\hline & & Learning \\
\hline & & $\begin{array}{l}\text { Declining enjoyment and } \\
\text { engagement }\end{array}$ \\
\hline & & $\begin{array}{l}\text { Sports/Extracurricular/non- } \\
\text { academic activity }\end{array}$ \\
\hline & & Negativity \\
\hline & & A favorite course \\
\hline & \multirow[t]{2}{*}{$\begin{array}{l}\text { Problems with } \\
\text { instructional content }\end{array}$} & $\begin{array}{l}\text { Understanding school's } \\
\text { purpose }\end{array}$ \\
\hline & & $\begin{array}{l}\text { Cultural inclusion/Self- } \\
\text { knowledge }\end{array}$ \\
\hline & \multirow[t]{3}{*}{$\begin{array}{l}\text { Problems with } \\
\text { instructional delivery }\end{array}$} & Needed more caring teachers \\
\hline & & $\begin{array}{l}\text { Needed more individual } \\
\text { attention }\end{array}$ \\
\hline & & Absence of Black males \\
\hline \multirow{14}{*}{$\begin{array}{l}\text { High Risk Activity } \\
\text { (Strategy in the } \\
\text { Negative Cycle) }\end{array}$} & \multirow[t]{8}{*}{ Illegal } & Drug use \\
\hline & & Drug sales \\
\hline & & Theft \\
\hline & & Burglary \\
\hline & & Robbery \\
\hline & & Assault \\
\hline & & Killing \\
\hline & & Use of weapons \\
\hline & \multirow[t]{6}{*}{ Antisocial/Irresponsible } & Gang affiliation \\
\hline & & Violence \\
\hline & & School misbehavior \\
\hline & & Skipping school \\
\hline & & Early sexual activity \\
\hline & & Multiple sexual partners \\
\hline
\end{tabular}




\begin{tabular}{|c|c|c|}
\hline \multirow{10}{*}{$\begin{array}{l}\text { Outcomes and } \\
\text { Consequences } \\
\text { (Consequences in the } \\
\text { Negative Cycle) }\end{array}$} & \multirow[t]{4}{*}{ Meeting Important Needs } & Family needs \\
\hline & & Basic necessities \\
\hline & & Sense of identity \\
\hline & & Employment \\
\hline & \multirow[t]{6}{*}{ Merits of } & Non-constructive \\
\hline & & Neglect of responsibility \\
\hline & & Broken family relationships \\
\hline & & $\begin{array}{l}\text { Ceasing from illegal } \\
\text { activity/substance abuse }\end{array}$ \\
\hline & & Changing associations \\
\hline & & Freedom vs prison \\
\hline \multirow{8}{*}{$\begin{array}{l}\text { Recognition of } \\
\text { Problematic Identity and } \\
\text { Choices } \\
\text { Acknowledging those } \\
\text { choices or outcomes of } \\
\text { those choices as } \\
\text { problematic } \\
\text { and recognizing a need for } \\
\text { change } \\
\text { (Causal Condition of } \\
\text { Change Trajectory) }\end{array}$} & Personal Choices & Decisions for well-being \\
\hline & & $\begin{array}{l}\text { Pursuit of Education/School } \\
\text { Activities }\end{array}$ \\
\hline & & Affiliations with others \\
\hline & $\begin{array}{l}\text { Recognition of desire for } \\
\text { difference }\end{array}$ & Self-Oriented differences \\
\hline & & School-oriented differences \\
\hline & Community & Socially-oriented differences \\
\hline & & Family-oriented differences \\
\hline & No desire for change & $\begin{array}{l}\text { Appreciation of identity as a } \\
\text { composite of one's experiences }\end{array}$ \\
\hline \multirow{8}{*}{$\begin{array}{l}\text { Exploration of Better } \\
\text { Alternatives } \\
\text { Progression from } \\
\text { destructive to positive } \\
\text { choices } \\
\text { (Strategy in the Change } \\
\text { Trajectory) }\end{array}$} & \multirow{8}{*}{$\begin{array}{l}\text { Making positive choices } \\
\text { \& Establishing new habits } \\
\text { (Positive choices to help } \\
\text { self) }\end{array}$} & $\begin{array}{l}\text { Embracing spirituality and } \\
\text { religion }\end{array}$ \\
\hline & & $\begin{array}{l}\text { Seeking support for and taking } \\
\text { steps to change }\end{array}$ \\
\hline & & $\begin{array}{l}\text { Pursuing/committing to } \\
\text { employment }\end{array}$ \\
\hline & & Committing to family \\
\hline & & Relocating after incarceration \\
\hline & & $\begin{array}{l}\text { Adopting/pursuing specific } \\
\text { quality(ies) or worldview }\end{array}$ \\
\hline & & Emulating others who changed \\
\hline & & Listen to my parents \\
\hline
\end{tabular}




\begin{tabular}{|c|c|c|}
\hline \multirow{11}{*}{$\begin{array}{l}\text { Acquisition of } \\
\text { Knowledge and Skill } \\
\text { Development } \\
\text { (Strategy in the Change } \\
\text { Trajectory) }\end{array}$} & \multirow[t]{11}{*}{$\begin{array}{l}\text { Increasing } \\
\text { Knowledge/Skills }\end{array}$} & Work ethic \\
\hline & & $\begin{array}{l}\text { Patience Continuing/furthering } \\
\text { education }\end{array}$ \\
\hline & & Useful skills \\
\hline & & Motivation \\
\hline & & Nothing \\
\hline & & Learned in prison \\
\hline & & Learned later \\
\hline & & Value of family \\
\hline & & Importance of education \\
\hline & & $\begin{array}{l}\text { Self-knowledge, discipline, } \\
\text { trust to support learning }\end{array}$ \\
\hline & & Traits to support learning \\
\hline \multirow{11}{*}{$\begin{array}{l}\text { Recognition of the } \\
\text { Importance of Education } \\
\text { (Consequence in the } \\
\text { Change Trajectory) }\end{array}$} & \multirow{9}{*}{$\begin{array}{l}\text { Some useful } \\
\text { knowledge/ability }\end{array}$} & Knowledge and skills \\
\hline & & $\begin{array}{l}\text { Preparation for vocational and } \\
\text { professional opportunities }\end{array}$ \\
\hline & & $\begin{array}{l}\text { Self-worth/sense of } \\
\text { productivity }\end{array}$ \\
\hline & & $\begin{array}{l}\text { It's important/ } \\
\text { necessary/beneficial }\end{array}$ \\
\hline & & Academic skill \\
\hline & & $\begin{array}{l}\text { Knowledge or skill set for how } \\
\text { to learn }\end{array}$ \\
\hline & & Problem-solving skills \\
\hline & & Value of formal education \\
\hline & & Important but problematic \\
\hline & \multirow[t]{2}{*}{$\begin{array}{l}\text { Current Personal } \\
\text { Difficulties }\end{array}$} & Financial Difficulties \\
\hline & & Job Stressors \\
\hline
\end{tabular}




\begin{tabular}{|c|c|c|}
\hline \multirow{11}{*}{$\begin{array}{l}\text { Facilitating/Sustaining } \\
\text { Values } \\
\text { (Intervening Condition) }\end{array}$} & & $\begin{array}{l}\text { exercising self discipline to } \\
\text { make good choices }\end{array}$ \\
\hline & & Maintaining a sense of peace \\
\hline & & $\begin{array}{l}\text { Experiencing freedom and } \\
\text { control }\end{array}$ \\
\hline & & Family relationships \\
\hline & & Helping Others \\
\hline & & $\begin{array}{l}\text { Making good choices/self- } \\
\text { discipline }\end{array}$ \\
\hline & & Peace of mind \\
\hline & & Helping others \\
\hline & & Freedom/Control \\
\hline & & Spirituality \\
\hline & & Relationships \\
\hline \multirow{15}{*}{$\begin{array}{l}\text { Legitimate Goals } \\
\text { Setting and pursuing } \\
\text { (Core Phenomenon) }\end{array}$} & Important Now & $\begin{array}{l}\text { Living responsibly to Self and } \\
\text { others }\end{array}$ \\
\hline & & $\begin{array}{l}\text { Productivity, Achievement, } \\
\text { and Impact }\end{array}$ \\
\hline & & Relationships and Spirituality \\
\hline & & Physical Health \\
\hline & \multirow[t]{4}{*}{ Current Goals } & $\begin{array}{l}\text { Representations of } \\
\text { Accomplishments/Achievemen } \\
\text { ts }\end{array}$ \\
\hline & & Family \\
\hline & & Helping others \\
\hline & & $\begin{array}{l}\text { Possessions/Traits for Higher } \\
\text { Quality of Living }\end{array}$ \\
\hline & \multirow[t]{4}{*}{$\begin{array}{l}\text { Personal Definitions of } \\
\text { legitimate Goals }\end{array}$} & Achievement Goals \\
\hline & & Responsibility \\
\hline & & Meaningful and Achievable \\
\hline & & Improving Quality of Life \\
\hline & \multirow[t]{3}{*}{ Family } & Provide for family/children \\
\hline & & Marriage/Family \\
\hline & & Relationship \\
\hline
\end{tabular}


Todd F. Robinson was born on June 17, 1969, in Milwaukee, Wisconsin. He attended Rufus King High School for the College Bound, which he intentionally chose in order to ensure acceptance to and academic scholarships for college. He earned a bachelor's degree in business administration from the University of Wisconsin in 1992. After working in human resources for two years, he left his job to seek something more meaningful. He was ordained as a minister while completing his master's degree in counseling psychology at the University of Missouri-Columbia. His exposure during that time spawned an interest in understanding how decisions are made about children in schools. He applied to the doctoral program in school psychology at the University of Missouri-Columbia and began coursework immediately after completing his master's degree. Along the way, he got married, had a child, and worked as a Licensed Professional Counselor in the Missouri Department of Corrections. This reassured him of his need to finish his doctorate in hopes of contributing to improved educational outcomes and fewer incarcerations for African American males. He completed his predoctoral internship in Loudoun County Public Schools in Loudoun County, Virginia in August of 2012. In October of 2012, he began working in Baltimore City Public Schools, in Baltimore, Maryland, where he is currently employed. His interests are to use his training and experience to help improve the educational experience for African American males and dramatically reduce the incarceration rates of the same. 